\title{
MOTIVATED ERRORS
}

\author{
Christine L. Exley \\ Judd B. Kessler \\ Working Paper 26595 \\ http://www.nber.org/papers/w26595
}

\section{NATIONAL BUREAU OF ECONOMIC RESEARCH \\ 1050 Massachusetts Avenue \\ Cambridge, MA 02138 \\ December 2019}

Research support was provided by the Wharton School of the University of Pennsylvania and Harvard Business School. The views expressed herein are those of the authors and do not necessarily reflect the views of the National Bureau of Economic Research.

NBER working papers are circulated for discussion and comment purposes. They have not been peer-reviewed or been subject to the review by the NBER Board of Directors that accompanies official NBER publications.

(C) 2019 by Christine L. Exley and Judd B. Kessler. All rights reserved. Short sections of text, not to exceed two paragraphs, may be quoted without explicit permission provided that full credit, including ( $)$ notice, is given to the source. 
Motivated Errors

Christine L. Exley and Judd B. Kessler

NBER Working Paper No. 26595

December 2019

JEL No. C91,D64,D91

\section{$\underline{\text { ABSTRACT }}$}

In three sets of experiments involving over 4,200 subjects, we show that agents motivated to be selfish make systematic decision errors of the kind generally attributed to cognitive limitations or behavioral biases. We show that these decision errors are eliminated (or dramatically reduced) when self-serving motives are removed. We say that individuals make "motivated errors." They make decision errors, but only when it is self-serving to do so.

Christine L. Exley

Harvard Business School

clexley@gmail.com

Judd B. Kessler

The Wharton School

University of Pennsylvania

3620 Locust Walk

Philadelphia, PA 19104

and NBER

judd.kessler@wharton.upenn.edu 


\section{Introduction}

Most people would like to believe that they are good. ${ }^{1}$ Yet, many of their decisions are not good - they are selfish, lazy, impatient, indulgent, or worse. How do people resolve this tension? Previous research has highlighted the role of motivated decisions, which allows agents to rationalize their decisions in a more favorable light. ${ }^{2}$ In particular, the prior literature on motivated decisions has demonstrated two broad ways in which agents rationalize decisions that could be viewed as undesirable.

The first way involves appealing to uncertainty in how decisions map to outcomes. The intuition is as follows. Choosing a decision that benefits oneself to the detriment of others is undesirable, but choosing a decision that benefits oneself but may not harm others - because of uncertainty in how decisions map to outcomes - may be less undesirable. Such motivated decisions are often facilitated by information avoidance. In the canonical example of Dana, Weber and Kuang (2007), agents choose to stay uninformed about the state of the world in order to maintain uncertainty about whether a selfish action harms another subject. ${ }^{3}$

The second way involves attributing undesirable decisions to more innocuous preferences or beliefs. The intuition is as follows. It is bad to be selfish, but there is nothing wrong with holding particular preferences (over, say, risk) or holding particular beliefs (over, say, what payoffs are likely to arise), even if those preferences or beliefs lead you to make selfish decisions. This attribution is possible in settings where there is uncertainty about whether an undesirable action can be attributed to such innocuous preferences or beliefs. In one of the earliest examples, Snyder et al. (1979) shows that subjects, when deciding whether or not to watch a movie with an individual who has a disability, are more likely to avoid this individual when their avoidance "could masquerade as a movie preference" rather than a dislike for an individual who has a disability. More recently, empirical work documents that individuals appear to use their fairness preferences (Konow, 2000), ambiguity preferences (Haisley and Weber, 2010), risk preferences (Exley, 2015), and beliefs about factors that influence payoffs — such as how others behave (Di Tella et al., 2015) — to rationalize decisions that could otherwise be attributed to selfishness. ${ }^{4}$

\footnotetext{
${ }^{1}$ In November 2018, we ran a Google Consumer Survey that was answered by 1,536 individuals. When asked to indicate the extent of agreement with the following statement "Overall, I am a good person" on a scale from 1 (strongly disagree) to 5 (strongly agree), these results - after being weighted by age, gender and region to match the 2015 CPS - were as follows: 5 (48\%), $4(26 \%), 3(14 \%), 2(4 \%)$, and $1(8 \%)$

${ }^{2}$ Such rationalization may be desired by agents with self-image concerns. There is a rich theoretical literature on the role of self-image (Rabin, 1995; Bodner and Prelec, 2003; Bénabou and Tirole, 2004, 2006; Mijović-Prelec and Prelec, 2010; Bénabou and Tirole, 2011; Grossman, 2015; Grossman and van der Weele, 2017; Bénabou, Falk and Tirole, 2018; Foerster and van der Weele, 2018a).

${ }^{3}$ In Appendix B.3, we discuss the robust literature on information avoidance that has followed from Dana, Weber and Kuang (2007).

${ }^{4}$ Other examples include cases where decisions may be rationalized by: condo preferences (Hsee, 1996), fairness preferences related to disputes (Babcock et al., 1995), honesty preferences (Danilov and Saccardo, 2016), preferences about charity performance metrics (Gneezy, Keenan and Gneezy, 2014; Exley, Forthcoming), and beliefs about one's competence (Liu and Lin, 2018). Ambiguity and risk preferences may also be relevant when payoffs explicitly depend on ambiguity or risk (Dana, Weber and Kuang, 2007; Oberholzer-Gee and Eichenberger, 2008; Gneezy et al.,
} 
In this paper, we document a third way in which individuals make motivated decisions. Individuals make unambiguous decision errors - acting as if they suffer from cognitive limitations or behavioral biases - in order to make more selfish choices. We describe this behavior as individuals making "motivated errors."

How do we document motivated errors? As noted above, all prior examples of motivated decisions arise in settings with underlying uncertainty, either uncertainty in how decisions map to outcomes or uncertainty about whether innocuous preferences or beliefs drive decisions. ${ }^{5}$ We construct experimental environments in which there is no uncertainty that selfish choices lead to selfish outcomes; and our experimental designs investigate how participants respond to payoff-irrelevant information when making decisions over payoffs, so there is no preference or belief that can justify responding to the information. In a series of experiments involving over 4,200 subjects, we document that individuals respond to payoff-irrelevant information - acting as if they suffer from cognitive limitations or behavioral biases — when it is self-serving to do so, but they make few to no errors when self-serving motives are removed. By acting as if they suffer from cognitive limitations or behavioral biases, individuals appear to "create" uncertainty (e.g., about whether selfishness was caused by a decision error) in order to rationalize undesirable choices.

In our first set of experiments (Study 1), subjects choosing between a payoff for themselves and a payoff for charity are less likely to choose the payoff for charity when a zero is added to it. For instance, subjects are less likely to choose a payoff for charity when told that $55+55+55+55+0$ cents will be donated than when told that $55+55+55+55$ cents will be donated. ${ }^{6}$ However, when self-serving motives are removed (i.e., when participants choose between two payoffs that both benefit charity), decisions are no longer influenced by the addition of a zero. Agents only act as if they cannot properly add a zero when doing so can rationalize selfish decisions. ${ }^{7}$

2015; Garcia, Massoni and Villeval, 2018; Regner, 2018; Olschewski et al., 2019); when payoffs are influenced by the (unknown) behavior of others (Falk and Szech, 2013; Bartling and Özdemir, 2017; Falk and Szech, 2017; Gneezy, Saccardo and van Veldhuizen, 2018); or when payoffs are determined by some unknown, even if it could become easily known, state of the world (see citations in Appendix B.3).

${ }^{5}$ In these demonstrations, uncertainty is built into the decision environment. Indeed, empirical evidence for motivated decisions almost always involves showing decreases in undesirable decisions when uncertainty in the decision environment in exogenously decreased. For example, evidence for motivated decisions is rampant when agents can appeal to subjective preferences about whether one option is "better" than the other option, and it is dramatically reduced when agents receive information that makes clear which option is preferable (Hsee, 1996; Gneezy et al., 2015; Danilov and Saccardo, 2016; Gneezy, Saccardo and van Veldhuizen, 2018). In addition, motivated decisions often occur when agents may appeal to ambiguity or risk preferences, and it is decreased when agents receive information that resolves (some) uncertainty about how outcomes result from decisions (Dana, Weber and Kuang, 2007; Oberholzer-Gee and Eichenberger, 2008; Haisley and Weber, 2010; Falk and Szech, 2013; Bartling and Özdemir, 2017; Falk and Szech, 2017; Regner, 2018; Olschewski et al., 2019). Even in studies that pursue alternative identification approaches - such as Di Tella et al. (2015) or Exley (2015) - uncertainty remains in the decision environment and allows agents to appeal to beliefs that need not be self-serving (given the unknown behavior of others, as in Di Tella et al. (2015)) or risk preferences that need not be self-serving (given the unknown outcomes that result from lotteries, as in Exley (2015)).

${ }^{6}$ This setting is absent underlying uncertainty. When subjects choose between a payoff for themselves and a payoff for charity, there is no uncertainty that selfish decisions result in selfish outcomes. In addition, a rational agent cannot hold preferences or beliefs that justify responding to payoff-irrelevant information when making decisions over payoffs.

${ }^{7}$ As further evidence that subjects are just acting as if they cannot properly add a zero, we show in Section 2.3 
In our second set of experiments (Study 2), we show that agents motivated to be selfish are more likely to respond to a salience manipulation. When choosing between a payoff for themselves and a payoff that benefits multiple charities, participants are less likely to choose the latter when it makes salient a charity that does not benefit. For instance, participants are less likely to choose payoffs for charity when they are told that each of charities $A, B, C$, and $D$ receives 55 cents and charity $E$ receives 0 cents than when they are told that each of the charities $A, B, C$, and $D$ receives 55 cents (where charity $E$ is not mentioned and any charity not mentioned is known to receive 0 cents). However, when self-serving motives are removed, participants' decisions are substantially less albeit still statistically significantly — influenced by the salience manipulation. Agents are more likely to act as if the saliency of information known to them matters when doing so can rationalize selfish decisions. ${ }^{8}$

In our third set of experiments (Study 3), we show that agents motivated to be selfish are more likely to respond to anchoring manipulations. When choosing between a payoff for themselves and a payoff for charity, participants are less likely to choose 200 cents for charity when it is anchored to 400 cents by being described as the smaller of 400 cents and 200 cents (in one anchoring treatment) or as 400-200 cents (in another anchoring treatment) than when it is described directly as 200 cents. However, when self-serving motives are removed, participants no longer respond to the anchoring manipulations. ${ }^{9}$

The first main contribution of our paper is to provide the first empirical evidence for motivated decisions in environments without underlying uncertainty. ${ }^{10}$ As noted above, that motivated decisions can arise in settings absent underlying uncertainty allows us to show a new way in which motivated decisions arise, which we highlight as our second main contribution. It also qualita-

that when participants are directly asked to calculate these sums, they do so correctly in $98 \%$ of cases and their ability to do so does not depend on whether a 0 is added to the sum.

${ }^{8}$ We ran Study 2 first, and after observing the strength of our results in Study 2, we sought to test whether we could push the empirical boundaries of motivated errors further, by documenting it in a even simpler environment (resulting in Study 1) and in new environments (resulting in Study 3).

${ }^{9}$ In Study 3, we additionally show that subjects make motivated errors in the spirit of what we found in Study 1 and 2. When self-serving motives are present, participants are less likely to choose 200 cents for charity when it is described as $50+50+50+50+0$ cents than when it is described directly as 200 cents. This behavior is dramatically reduced in the absence of self-serving motives. Note that in Study 3 we are comparing $50+50+50+50+0$ to 200 cents rather than to the summation without the last 0, as in Study 1, and so one can consider it a response to addition generally, rather than to simply adding a 0 .

${ }^{10}$ This paper focuses on motivated decisions rather than motivated beliefs, for reasons outlined in footnote 12. However, there is a rich related literature on motivated beliefs about: ability (Eil and Rao, 2011; Ertac, 2011; Grossman and Owens, 2012; Mobius et al., 2014; Buser, Gerhards and Van der Weele, 2018; Coutts, 2018; Heger and Papageorge, 2018; Schwardmann and van der Weele, 2017; Chew, Huang and Zhao, 2018; Zimmermann, 2018), politics (Thaler, 2019), beauty (Eil and Rao, 2011), others' prosocial behavior (Di Tella et al., 2015; Palma and $\mathrm{Xu}, 2019$ ), financial decisions (Kuhnen, 2015), and non-ego relevant but desirable events (Gotthard-Real, 2017). See Bénabou and Tirole (2016) for a review, Bénabou and Tirole (2002) and Köszegi (2006) for related theoretical work, and Schwardmann, Tripodi and van der Weele (2019) for evidence from the field. Ashraf, Bandiera and Lee (2014) even shows that individuals may reduce their effort if it allows them to hold more egoistic beliefs. Because of the nature of beliefs - being about an unknown state of the world - the literature on motivated beliefs has also focused on decision environments with underlying uncertainty (e.g., when there is uncertainty about how one performed on a test, the motivated belief literature explores how individuals update in response to noisy signals about performance). 
tively increases the range of environments in which motivated decisions might be relevant, which we highlight as our third main contribution.

Our second main contribution is to show a new way in which motivated decisions arise: individuals make unambiguous decision errors when motivated to do so - acting as if they suffer from cognitive limitations or behavioral biases — which we call "motivated errors." 11 Documenting motivated errors in decisions connects us to a recent literature on motivated errors in beliefs, which has documented that agents appear unable to recall information when it allows them to hold selfserving beliefs (see Chew, Huang and Zhao (2018), Zimmermann (2018) and Saucet and Villeval (2019), which - guided by Bénabou and Tirole (2002) — show that motivated reasoning leads to false or selective memory). That said, we find it unlikely that the motivated errors in decisions we document are solely reflective of motivated beliefs (e.g., we find it unlikely that subjects believe that the smaller of 400 and 200 is below 200, even when motivated to do so). Even more importantly, we believe it is essential to study both motivated decisions and motivated beliefs, as their prevalence and some of their underlying drivers may differ. ${ }^{12}$

Our third main contribution is providing evidence for more unconstrained notions of motivated decisions. Because prior work showed motivated decisions (and motivated beliefs, see footnote 10) arising only in settings with underlying uncertainty, a common intuition held is that motivated decisions would be constrained to such settings. ${ }^{13}$ To the extent that motivated decisions are constrained by individuals' "ability to construct seemingly reasonable justifications for these conclusions" (Kunda, 1990) or by the environment providing "sufficient flexibility to allow plausible justification" (Gino, Norton and Weber, 2016), our results suggest that removing underlying uncertainty from the decision environment is an insufficient constraint. By showing that agents make motivated errors, we highlight that motivated decisions could — in principle — arise in nearly any environment. This finding suggests the potential relevance of motivated decisions in more contexts than had previously been considered and highlights the importance of more research on the topic. ${ }^{14}$

\footnotetext{
${ }^{11}$ Evidence observed in prior literature on motivated decisions could relate to the aforementioned channels that rely on appeals to underlying uncertainty to explain agents' decisions even under the assumption that agents do not make errors in their decisions. This is not the case in our paper. While the prior literature on motivated decisions has documented distorted - even difficult to rationalize - decisions, we are the first to show unambiguous errors in decisions.

${ }^{12}$ For instance, motivated beliefs can arise without resulting in motivated decisions (e.g., if a motivated distortion in beliefs is not large enough to change decisions), and motivated decisions can arise absent motivated beliefs (e.g., due to a change in preferences rather than a change in beliefs) or absent the ability to observe motivated beliefs (e.g., because the elicitation of beliefs could change what beliefs people hold).

${ }^{13}$ Early work on self-deception in psychology stressed the role of ambiguity (Batson et al., 1997), a recent review of the psychology work notes that "[a]mbiguity has been shown to be necessary for self-deception" (Chance and Norton, 2015), and a recent review of the literature in psychology and economics stresses the importance of uncertainty by noting "In this paper, we will argue that there is a widespread tendency for individuals to exploit justifications and uncertainties present in decision-making environments in order to act egoistically" (Gino, Norton and Weber, 2016).

${ }^{14}$ Gino, Norton and Weber (2016) highlights that "an underexplored element in much of this research is the frequent tendency of decision makers to engage in motivated information processing." In somewhat related work, Batson et al. (1999) investigates two ways in which individuals may feel moral while not being moral: (i) they may convince or deceive themselves into thinking their behavior is moral, or (ii) they may simply avoid reflecting on the morality of their behavior. While this second channel is also more unconstrained, it is different than the type of motivated
} 
Our fourth main contribution is showing that behavior that could be attributed to a behavioral bias (such as anchoring in Study 3) might instead be indicative of self-serving motives. Since participants in our experiments respond in systematic ways to irrelevant information, they look like they are subject to behavioral biases. Indeed, had we only explored behavior in environments with self-serving motives, one could have easily imagined attributing the systematic errors we observe in our three studies to heuristics or biases. ${ }^{15}$ That the motivated errors we document could have been mistaken for behavioral biases supports the call put forth in Bénabou and Tirole (2016) for more work on how behavior that may appear to be indicative of "wired-in cognitive mistakes" could instead be indicative of self-serving motives.

Our fifth main contribution, discussed in more detail in the results sections below, is to highlight why it is important to diagnose whether an error is motivated in nature. We find that debiasing techniques traditionally used to overcome behavioral biases or cognitive limitations prove largely ineffective at mitigating motivated errors. A recent example of standard debiasing techniques used to overcome behavioral biases can found in Enke and Zimmermann (2019), in which cognitive limitations cause correlation neglect and prevent agents from making accurate calculations. In that setting — where motivations are not relevant — making sure that agents pay attention to the correlated nature of signals or simplifying the underlying correlation structure helps agents make fewer mistakes. More generally, errors due to cognitive limitations are expected to become less pronounced as decision environments are made simpler, as agents are made to pay more attention to a decision, or as agents gain experience with a decision. ${ }^{16}$ We find that none of these techniques eliminate the motivated errors we observe. Consequently, determining how to counter systematic errors may be facilitated by the identification of whether an error is fully, or even in part, driven by self-serving motives.

The rest of the paper proceeds as follows. Section 2 describes the design and results of Study 1.

decisions discussed in this paper - which is focused on the first channel - because the second channel involves a lack of reasoning as opposed to motivated reasoning. Thus, it could not explain why individuals exploit excuses, such as the addition of a zero to a bundle (or, for that matter, risk, ambiguity, ambiguous fairness norms, etc.), because excuses are only relevant when individuals are trying to rationalize their decisions.

${ }^{15}$ Absent identifying the role of self-serving motives, our findings from Studies 1 and 2 could simply reflect the affect heuristic (Gilovich, Griffin and Kahneman, 2002). Study 1 could also be considered evidence of errors arising from irrelevant attributes as shown in Chadd, Filiz-Ozbay and Ozbay (2019); Study 2 could relate to narrow bracketing (Barberis, Huang and Thaler, 2006; Rabin and Weizsäcker, 2009; Imas, 2016; Exley and Kessler, 2019), salience (Bordalo, Gennaioli and Shleifer, 2012, 2013; Taubinsky and Rees-Jones, Forthcoming), focusing (Köszegi and Szeidl, 2013), or relative thinking (Bushong, Rabin and Schwartzstein, 2017); and Study 3 relates to the large literature on anchoring (see, e.g., Tversky and Kahneman (1974)). More generally, this contribution connects us to the early work in behavioral economics that highlighted the role of heuristics when agents lacked the cognitive capacity to process all relevant information (Simon, 1955; Tversky and Kahneman, 1973; Conlisk, 1996) and explained subjects' responses to irrelevant information as arising due to "imperfections of human perception and decision," which they analogized to the limits of humans' visual perception (Tversky and Kahneman, 1981, 1986; Kahneman, 2011) and has more recently been considered through the lens of inattention (Sims, 2003; Gabaix, 2014; Caplin, 2016; Gabaix, 2017; Caplin, Dean and Leahy, 2018).

${ }^{16}$ For reviews, see Conlisk (1996); Rabin (1998); DellaVigna (2009); Madrian (2014); Gabaix (2017); for related examples, see List (2003); Chetty, Looney and Kroft (2009); Finkelstein (2009); Brocas et al. (2014); Hanna, Mullainathan and Schwartzstein (2014); Schwartzstein (2014); Taubinsky and Rees-Jones (Forthcoming); Enke (2017). 
Section 3 describes design and results of Study 2. Section 4 describes design and results of Study 3. Section 5 concludes.

\section{Study 1: Adding a Zero}

In our first set of experiments (Study 1), payoff-irrelevant information influences agents' decisions over payoffs only when self-serving motives are relevant. When choosing between a payoff for themselves and a payoff for charity, participants are more likely to favor a payoff for themselves when a zero is added to the payoff for charity. By contrast, when choosing between two payoffs for charity, participants no longer respond to the addition of the zero. Because self-serving motives lead to these decision errors, we call them "motivated errors."

In this section, we present the design and results from this set of experiments. In addition, we show that motivated errors survive standard debiasing attempts. Motivated errors persist as participants gain experience (i.e., in the latter half of decisions they make). Motivated errors persist when participants pay attention to the amounts that comprise the charity payoff (i.e., in decisions where participants choose to view all of the amounts, even though they could avoid them). Motivated errors even persist, albeit less so, when the (already simple) decision environment is made simpler by the total amount in the charity payoff being displayed on the decision screen. We only eliminate motivated errors by making participants correctly enter the total amount in the charity payoff before making a decision, which gives insight into the underlying mechanisms for motivated errors (see Section 2.4).

\subsection{Experimental Design}

Study 1 included 1,168 participants in one of six versions. ${ }^{17}$ In all versions, each participant received $\$ 4$ for completing the 25-minute study. In addition, one randomly selected decision for each participant was implemented for bonus payment and resulted in an additional payment for the participant or a donation to charity.

In all versions, participants make 48 binary choices in which they choose between a "bundle," which changes from decision to decision, and an "outside option," which is fixed for all 48 decisions.

\footnotetext{
${ }^{17}$ From January 16-17, 2018, we recruited and randomized 600 participants from Amazon's Mechanical Turk (MTurk) into one of three study versions: Self/Charity, Charity/Charity, Self(150)/Self, and 599 participants completed the study. On January 18, 2018, we recruited and randomized 401 participants from MTurk into one of two study versions: Self/Charity-Choice, Self/Charity-Sum, and all 401 participants completed the study. On December 28, 2018, we recruited 200 participants from MTurk into the Self/Charity-Unavoidable Sum version, and 199 participants completed the study. However, we exclude 31 participants from the Self/Charity-Unavoidable Sum version because they completed in prior versions of our study (due to a change in research assistants this exclusion had to occur after collecting the data). The Self/Charity-Unavoidable Sum version was run after the other versions in response to helpful comments from anonymous referees. To be eligible for any of our study versions, workers must have previously completed at least 100 HITs with a $95 \%$ or better approval rating and must be working from a United States IP address. Overall, $49 \%$ of participants are female, the median age is 33 years old, and the median educational attainment is an Associate's Degree. Across these demographic variables, there is only one significant difference across the Self/Charity, Charity/Charity, and Self(150)/Self versions and there are no significant differences across the Self/Charity-Choice and Self/Charity-Sum versions, demonstrating successful randomization. Full instructions for Study 1 can be found in Appendix D.1.
} 
In each decision, the value of the bundle is equal to the sum of 4 or 5 summands. For simplicity, each summand in a bundle is either 0 or a single positive number that (usually) appears multiple times. Consequently, the sum of a bundle can always be calculated as $n \times d$ (where $n$ is the number of times the positive number $d$ appears in the bundle, with all remaining summands being 0 ).

The six versions of Study 1 - Self/Charity, Charity/Charity, Self(150)/Self, Self/CharityChoice, Self/Charity-Sum, Self/Charity-Unavoidable Sum — vary along three dimensions: (1) the recipient and level of the outside option, (2) the recipient of the bundle, and (3) what information about the bundle participants have to learn before making each choice. The differences across the six versions of Study 1 are best visualized in Table 1. The naming of the versions follows two rules. First, the name indicates the recipient of the outside option followed by the recipient of the bundle. For example, in the Self/Charity version, the outside option benefits the participant (thus Self/) and the bundle benefits a charity (thus Charity). Second, any text after a hyphen indicates a difference in information structure relative to the Self/Charity version. For instance, in the Self/Charity-Choice version, participants can choose to avoid more information than they can in the Self/Charity version (thus -Choice).

Table 1: Study 1 Versions

\begin{tabular}{|c|c|c|c|c|}
\hline \multicolumn{2}{|c|}{ Outside Option to... } & ...Charity & \multicolumn{2}{|c|}{...Self } \\
\hline \multirow{4}{*}{ Information is } & Optional & & $\begin{array}{c}\text { Self/Charity-Choice } \\
(\mathrm{n}=195)\end{array}$ & \\
\hline & Required & $\begin{array}{l}\text { Charity/Charity } \\
(\mathrm{n}=199)\end{array}$ & $\begin{array}{c}\text { Self/Charity } \\
(\mathrm{n}=198)\end{array}$ & $\begin{array}{l}\text { Self(150)/Self } \\
\quad(\mathrm{n}=202)\end{array}$ \\
\hline & $\begin{array}{l}\text { Required and } \\
\text { Sum Shown }\end{array}$ & & $\begin{array}{l}\text { Self/Charity-Sum } \\
(\mathrm{n}=206)\end{array}$ & \\
\hline & $\begin{array}{l}\text { Required and } \\
\text { Sum Shown } \\
\text { Unavoidably }\end{array}$ & & $\begin{array}{c}\text { Self/Charity- } \\
\text { Unavoidable Sum } \\
(\mathrm{n}=168)\end{array}$ & \\
\hline \multicolumn{2}{|l|}{ Bundle to... } & \multicolumn{2}{|c|}{...Charity } & ...Self \\
\hline
\end{tabular}

We begin by describing the Self/Charity version in depth, since the other five versions are easily explained as slight variations off of this version. In the Self/Charity version, the recipient of the outside option is the participant and the level of the outside option is calibrated on the participant level; the recipient of the bundle is the national chapter of the Make-A-Wish Foundation, a charity; and participants must learn about each summand in the bundle before making their choice. In the remainder of this section, we explain how the bundles are constructed, we explain how and why we calibrated the outside option at the participant level, and we describe how the other five versions differ from the Self/Charity version.

\section{Bundles in the Self/Charity version}

Each bundle in the Self/Charity version of Study 1 includes four or five summands (called "amounts" to participants) that are either zero or the same non-zero number. Participants are 
informed that if the bundle is chosen, the sum of these four or five amounts will be donated to the Make-A-Wish Foundation national chapter. The first amount in a bundle is always revealed by default (see Figure 1 for an example). Participants are then required to reveal the remaining three or four amounts in a bundle by clicking on the header above each amount. We present the bundles to participants in this interactive manner so that we could require them to view all of the amounts in a bundle. (In the Self/Charity-Choice version, detailed later in this section, this interface also allows us to observe which amounts participants choose not to view). To ensure participants comprehend this structure, we require participants to correctly answer questions about how much money would be given to charity in several example bundles before they make choices in the study (see Appendix Figure D.5).

Figure 1: Example of how a bundle initially appears in Study 1

\begin{tabular}{|l|}
\hline Amount 1: \\
\hline \hline 54 cents \\
\hline , Amount 2: \\
\hline . Amount 3: \\
\hline , Amount 4: \\
\hline
\end{tabular}

Clicking on each header reveals the number of cents associated with that amount.

To facilitate comparisons across each participant's decisions, we carefully structured the 48 bundles (importantly, however, participants are not informed of this structure). In particular, we started with 12 "baseline" bundles, which we call $n / 4$-bundles, since they include four amounts of which $n$ amounts are non-zero (so, if $n<4$, then $4-n$ amounts are zero). Each non-zero amount within a bundle equals $d$, which is constant within a bundle but varies across bundles. Thus, the sum going to charity if a baseline $n / 4$-bundle is chosen is $n \times d$ cents. The $n$ and $d$ parameters for the baseline bundles are chosen such that $n \times d$ varies systematically around 150 cents. We have four baseline bundles with $n=2$, four baseline bundles with $n=3$, and four baseline bundles with $n=4$. We randomly select $d \in\{51,52,53,54,55,56,57,58,59\}$ at the bundle level, so that $n \times d$ is substantially below 150 cents for the bundles with $n=2$, slightly above 150 cents for bundles with $n=3$, and substantially above 150 cents for the bundles with $n=4$. The amounts in the bundles appear in a designated order, and we vary the order of the zeros in the baseline bundles as shown in Appendix Table A.1.

From each of 12 baseline bundles, we construct an n/5-bundle by "adding a zero" to it. Each $n / 5$-bundle mirrors the payoff structure of an $n / 4$-bundle except for the addition of a fifth amount that is zero. From each of these 12 baseline bundles, we additionally construct a $(n+1) / 5$-bundle by "improving" it. Each $(n+1) / 5$-bundle mirrors the payoffs structure of an $n / 4$-bundle except for the 
addition of a fifth amount that is $d$. We call the 12 baseline bundles and the 24 bundles constructed from them our "main bundles."

In addition to our main bundles, we have 12 non-main bundles with four amounts each. We included these bundles both to balance the number of bundles of each size (i.e., to have 24 bundles with four amounts along with the 24 bundles with five amounts) and to provide additional data to perform secondary analyses conducted in Section 2.3. Until then, decisions involving these non-main bundles are excluded from our analysis (see Appendix Table A.2 for details on these bundles).

The order in which participants make their 48 binary decisions varies. Half of participants make their 24 decisions involving bundles with four amounts first and the other half make their 24 decisions involving bundles with five amounts first. In addition, within each block of 24 decisions, the order in which each bundle is shown randomly varies for each participant.

\section{Outside options in the Self/Charity version}

The value of donations in the bundles vary systematiically around 150 cents because we set the outside option to be equivalent to a donation of 150 cents. Of course, each participant may have a different value for a 150-cent donation to charity and most are likely to value money for themselves more than money for charity. Consequently, we calibrate the outside option for each participant in the Self/Charity version to a value of money for themselves that is equivalent to 150 cents for charity (and directly set the outside option in the Charity/Charity version to be 150 cents for charity). This calibration allows us to keep the value of the outside option similar across study versions with and without self-serving motives. This is a methodological contribution that we have also used in our other work (Exley, 2015, Forthcoming; Exley and Kessler, 2019). ${ }^{18}$ We discuss the calibration procedure further in Section 2.3 and Appendix B.2, but we highlight its features here as well.

By calibrating the outside option in the Self/Charity version to be equivalent to 150 cents for charity, we can ensure that each participant is close to indifferent between the outside option and the bundle for the $n=3$ decisions (and further from indifferent for the $n=2$ and $n=4$ decisions) so that we have a well-controlled measure of how likely the participant is to select the bundle. If we had not calibrated the outside option and instead set it directly, we might have ended up in an environment where participants found the outside option in the Self/Charity version to be much more (or much less) appealing than all of the bundles. If that had happened, we might have seen subjects always choosing (or never choosing) the outside option in the Self/Charity version. A bad calibration — that sets the outside option too high or too low relative to the bundles — could therefore prevent us from observing that adding a zero affects behavior. ${ }^{19}$ Moreover, we stress that a bad calibration cannot contribute to us finding that adding a zero affects behavior. The

\footnotetext{
${ }^{18}$ See a discussion of the advantages of this procedure in Gauriot, Heger and Slonim (2019).

${ }^{19}$ This makes it even more informative that, as detailed in Appendix B.2, our results persist in a version of Study 2 in which the calibration is not used to set the outside option. Indeed, in this version, participants select the outside option substantially more often, which could have resulted in a "floor effect" in which participants could not be further discouraged from choosing the bundle when a zero is added to it.
} 
identification strategy in our study relies on comparing the rates at which the bundles are chosen with and without an additional zero. Participants should never respond to the addition of the zero, regardless of the level of the outside option.

How do we implement the participant-level calibration? Before facing the 48 binary decisions, each participant completes a multiple price list that aims to elicit an $X$ value that makes the participant indifferent between $X$ cents for themselves and 150 cents for the national chapter of the Make-A-Wish Foundation. Once we identify this $X$ value, we set each individual participant's outside option to $X$ cents for themselves since, as detailed above, the outside option in the Charity/Charity version is 150 cents to the national chapter.

The multiple price list generates an indifference range for $X$. We assign participants an $X$ value equal to the lower bound of their indifference range, unless the lower bound of the indifference range is 0 , in which case we assign $X=5$ cents. $^{20}$ The distribution of $X$ values are displayed in Panel A of Appendix Figure A.1 and, as will be shown throughout the paper, our results are robust to a restricted sample that excludes the $12 \%$ of participants whose lower bound implies $X=0$ and for whom we assign $X=5$ cents.

\section{Additional versions of Study 1}

Each of the five other versions of Study 1 have a slight variation off of the Self/Charity version, and they are described here. Additional details are shown in the corresponding sections where we discuss the results from these versions.

The Charity/Charity version is like the Self/Charity version, except that the outside option for all the decisions is 150 cents going to the national chapter of the Make-A-Wish Foundation. Since the national chapter of the Make-A-Wish Foundation is the recipient of both the bundle and the outside option, participants who want to maximize donations to the charity should choose the bundle whenever its sum is greater than 150 cents. This allows us to examine decisions in a setting where stakes are comparable to the Self/Charity version (due to the calibration procedure) but where self-serving motives are absent. The results of this version are reported in Section 2.3.

The Self(150)/Self version is like the Self/Charity version, except that the recipient of the bundle is the participant and the outside option for all the decisions is 150 cents going to the participant. Since the participant is the recipient of both the bundle and the outside option, participants who want to maximize earnings in the experiment should choose the bundle whenever its sum is greater than 150 cents. This allows us to consider how the absence of self-serving motives influences

\footnotetext{
${ }^{20}$ In particular, as shown in Appendix Figure D.3, the price list contains 31 rows. On each row, the participant must decide between 150 cents being given to the Make-A-Wish Foundation national chapter and an amount of money for themselves that varies from 0 cents to 150 cents in five-cent increments (i.e., the price list gives $5 \times(r-1)$ cents to the participant on the $r^{t h}$ row). If a participant switches from choosing the first payment option on the $r^{t h}$ to the second payment option on the $(r+1)^{t h}$ row, then that participant is indifferent between 150 cents for the national chapter and $X$ cents for themselves, where $5 \times(r-1) \leq X \leq 5 \times r$. Setting $X$ to the lower bound ensures that, if anything, participants should prefer bundles over their outside option more when the outside option is $X$ cents for themselves than when it is 150 cents for the national chapter of the Make-A-Wish Foundation. To obtain more precise estimates of $X$ cents, one could employ a version of the DOSE approach in Wang, Filiba and Camerer $(2010)$.
} 
decisions in a setting where participants' own money is still at stake. As evident from our extensive discussion of the calibration procedure, however, we view the Charity/Charity version — and not the Self(150)/Self version - as the appropriate "control" for the Self/Charity version. The results of the $\operatorname{Self}(150) /$ Self version are reported in Section 2.3.

The Self/Charity-Choice and Self/Charity-Sum versions are like the Self/Charity version, except for what participants must learn about each bundle. In the Self/Charity-Choice version, participants are shown the first amount in each bundle by default but do not need to reveal the other three or four amounts before making a choice about the bundle. This allows us to examine whether our results persist among decisions in which participants are known to pay attention to the information in a bundle. In Self/Charity-Sum, participants must view all of the amounts in the bundle before making a choice, just like in the Self/Charity version, but they are also shown the sum of the amounts in the bundle on the decision screen (i.e., the computer sums the amounts for them and displays this sum). This allows us to examine participants' decisions when the already simple decision environment is simplified further. The results of both of these versions are reported in Section 2.4.

The Self/Charity-Unavoidable Sum version is like the Self/Charity-Sum version, except that the sum of the amounts in each bundle is made "unavoidable" to participants in two ways. First, the sum itself is made more salient on the decision screen. Second, prior to facing each decision screen, we informed participants about the sum of the bundle they were about to be shown, and they were required to correctly enter this amount into a text box before proceeding to the decision screen. The results of this version - and a discussion of how it is informative above and beyond what we already learn from the Self/Charity-Sum version — are reported in Section 2.4.

\subsection{Documenting errors in decisions}

In the Self/Charity version, we find clear evidence that participants make systematic errors in their decisions. In particular, participants are less likely to choose a bundle when a zero is added to it, even though the donation made by the bundle (i.e., the sum of the amounts in the bundle) has not changed.

Figure 2 shows our results graphically, collapsing across all our main bundles. The shading of the bars indicates the number of non-zero amounts in the bundle, which determines the sum of the bundle and whether the sum is above or below 150 cents. $^{21}$ It is clear that participants' willingness to choose a bundle is not solely driven by the number of non-zero amounts. For each of the four-amount bundles (i.e., the 4/4-bundles, the 3/4-bundles, and the 2/4-bundles), there are corresponding five-amount bundles that involve the same number of non-zero donation amounts (i.e., the 4/5-bundles, the 3/5-bundles, and the 2/5-bundles). The fact that these five-amount bundles contain an additional zero is payoff irrelevant, but adding a zero causes a substantial drop

\footnotetext{
${ }^{21}$ In the 5/5-bundles, 5 of the donation amounts are non-zero, so the sum is 255 to 295 cents. In the $4 / 4$ - and 4/5-bundles, 4 of the donation amounts are non-zero, so the sum is 204 to 236 cents. In the 3/4- and 3/5-bundles, 3 of the donation amounts are non-zero, so the sum is 153 to 177 cents. In the 2/4-and 2/5-bundles, 2 of the donation amounts are non-zero, so the sum is 102 to 118 cents.
} 
in willingness to choose a bundle.

Figure 2: In the Self/Charity version of Study 1, fraction choosing a main bundle

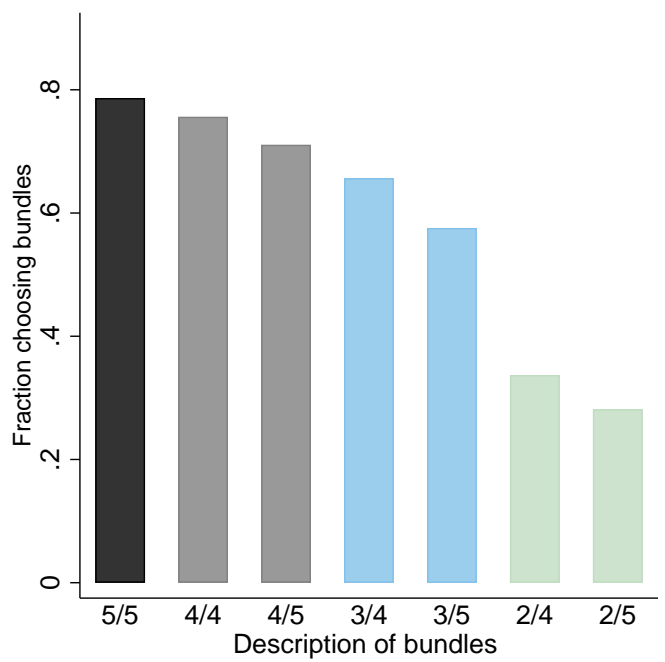

Data include all participants' decisions in all main bundles in the Self/Charity version of Study 1.

Table 2 presents the results from the main bundles in a regression framework that includes additional controls and carefully isolates the impact of adding a zero and the impact of adding a non-zero amount to a baseline $n / 4$-bundle. In particular, we report results from the following linear probability model:

$$
P(\text { choose bundle })=\beta_{1}\left({ }^{+} 0\right)+\beta_{2}\left({ }^{+} 1\right)+\sum_{n=2}^{4} \sum_{d=51}^{59} k_{n} \times l_{d}+\epsilon
$$

where $\left({ }^{+} 0\right)$ is an indicator for an $n / 5$-bundle that is constructed by adding a fifth amount that is equal to zero to a baseline $n / 4$-bundle, $\left({ }^{+} 1\right)$ is an indicator for an $(n+1) / 5$-bundle that is constructed by adding a fifth amount that is non-zero to a baseline $n / 4$-bundle (averaging the effect over the possible $d$ values), $k_{n}$ are dummies for the number of non-zero amounts within the underlying baseline $n / 4$-bundle (see Table A.1), and $l_{d}$ are dummies for the value of the non-zero amounts in the bundle, which range from 51 to 59 cents.

individuals make decisions in a setting in which they cannot fully access all relevant information unless they have perfect recall of information that was previously provided to them. Not only is there is noise in the information we provide to participants in our studies, all relevant information is on the decision screens in our studies.)

The coefficient estimate on $\left({ }^{+} 0\right)$ in Column 1 of Table 2 shows that adding a zero significantly decreases participants' willingness to choose a bundle by 6 percentage points. This effect is large. It is $10 \%$ of the likelihood of choosing a baseline bundle, which is 0.58 . It is more than half the magnitude of the 10 percentage point increase observed from adding a non-zero amount to a bundle 
(see the coefficient estimate on $\left({ }^{+} 1\right)$, which on average increases the total amount donated in a main bundle by 33\%. In addition, the 6 percentage point average effect reflects a large fraction of participants responding to the addition of the zero in this biased way: $50 \%$ of our participants make errors at least once by choosing an $n / 4$-bundle but not the $n / 5$-bundle constructed by adding a zero to it.

Table 2: In the Self/Charity version of Study 1, regression of choosing a main bundle

\begin{tabular}{|c|c|c|c|c|c|}
\hline Sample: & $\begin{array}{c}\text { main } \\
\text { bundles } \\
(1)\end{array}$ & $\begin{array}{r}\text { full } \\
\text { if } 4 / 4 \\
\text { baseline } \\
(2)\end{array}$ & $\begin{array}{c}\text { if } 2 / 4 \text { or } 3 / 4 \\
\text { baseline } \\
(3)\end{array}$ & $\begin{array}{c}\text { choice varies } \\
\text { main } \\
\text { bundles } \\
(4)\end{array}$ & $\begin{array}{c}X \text { is lower bound } \\
\text { main } \\
\text { bundles } \\
(5)\end{array}$ \\
\hline$\left({ }^{+} 0\right)$ & $\begin{array}{c}-0.06^{* * *} \\
(0.01)\end{array}$ & $\begin{array}{c}-0.04^{* * *} \\
(0.02)\end{array}$ & $\begin{array}{c}-0.07^{* * *} \\
(0.01)\end{array}$ & $\begin{array}{c}-0.08^{* * *} \\
(0.01)\end{array}$ & $\begin{array}{c}-0.07^{* * *} \\
(0.01)\end{array}$ \\
\hline$\left({ }^{+} 1\right)$ & $\begin{array}{c}0.11^{* * *} \\
(0.01)\end{array}$ & $\begin{array}{l}0.03^{* *} \\
(0.02)\end{array}$ & $\begin{array}{c}0.15^{* * *} \\
(0.02)\end{array}$ & $\begin{array}{c}0.14^{* * *} \\
(0.02)\end{array}$ & $\begin{array}{c}0.12^{* * *} \\
(0.01)\end{array}$ \\
\hline $\mathrm{N}$ & 7128 & 2376 & 4752 & 5616 & 6336 \\
\hline$k_{n} * l_{d}$ FEs & yes & yes & yes & yes & yes \\
\hline
\end{tabular}

${ }^{*} p<0.10,{ }^{* *} p<0.05,{ }^{* * *} p<0.01$. Standard errors are clustered at the participant-level and shown in parentheses. The results are from a linear probability model of the likelihood to choose a main bundle in the Self/Charity version of Study 1 , where $\left({ }^{+} 0\right)$ is an indicator for an $n / 5$-bundle that is constructed by adding a fifth amount that is equal to zero to a baseline $n / 4$-bundle, $\left({ }^{+} 1\right)$ is an indicator for an $(n+1) / 5$-bundle that is constructed by adding a fifth amount that is non-zero to a baseline $n / 4$-bundle, $k_{n} * l_{d}$ FEs include all possible interactions of dummies for the number of non-zero amounts within the underlying baseline $n / 4$-bundle (see Table A.1) and dummies for the value of the non-zero amount $d$ in the bundle to fully control for the sum of the amounts in the baseline bundle. Columns 1-3 analyze all participants' decisions: in all main bundles in Column 1, involving the baseline 4/4-bundles in Column 2, and involving the baseline 2/4- and 3/4-bundles in Column 3. Column 4 analyzes all main bundles but among a restricted sample of participants who choose the bundle at least once and choose their outside option at least once across all 48 decisions. Column 5 analyzes all main bundles but among a restricted sample of participants with outside option $X$ set to the lower bound of their indifference range (and thus excludes participants with a zero lower bound).

What can we say about why participants respond to the addition of the zero? First, participants do not solely interpret five-amount bundles more negatively than four-amount bundles, since adding a non-zero amount to a bundle increases participants' willingness to choose it. More is not less. ${ }^{22}$ Our effect is instead driven by participants responding to the addition of a zero to a bundle. Adding a zero makes a bundle less attractive, even though it does not change the sum of donations to charity.

Second, our results are not solely about the presence of a zero in a bundle. ${ }^{23}$ Column 2 of Table 2 examines the impact of adding a zero to a baseline bundle absent any zeros (i.e., to 4/4-bundles) while Column 3 of Table 2 examines the impact of adding a zero to a baseline bundle with one or

\footnotetext{
${ }^{22}$ This is not surprising. The donation from choosing a bundle in our experiment is known with certainty, and so our setting differs from prior literature that has documented a "more is less" phenomenon in environments in which underlying uncertainty about the value of a bundle allows agents to update about the bundle's overall quality when a good is added (Hsee, 1998; List, 2002; Leszczyc, Pracejus and Shen, 2008).

${ }^{23}$ This result helps us to differentiate from effects related to the presence of a zero, such as those observed in Magen, Dweck and Gross (2008) and Read, Olivola and Hardisty (2016), which show that decision-makers choosing between money now and money later can be made more patient by reminding them that taking money now means receiving $\$ 0$ later.
} 
two zeros (i.e., to 2/4-bundles or 3/4-bundles). The negative effect of adding a zero persists in both cases: adding a zero decreases participants' willingness to choose a bundle by 4 percentage points when a zero is not already present and by 7 percentage points when a zero is already present.

Our findings are also robust to different restrictions on the set of participants we consider. Column 4 and Column 5 of Table 2 examine whether our effect persists with more restricted samples of participants. Column 4 only includes participants who choose the bundle at least once and choose their outside option at least once. ${ }^{24}$ Not surprisingly, the impact of adding a zero is even larger (i.e., it is 8 percentage points) for this sample. Column 5 shows that our results are robust to excluding participants for whom we assigned an outside option of 5 cents because the lower bound of their indifference range was 0 cents.

\subsection{Documenting motivated errors}

In the previous subsection, we document systematic errors in decisions. When a zero is added to a bundle, participants are less likely to choose that bundle, even though the additional zero does not change the donation made by the bundle. Participants act as if $(n \times d)+0<(n \times d)$. A natural inclination for behaviorally minded researchers is to attempt to identify a cognitive limitation, behavioral bias, or heuristic that might explain these errors (see the related discussion footnote 15). For example, one might hypothesize that participants systematically miscalculate the amount in the bundle when a zero is added because they think in terms of the average amount (which is mechanically lower when there are more zeros) or because they overweigh the last amount in the bundle (which is zero when a zero is added). ${ }^{25}$

We instead examine whether self-serving motives might cause agents to make these errors. Thus, we consider two additional versions of Study 1 that eliminate self-serving motives. As described above, participants in the Self/Charity version made binary decisions between a bundle of money for a charity and an outside option of money for themselves and so had a potentially motivated reason to choose the outside option. In the Charity/Charity version, we eliminate the self-serving motive by having participants choose between the bundle for charity and an outside option of 150 cents for the same charity. Similarly, participants in the Self(150)/Self version chose between the bundle for themselves and an outside option of 150 cents for themselves. In these two versions, there is no self-serving motive to choose the outside option.

Panel A of Figure 3 reproduces Figure 2 for the Charity/Charity version. As expected, whether there are 3 or more non-zero amounts in a bundle (and thus the sum of the bundle is more than 150 cents) is the key determinant in whether the bundle is selected. Notably however, adding a zero to a bundle does not influence whether the bundle is selected. Participants' unresponsiveness to the addition of a zero is confirmed by the near-zero coefficient estimates on $\left({ }^{+} 0\right)$ in Panel A of

\footnotetext{
${ }^{24}$ Across all 48 decisions, $10 \%$ of participants never choose the outside option, and $11 \%$ of participants always choose the outside option.

${ }^{25}$ Counter to this latter possibility, when we regress choice on the location of zeros in a bundle, we do not find evidence that the location of zeros matters. In addition, results from some of our other study versions, discussed in Section 2.4, show that there is little scope for miscalculations or for inattention to produce these errors.
} 
Table 3. Similarly, Panel B of Figure 3 reproduces the figure for the Self(150)/Self version. The pattern looks almost identical to Panel A and participants' unresponsiveness to the addition of a zero is again confirmed by the near-zero coefficient estimates on $\left({ }^{+} 0\right)$ in Panel B of Table 3.

Figure 3: In the Charity/Charity and Self(150)/Self versions of Study 1, fraction choosing a main bundle

Panel A: Charity/Charity version

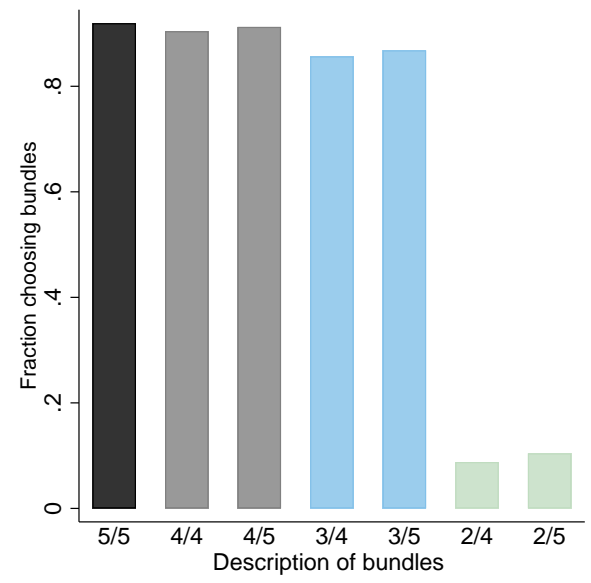

Panel B: Self(150)/Self version

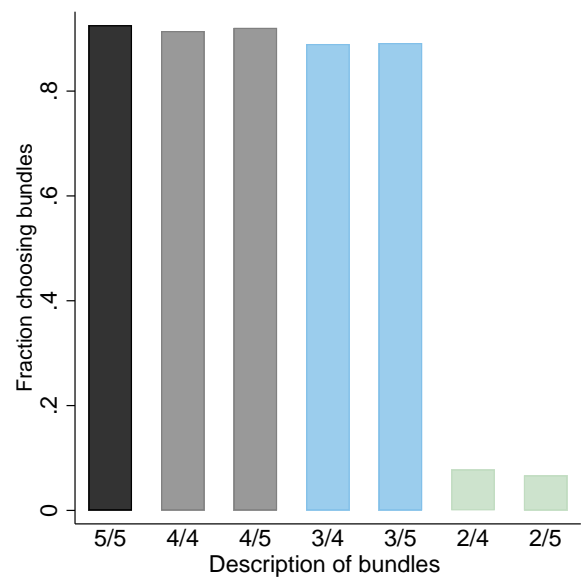

Data include all participants' decisions in all main bundles: in the Charity/Charity version of Study 1 in Panel A and in the Self(150)/Self version of Study 1 in Panel B.

That participants do not respond to the addition of a zero in the absence of self-serving motives means that participants are capable of accurately ignoring the addition of a zero when making their decisions. This implies that participants in the Self/Charity version are motivated to respond to the addition of a zero in a self-serving way.

To statistically confirm that the effect of adding a zero is different when self-serving motives are present and absent, we compare results from the Self/Charity and Charity/Charity versions. In both versions, participants face the same bundles going to the Make-A-Wish Foundation national chapter. The only difference is the outside option to choosing a bundle, which is $X$ cents for participants in Self/Charity and 150 cents for the national chapter in Charity/Charity. Since we estimate each participant's $X$ value to make them indifferent between $X$ cents for themselves and 150 cents for the national chapter, the comparison between these versions isolates the impact of removing self-serving motives without changing stakes. ${ }^{26}$

Appendix Table A.3 presents the corresponding results. The coefficients on $\left({ }^{+} 0\right)$ and $\left({ }^{+} 1\right)$ show the effects in Self/Charity version (which are mechanically the same as in Table 2). The coefficient on Charity/Charity and the associated interactions show how these effects differ in the Charity/Charity version. In particular, the coefficient on Charity/Charity* $\left.{ }^{+} 0\right)$ shows that the effect of adding a zero is fully eliminated when self-serving motives are removed.

\footnotetext{
${ }^{26}$ Note that a comparison between the Self/Charity and Self(150)/Self versions would involve a comparison across versions with different stakes and thus is not used.
} 
Table 3: In the Charity/Charity and Self(150)/Self versions of Study 1, regression of choosing a main bundle

\begin{tabular}{|c|c|c|c|c|c|}
\hline Sample: & $\begin{array}{l}\text { main } \\
\text { bundles } \\
(1)\end{array}$ & $\begin{array}{c}\text { full } \\
\text { if } 4 / 4 \\
\text { baseline } \\
(2)\end{array}$ & $\begin{array}{c}\text { if } 2 / 4 \text { or } 3 / 4 \\
\text { baseline } \\
(3)\end{array}$ & $\begin{array}{c}\text { choice varies } \\
\text { main } \\
\text { bundles } \\
(4)\end{array}$ & $\begin{array}{c}X \text { is lower bound } \\
\text { main } \\
\text { bundles } \\
(5)\end{array}$ \\
\hline \multicolumn{6}{|c|}{ Panel A: Charity/Charity version } \\
\hline$\left({ }^{+} 0\right)$ & $\begin{array}{c}0.01 \\
(0.01)\end{array}$ & $\begin{array}{c}0.01 \\
(0.01)\end{array}$ & $\begin{array}{c}0.01 \\
(0.01)\end{array}$ & $\begin{array}{c}0.01 \\
(0.01)\end{array}$ & $\begin{array}{c}0.01 \\
(0.01)\end{array}$ \\
\hline$\left({ }^{+} 1\right)$ & $\begin{array}{c}0.28^{* * *} \\
(0.01)\end{array}$ & $\begin{array}{c}0.02 \\
(0.01)\end{array}$ & $\begin{array}{c}0.42^{* * *} \\
(0.02)\end{array}$ & $\begin{array}{c}0.29^{* * *} \\
(0.01)\end{array}$ & $\begin{array}{l}0.29^{* * *} \\
(0.01)\end{array}$ \\
\hline $\mathrm{N}$ & 7164 & 2388 & 4776 & 7092 & 6156 \\
\hline$k_{n} * l_{d}$ FEs & yes & yes & yes & yes & yes \\
\hline \multicolumn{6}{|c|}{ Panel B: Self(150)/Self version } \\
\hline$\left({ }^{+} 0\right)$ & $\begin{array}{l}-0.00 \\
(0.01)\end{array}$ & $\begin{array}{c}0.01 \\
(0.01)\end{array}$ & $\begin{array}{l}-0.01 \\
(0.01)\end{array}$ & $\begin{array}{l}-0.00 \\
(0.01)\end{array}$ & $\begin{array}{l}-0.01 \\
(0.01)\end{array}$ \\
\hline$\left({ }^{+} 1\right)$ & $\begin{array}{c}0.29^{* * *} \\
(0.01)\end{array}$ & $\begin{array}{c}0.01 \\
(0.01)\end{array}$ & $\begin{array}{c}0.42^{* * *} \\
(0.01)\end{array}$ & $\begin{array}{c}0.29^{* * *} \\
(0.01)\end{array}$ & $\begin{array}{l}0.28^{* * *} \\
(0.01)\end{array}$ \\
\hline $\mathrm{N}$ & 7272 & 2424 & 4848 & 7128 & 6336 \\
\hline$k_{n} * l_{d}$ FEs & yes & yes & yes & yes & yes \\
\hline
\end{tabular}

${ }^{*} p<0.10,{ }^{* *} p<0.05,{ }^{* * *} p<0.01$. Standard errors are clustered at the participant-level and shown in parentheses. The results are from a linear probability model of the likelihood to choose a main bundle in the Charity/Charity version of Study 1 in Panel A and in the Self(150)/Self version of Study 1 in Panel $\mathrm{B}$, where $\left({ }^{+} 0\right)$ is an indicator for an $n / 5$-bundle that is constructed by adding a fifth amount that is equal to zero to a baseline $n / 4$-bundle, $\left({ }^{+} 1\right)$ is an indicator for an $(n+1) / 5$-bundle that is constructed by adding a fifth amount that is non-zero to a baseline $n / 4$-bundle, $k_{n} * l_{d}$ FEs include all possible interactions of dummies for the number of non-zero amounts within the underlying baseline $n / 4$-bundle (see Table A.1) and dummies for the value of the non-zero amount $d$ in the bundle to fully control for the sum of the amounts in the baseline bundle. Columns 1-3 analyze all participants' decisions: in all main bundles in Column 1, involving the baseline 4/4-bundles in Column 2, and involving the baseline 2/4- and 3/4-bundles in Column 3. Column 4 analyzes all main bundles but among a restricted sample of participants who choose the bundle at least once and choose their outside option at least once across all 48 decisions. Column 5 analyzes all main bundles but among a restricted sample of participants with outside option $X$ set to the lower bound of their indifference range (and thus excludes participants with a zero lower bound).

Evidence for motivated errors is also readily apparent at the individual level. First, the fraction of participants who make at least one error - choosing an n/4-bundle but not the n/5-bundle constructed from it - is $50 \%$ in the Self/Charity version but only $26 \%$ in the Charity/Charity version $(p<0.01)$. Second, the fraction of participants who make at least two errors of this form, with the second error arising in response to a bundle that have a different sum than the bundles in the first error, is $29 \%$ in the Self/Charity version but only $14 \%$ in the Charity/Charity version $(p<0.01)$. This latter result shows that participants' decisions do not simply reflect the use of an additional zero as a way to break indifference between the bundle and the outside option, since they could not be indifferent between their outside option and two bundles with different total amounts. Third, we find that the fraction of participants who display non-monotonic behavior (with regard 
to the sum of donations made by a bundle) is $37 \%$ in the Self/Charity version but is only $25 \%$ in the Charity/Charity version $(p<0.01) .{ }^{27}$ As expected, this non-monotonic classification is significantly correlated with whether participants respond to the addition of a zero.

We note that the comparison between the Self/Charity version and the Charity/Charity also allows us to specifically rule out any potential explanations for the response to adding a zero that are related to the experimental design itself, including experimenter demand effects (see, e.g., De Quidt, Haushofer and Roth (2017)). For instance, one could have worried that participants respond negatively to the addition of a zero because they think the experimenter wants them to respond negatively to the addition of a zero. However, this form of experimenter demand would have resulted in a response to the additional zero in both the Charity/Self and Charity/Charity versions, and we only observe it in the former.

Finally, we highlight that participants are able to correctly sum the amounts in the bundle - and that their ability to correctly sum the numbers does not depend on adding a zero lending additional credence to the notion that they are using the additional zero as an excuse. In a supplemental study, the Calculation study, participants are shown 12 of our main bundles (six n/4-bundles and the six n/5-bundles constructed from them) and are asked to report the sum of each bundle. $^{28}$ To incentivize accuracy, participants are told that one bundle will be randomly selected and the participant will receive a 25-cent bonus if they correctly sum the amounts in that bundle. Nearly all calculations are accurate: $98 \%$ and $99 \%$ of the calculations involving the $n / 4^{-}$ bundles and the $n / 5$-bundles, respectively, are accurate (and this one percentage point difference is not statistically significant). Participants are able to sum the bundles regardless of whether the bundle includes an additional 0 .

\subsection{Attempting to debias motivated errors}

We have documented evidence of motivated errors. In this subsection, we draw from a vast related literature and explore whether common debiasing strategies mitigate these motivated errors. We first specifically consider whether motivated errors are less likely as agents gain experience, when agents pay attention, and when the (already simple) decision environment is made simpler. None of these debiasing strategies (fully) mitigate motivated errors. We then provide results from the

\footnotetext{
${ }^{27}$ Our measure of non-monotonicity uses decisions from four non-main bundles that are denoted as $4^{L} / 4$-bundles because all four amounts are non-zero, but each amount is smaller than the amounts in the main bundles. The non-zero amounts in these bundles are randomly selected to be $d^{L}$ cents, where $d^{L} \in\{30,31,32,33,34,35,36,37,38\}$ (for more details about these bundles, see Appendix Table A.2). These bundles were constructed so that the sum of each bundle was close to, but lower than, the sum of each 3/4-bundle and each 3/5-bundle (i.e., $3 \times d>4 \times d^{L}$ for all $d$ and $d^{L}$ ). Thus, we call a participant non-monotonic if the participant chooses one or more $4^{L} / 4$-bundles and fails to choose all of the 3/4-bundles and 3/5-bundles. While we could construct other measures of non-monotonic behavior, even among this set of 16 bundles, this measure seems particularly natural since it utilizes bundles designed to be close in sum to our main bundles but with significantly lower individual donation amounts.

${ }^{28}$ On October 22 2019, we recruited 100 participants from Amazon's Mechanical Turk to complete the Calculation study. Each participant received $\$ 3$ for completing the 20-minute study as well as any additional bonus payments from one randomly selected decision. In addition, as with our other studies, workers must have previously completed at least 100 HITs with a 95\% or better approval rating and must be working from a United States IP address.
} 
Self/Charity-Unavoidable Sum version that we designed to fully mitigate motivated errors and that succeeded in doing so.

\section{The impact of experience}

Since we document evidence for motivated errors using a within-subject design, we can ask whether errors are mitigated as a participant gains experience over the 48 decisions in our study. Put differently, we can ask whether the response to adding a zero lessens or disappears with experience. We answer this question in two ways. First, we exploit that participants either make all 24 decisions involving four-amount bundles and then make all 24 decisions involving five-amount bundles or vice versa. Second, we exploit that the order of bundles randomly varies within the set of 24 four-amount bundles and within the set of 24 five-amount bundles.

Appendix Table A.4 examines whether our results differ as participants gain experience. For simplicity, only the results related to adding a zero are shown. Columns 1 and 2 split participants based on whether they faced the four-amount bundles first (and so the zeros were added in the second half of the study, Column 1) or the five-amount bundles first (so the zeros were added in the first half of the study, Column 2). Columns 3 and 4 show the results from decisions involving main bundles that occur "early" in each set (from the first half of each set, decisions 1-12 and 25-36, Column 3) or "late" in each set (from the second half of each set, decisions 13-24 and 37-48, Column 4). Rather than mitigating motivated errors, experience, if anything, exacerbates them (i.e., the estimated magnitude is larger in Column 4 than in Column 3).

That participants' decisions are influenced by an additional zero to the same degree when they first make decisions involving bundles that contain an additional zero (Column 1) as when they first make decisions involving bundles that do not contain an additional zero (Column 2) also provides evidence against cognitive dissonance or consistency influencing participants' decisions to a substantial degree (Cialdini, 1984; Bazerman, Loewenstein and White, 1992; Babcock et al., 1995; Konow, 2000; Haisley and Weber, 2010; Gneezy et al., 2012; Bohnet and Bazerman, 2016; Falk and Zimmermann, 2016; Golman et al., 2016; Gneezy et al., 2015; Gneezy, Saccardo and van Veldhuizen, 2018; Falk and Zimmermann, Forthcoming). Of course, the number of decisions that participants make in our study may minimize the role of these mechanisms, since participants may be less constrained by prior decisions if they cannot fully remember those prior decisions (Bénabou and Tirole, 2002; Zimmermann, 2018).

\section{The impact of attention}

Even though participants must reveal all of the amounts in the Self/Charity version, they may make errors because they fail to carefully attend to the amounts in the bundle. For instance, they may notice an additional 0 in a bundle but fail to pay attention to the other amounts in a bundle. To assess whether attention mitigates motivated errors, we ran the Self/Charity-Choice version in which participants have the option to avoid information about a bundle. While participants must still view the first amount in a bundle (as it is revealed by default), they can choose whether to click to reveal each of the remaining amounts in the bundle before making their choice. If 
attention mitigates motivated errors, they should not persist among the "attentive decisions" in which participants self-select into acquiring all of the information about a bundle before making their choice.

Column 1 of Appendix Table A.5 presents results from the $44 \%$ of decisions involving main bundles that we classify as attentive in the Self/Charity-Choice version - because participants chose to reveal all the information about the bundles — and the main bundles in the Self/Charity version. Motivated errors are present even when restricting to these attentive decisions. The coefficient on $\left({ }^{+} 0\right)$ applies to the attentive decisions in the Self/Charity-Choice version and shows that adding a zero significantly decreases participants' willingness to choose a bundle by 11 percentage points. The statistically significant positive coefficient on Self/Charity* $\left(^{+} 0\right)$ shows that the negative effect of adding a zero is larger among attentive decisions in the Self/Charity-Choice version than across all the decisions in the Self/Charity version.

While the main takeaway from the Self/Charity-Choice version is that attention does not mitigate evidence for motivated errors, we can make two additional observations. First, the statistically significant negative coefficient on Self/Charity in Column 1 of Appendix Table A.5 shows that the baseline four-amount bundles are more likely to be chosen in attentive decisions in the Self/CharityChoice version than in the Self/Charity version. Consequently, that motivated errors are prevalent in attentive decisions directly implies that they persist in decisions where participants are particularly inclined to choose the bundle. Second, one could have thought that motivated errors are driven by participants who are motivated to be inattentive. That evidence for motivated errors persists after excluding the decisions in which agents are shown to be inattentive (i.e., decisions in which agents choose not to reveal all the information about a bundle) suggests that this is not the case. While Appendix B.3 provides a richer discussion on how our results relate to the the motivated information avoidance literature, that motivated errors persist among the attentive decisions is also related to motivated information acquisition, rather than avoidance, as in Spiekermann and Weiss (2016).

\section{The impact of simplifying the decision environment}

While our environment is exceedingly simple — the relevant calculation for the participant's binary decision involves adding two to five two-digit numbers in a manner that can also be achieved with basic multiplication - one could theoretically imagine making it even simpler. In particular, an extreme intervention to debias participants would be to do the requisite math for them by directly showing them the sum of the amounts in the bundle. Such an intervention reveals that a bundle generates the same donation to charity whether or not the zero is added to the bundle.

In the Self/Charity-Sum version, we provide this information on the sum. In particular, in addition to being required to reveal each amount in a bundle, participants are directly informed of the sum of the amounts in the bundle when making the choice. Figure 4 shows the decision screens for the Self/Charity version in Panel A and for the Self/Charity-Sum version in Panel B.

Column 2 of Appendix Table A.5 presents results from decisions involving the main bundles in 
Figure 4: Example question faced by participants in the Self/Charity, Self/Charity-Sum, and Self/Charity-Unavoidable Sum versions, assuming $X=100$

(a) Self/Charity version

If this is your randomly selected decision, which option would you prefer?

Option A: Make-A-Wish Foundation receives a

donation equal to the sum of the amounts shown below.
Option B: I receive 100 cents.
Option A: Make-A-Wish Foundation receives a

donation equal to the sum of the amounts

shown below.

(c) Self/Charity-Unavoidable Sum version

If this is your randomly selected decision, which option would you prefer?

(b) Self/Charity-Sum version

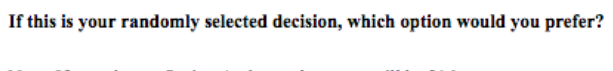

Note: If you choose Option A, the total amount will be 216 cents.

the Self/Charity-Sum and Self/Charity versions. The coefficient on $\left({ }^{+} 0\right)$ applies to the decisions in the Self/Charity-Sum version and its statistically significant negative coefficient demonstrates that motivated errors persist when we further simplify the decision environment by presenting the sum of donations made by the bundle. However, the statistically significant negative coefficient on Self/Charity* $\left(^{+} 0\right)$ reveals that presenting the sum does somewhat mitigate motivated errors.

\section{The impact of eliminating the ability to appear as if cognitive limitations are relevant}

Why does presenting the sum not entirely mitigate motivated errors? How can participants still act as if they cannot properly add a zero when they do not even need to add a zero to know the sum? There are two possible explanations as to how — even in this case — participants may be able to "create" uncertainty that helps them to justify selfish decisions.

The first explanation is that participants remain unaware of the sum even though it was displayed on their decision screens. Indeed, participants could be motivated not to pay attention to the sum because they want to exploit ignorance about the total amount in the charity payoff as an excuse to choose the selfish payoff. In this case, displaying the sum need not constrain their ability to create uncertainty about the value of the sum. While possible, this explanation is at odds with the fact that agents who desire to exploit such ignorance could have easily done so in the Self/CharityChoice version where they do not have to reveal all of the amounts in each charity payoff, yet our results persists among the "attentive decisions" in that version.

The second explanation is that participants are aware of the sum in the Self/Charity-Sum version but they act as if they are not. This could be relevant if the way in which motivated 
decisions arise is that participants desire to appear as if they are cognitively limited, even if they are not. Put differently, participants may care about whether there is uncertainty held by others - not necessarily themselves - as to whether they are aware of the sum. As discussed in Section 5 , such a desire could reflect conscious rationales if participants desire to rationalize their decisions to others (e.g., to the experimenter; or to others, even though no one else observes their decisions in the experiment).

To examine the impact of ensuring participants know the sum, we ran the Self/Charity-Unavoidable Sum version. Not only is the sum made more salient on the decision screen (see Panel C of Figure 4), participants are required to correctly report the sum for each charity payoff before making the associated decision (see Appendix Figure D.8). ${ }^{29}$ This combination proves successful at eliminating motivated errors. As shown in Column 3 of Appendix Table A.5, the coefficient on $\left({ }^{+} 0\right)$, which applies to the decisions in the Self/Charity-Unavoidable Sum version, is not significant (and is smaller in magnitude than all the other Self/Charity versions).

That only this final debiasing attempt — highlighting the sum and making participants report it back to us — succeeds at eliminating motivated errors indicates that individuals' ability to appear cognitively limited, or to create uncertainty that they can exploit, is particularly difficult to constrain. Only when individuals cannot be confused, nor appear confused to others, do we eliminate motivated errors. In the next section, we explore the robustness of our results by examining whether motivated errors arise in response to a salience manipulation.

\section{Study 2: Salience}

In our second set of experiments (Study 2), subjects make motivated errors in response to a salience manipulation. When choosing between a payoff for themselves and a payoff for multiple charities, participants are influenced by the saliency of something that is known to them. The corresponding errors in decisions are significantly less likely — but still arise — when self-serving motives are removed. These motivated errors survive the same debiasing techniques as in Study 1. Study 2 both shows robustness of the main results to a more-standard behavioral bias (i.e., salience) and shows that self-serving motives can also exacerbate errors that arise absent self-serving motives.

\subsection{Experimental Design}

A total of 1596 individuals participated in one of eight versions of Study $2 .{ }^{30}$ As in Study 1, each participant received $\$ 4$ for completing the 25-minute study. In addition, one randomly selected

\footnotetext{
${ }^{29}$ While this version ensures that participants are neither ignorant of the sum nor can act as if they are ignorant of the sum, we note that separating between these two possibilities is challenging. For instance, if we attempted to investigate whether individuals were doing correct calculations by asking them to report the sum, we would not know whether an individual who reported an incorrect sum was unaware of the correct sum or was trying to justify a selfish decision by acting unaware of the correct sum. That is, individuals might still misreport the sum to help rationalize their self-serving decisions (while actually knowing the correct sum). In addition, providing incentives for the proper calculation before a participant made a donation decision would fundamentally change the decision, and providing incentives after the donation decision would tell us whether the participant could report the sum but not whether the participant knew the sum at the time of the donation decision.

${ }^{30}$ As in Study 1, these participants were recruited from MTurk. See Appendix B for details.
} 
decision for each participant was implemented for bonus payment and resulted in an additional payment for the participant or a donation to charity.

Participants in Study 2 face the same 48 binary decisions as participants in Study 1 but each amount in a bundle is given to a different Make-A-Wish Foundation state chapter, rather than the sum of the amounts going to the national chapter. Which state chapters receive which amounts in a bundle is displayed on the decision screen for participants (see Figure 5 for an example). Participants are informed that any state chapter not included in a bundle receives no donation, and understanding questions ensure comprehension of this structure.

Figure 5: Example of how a bundle initially appears in Study 2

\begin{tabular}{l} 
If you choose to give to Make A-Wish Foundation state chapters, \\
the Louisiana chapter will receive: \\
\hline 54 cents \\
\hline $\begin{array}{l}\text { If you choose to give to Make A-Wish Foundation state chapters, } \\
\text { the Washington chapter will receive: }\end{array}$ \\
\hline $\begin{array}{l}\text { If you choose to give to Make A-Wish Foundation state chapters, } \\
\text { the North Carolina chapter will receive: }\end{array}$ \\
\hline $\begin{array}{l}\text { If you choose to give to Make A-Wish Foundation state chapters, } \\
\text { the Georgia chapter will receive: }\end{array}$ \\
\hline
\end{tabular}

Clicking on each header reveals the number of cents donated to that state chapter.

In Study 2, we ran four of the same versions as Study 1 (i.e., Self/Charity, Charity/Charity, Self/Charity-Choice, Self/Charity-Sum) and, as we will show below, we get the same pattern of results. In addition, we ran four additional study versions. The first two additional versions - Charity/Charity-Choice and Charity/Charity-Sum — are technically necessary as controls to test the effect of our debiasing techniques since we find evidence of errors in the Charity/Charity version. ${ }^{31}$ The final two treatments are discussed at length in Appendix B.2. Charity(ARC)/Charity underscores that the motivated errors we document are not driven by an added difficulty in making tradeoffs between two different recipients. Self(150)/Charity shows the value of our normalization and provides further evidence that our results persist absent the normalization. ${ }^{32}$

\subsection{Experimental Results}

Figure 6 shows the main results from the Self/Charity and Charity/Charity versions of Study 2. Panel A shows that making salient a charity that does not receive a donation (i.e., including it in the bundle rather than excluding it from the bundle) decreases willingness to choose the bundle in the Self/Charity version, even though the charity is known to receive no donation regardless of

\footnotetext{
${ }^{31}$ When biased behavior arises in both Self/Charity and Charity/Charity, the natural approach to considering whether a debiasing technique is effective at mitigating motivated errors is to compare how this difference between the two versions changes when debiasing techniques are used. We thus need to run Charity/Charity-Choice alongside Self/Charity-Choice and Charity/Charity-Sum alongside Self/Charity-Sum.

${ }^{32}$ Additional details about the versions of Study 2 can be found in Appendix B and Appendix Table B.1.
} 
whether or not it is included in the bundle. Panel B shows that these errors are less likely, but still present, when self-serving motives are removed in the Charity/Charity version.

Figure 6: In the Self/Charity version and the Charity/Charity version of Study 2, fraction choosing a main bundle

Panel A: Self/Charity

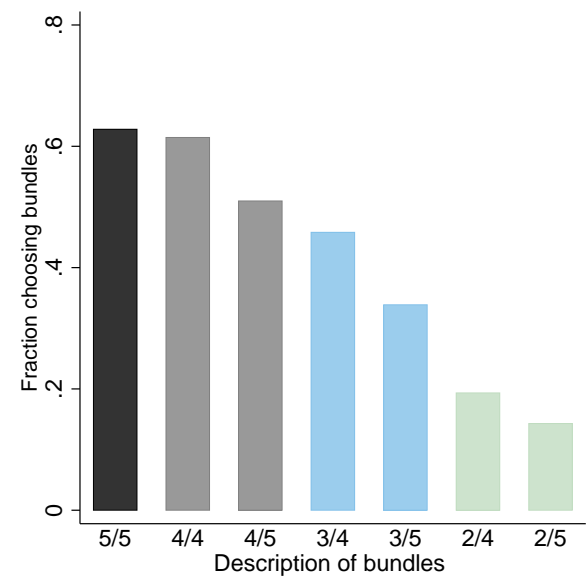

Panel B: Charity/Charity

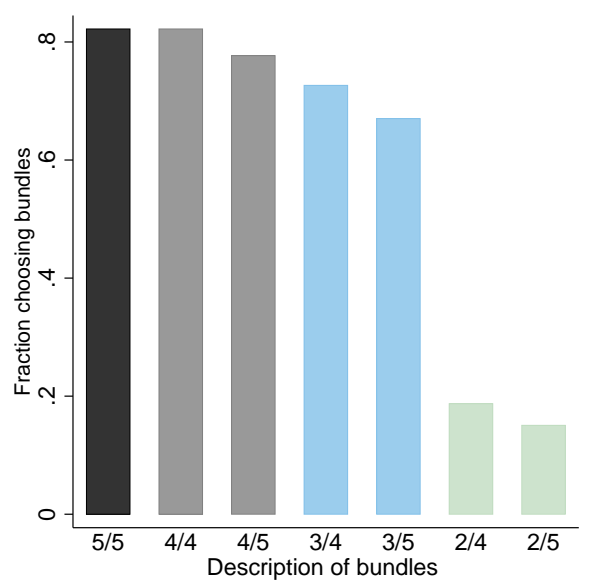

Data include all participants' decisions in all main bundles: in the Self/Charity version of Study 2 in Panel A and the Charity/Charity version of Study 2 in Panel B.

Appendix Table A.6 presents results from Figure 6 in a regression framework. The coefficient on $\left({ }^{+} 0\right)$ in Column 1 of Panel A shows that making salient a charity that does not receive a donation significantly decreases willingness to choose a bundle by 9 percentage points in the Self/Charity version. The coefficient on $\left({ }^{+} 0\right)$ in Column 1 of Panel B shows that making salient a charity that does not receive a donation also statistically significantly decreases willingness to choose a bundle by 4 percentage points in the Charity/Charity version. Appendix Table A.7 compares these coefficients and shows that the 5 percentage point difference between them is statistically significant. ${ }^{33}$

These results persist when restricting the type of bundles or restricting the sample of participants (as shown in Columns 2-5 of Appendix Tables A.6 and A.7). The results also survive our three main debiasing attempts. They persist when participants are relatively experienced (as shown in Appendix Table A.8), when subjects choose to be attentive (comparing results from Self/CharityChoice to results from Charity/Charity-Choice in Appendix Table A.9), and when we simplify the decision environment (comparing results from Self/Charity-Sum to Charity/Charity-Sum in Appendix Table A.9). ${ }^{34}$

\footnotetext{
${ }^{33}$ Appendix Table A.7 also shows that the bundle is chosen more often in Charity/Charity than Self/Charity, a difference that is itself reflective of self-serving motives.

${ }^{34}$ The last set of robustness tests shows that simplifying the (already simple) decision environment — by summing the donations made to charity in the bundle - does not mitigate the motivated error in Study 2, even though it was somewhat effective in Study 1. One possibility for the difference is that participants care about the distribution of donations made to various state chapters in Study 2, and thus the sum of donations is not a sufficient statistic about the bundle. Such distributional concerns could not have been relevant in Study 1 since all charity payoffs benefited a single charity. Note that we do not run the -Unavoidable Sum versions in Study 2 for similar reasons.
} 
While both Study 1 and Study 2 document evidence for motivated errors, they do so in different ways. Study 1 shows how self-serving motives create (otherwise non-existent) errors: motivated errors arise in the Self/Charity version but not in the Charity/Charity version. Study 2 shows how self-serving motives exacerbate (already existent) errors: errors arise in both the Self/Charity and Charity/Charity versions, but to a substantially greater degree in the Self/Charity version. ${ }^{35}$

\section{Study 3: Anchoring}

As in Study 1 and Study 2, Study 3 investigates whether there is evidence of motivated errors in response to payoff-irrelevant information. The structure of the first two studies allowed us to observe participants making multiple decisions and allowed us to run a variety of additional study versions to test debiasing strategies and to evaluate the robustness of our results. The structure of Study 3 is much simpler because the central purpose of Study 3 is to broaden the scope of our investigation of motivated errors and, secondarily, to show that our results are robust to a different experimental paradigm.

To broaden the scope of our investigation, two versions of Study 3 investigate one of the most well-studied behavioral biases: anchoring. We find that when participants are anchored to a 400cent donation to charity, they are substantially less likely to choose a 200-cent donation for charity when the alternative is money for themselves. When self-serving motives are removed, however, they no longer respond to these anchoring manipulations.

To show the robustness of our results to a new paradigm, a third version of Study 3 investigates the impact of complexity that arises from decisions in which participants must calculate a sum to determine how much money is going to charity. We find that when the alternative is money for themselves, participants are substantially less likely to choose 200 cents for charity when it is presented as $50+50+50+50+0$ cents rather than presented directly as 200 cents. When selfserving motives are removed, however, they respond substantially less to the presentation of the sum. Put differently, while Study 1 captures motivated errors that relate to the addition of a 0 , Study 3 captures motivated errors that arise from addition more generally.

Finally, all three versions of Study 3 provide additional evidence that our results are robust to our calibration procedure and to having participants make multiple main decisions. In Study 3, we employ a different calibration procedure and participants make a single main decision.

\subsection{Experimental Design}

Study 3 included 1505 participants randomized into one of eight study versions arising from a $2 \times 4$ design of $\{$ Self/Charity, Charity/Charity $\} \times\{$ Baseline, Anchor-1, Anchor-2, Addition $\} .{ }^{36}$

\footnotetext{
${ }^{35}$ Why do participants make errors even when self-serving motives are not relevant in the Charity/Charity version of Study 2? One natural explanation is that the decision environment in Study 2 is more "complex" than the decision environment in Study 1, thus causing more (unmotivated) errors. See also footnote 15 for a discussion of biases that could cause a response to a 0 in Study 2.

${ }^{36}$ As in Study 1 and Study 2, these participants were recruited from MTurk using the same qualification criteria as before. In particular, on October 22, 2019, we recruited and randomized 1505 participants from MTurk into one
} 
Each participant received $\$ 2$ for completing the 15 -minute study. In addition, one decision was randomly selected for each participant and determined any additional bonus payment.

In all versions, participants first complete 17 calibration decisions to determine their $X$ value such that they are indifferent between $X$ cents for themselves and 150 cents for the Make-A-Wish Foundation. Each decision involves a binary choice between: (i) 150 cents for charity and (ii) $Y_{i}$ cents for themselves where $Y_{i} \in\{0,5,10,20,30, \ldots, 150\}$. Each participant sees these 17 decisions in a random order.

For all participants who have an implied indifference range with a non-zero lower bound (i.e., for all participants who prefer the 150-cent donation to charity more than 0 cents for themselves and more than 5 cents for themselves), the $X$ value is set to $Y_{i-1}$ cents, where $Y_{i}$ is the smallest amount for which they prefer $Y_{i}$ cents for themselves over 150 cents for charity. For all other participants, the $X$ value is set to 5 cents. ${ }^{37}$

After completing the calibration decisions, participants make one final decision in which they choose between a 200-cent donation to the Make-A-Wish Foundation national chapter and an "outside option." The outside option equals a $X$-cent bonus payment for participants in the Self/Charity versions but a 150-cent donation to Make-A-Wish Foundation in the Charity/Charity versions. All that differs across the Baseline, Anchor-1, Anchor-2, and Addition versions is how information on Option A, the 200-cent donation, is presented.

In the Baseline version, the information about the 200-cent donation directly states that the donation amount equals 200 cents. In the other versions, the information about the 200-cent donation indirectly states the donation amount. In the Anchor-1 and Anchor-2 versions, participants are anchored to a higher donation amount of 400 cents because the information about the 200-cent donation states that it is: the smaller of 400 cents and 200 cents (in Anchor-1) or $400-200$ cents (in Anchor-2). In the Addition version, we introduce complexity - similar but even more complex than adding a 0 in Study 1 - since the information about the 200-cent donation describes it as equaling $50+50+50+50+0$ cents.

of these four versions. We intended to recruit 1500 participants, but due to a few subjects having difficulty with submitting their "completion" code on MTurk, we ended up with 1505 participants. Our randomization was weighted such that approximately twice as many participants would be randomized into one of the Baseline versions, since it would serve as the comparison group for all other versions. Overall, $48 \%$ of participants are female, the median age is 35 years old, and the median educational attainment is a Bachelor's Degree. Out of the $18 t-t e s t s$ that arise when comparing the three observable characteristics between the baseline version and each of the other three versions among either the Self/Charity versions or the Charity/Charity versions, there are no statistically significant differences. Full instructions for Study 3 can be found in Appendix D.3.

${ }^{37}$ As in Study 1 and Study 2, we show that our results are robust to restricting to the set of participants with $X$ values that reflect non-zero lower bounds of their indifference range. We also show that our results are robust to restricting to the set of participants who appear consistent in decisions: those with monotonic calibration decisions (i.e., such that they never choose $Y_{i-1}$ cents for themselves but not $Y_{i}$ cents for themselves for all $i$ ). This latter evidence indicates that our results persist among participants who are consistent in how they value money for themselves relative to money for charity (and thus may have less measurement error in their calibrations). 


\subsection{Experimental Results}

Figure 7 shows the results from Study 3. Panel A shows that, in the Self/Charity versions, both the anchoring versions and the addition version decrease the rate at which the 200-cent donation is chosen as compared to the baseline version. Panel B, however, shows that these effects are are either eliminated (in Anchor-1 and Anchor-2) or substantially reduced (in Addition) in the Charity/Charity versions when self-serving motives are absent.

Figure 7: In the Self/Charity version and the Charity/Charity version of Study 3, fraction choosing the 200-cent donation

Panel A: Self/Charity

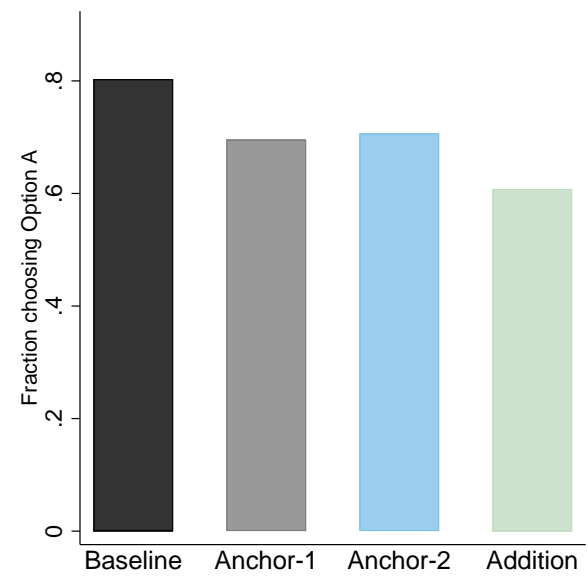

Panel B: Charity/Charity

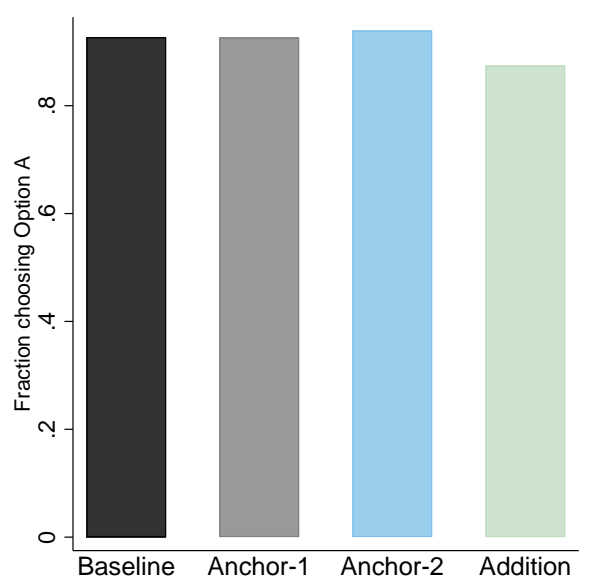

Data include all participants' decisions in the Self/Charity version of Study 3 in Panel A and the Charity/Charity version of Study 3 in Panel B.

Table 4 presents results from Figure 7 in a regression framework. In all regressions we compare the anchoring versions and addition version to the baseline version (the coefficient on Complex indicates that we are looking at an anchoring or addition version). In Column 1 of Panel A, Complex is negative and significant, showing that the first anchoring manipulation decreases willingness to choose the 200-cent donation by 11 percentage points in the Self/Charity version. By contrast, the coefficient on Complex in Column 1 of Panel B is 0 and statistically insignificant, showing that the first anchoring manipulation does not significantly influence willingness to choose the 200-cent donation in the Charity/Charity version. Column 2 presents similar results for the second anchoring manipulation. Column 3 presents an even larger impact of the addition treatment in the Self/Charity version, and a small, marginally statistically significant effect in the Charity/Charity version. Appendix Table A.10 confirms that the differences across the Self/Charity and Charity/Charity versions are statistically significant.

As we observed when considering results across both Study 1 and Study 2, our results in Study 3 again show that self-serving motives can create (otherwise non-existent) errors (i.e., in both of the anchoring versions) and exacerbate (already existent) errors (i.e., in the addition version). 
Unsurprisingly, Column 4 shows that the results persist when pooling across all study versions. Columns 5 and 6 show the robustness of our results to the sample restrictions noted in footnote 37. Notably, Column 6 shows that restricting to the set of participants with monotonic responses in the calibration procedure — indicating less measurement error in the calibration — results in, if anything, stronger evidence for motivated errors.

Table 4: In the Self/Charity and Charity/Charity versions of Study 3, regression of choosing the 200-cent donation

\begin{tabular}{|c|c|c|c|c|c|c|}
\hline \multirow{2}{*}{$\begin{array}{l}\text { Sample: } \\
\text { Version: }\end{array}$} & \multicolumn{4}{|c|}{ full } & \multirow{2}{*}{$\begin{array}{c}X \text { is lower } \\
\text { bound } \\
\text { All } \\
(5)\end{array}$} & \multirow{2}{*}{$\begin{array}{c}\text { monotonic } \\
\text { calibration } \\
\text { All } \\
(6)\end{array}$} \\
\hline & $\begin{array}{c}\text { Anchor-1 } \\
(1)\end{array}$ & $\begin{array}{c}\text { Anchor-2 } \\
(2)\end{array}$ & $\begin{array}{c}\text { Addition } \\
\quad(3)\end{array}$ & $\begin{array}{l}\text { All } \\
(4)\end{array}$ & & \\
\hline \multicolumn{7}{|c|}{ Panel A: Self/Charity versions } \\
\hline Complex & $\begin{array}{c}-0.11^{* *} \\
(0.04)\end{array}$ & $\begin{array}{c}-0.10^{* *} \\
(0.04)\end{array}$ & $\begin{array}{c}-0.20^{* * *} \\
(0.05)\end{array}$ & $\begin{array}{c}-0.13^{* * *} \\
(0.03)\end{array}$ & $\begin{array}{c}-0.09^{* * *} \\
(0.03)\end{array}$ & $\begin{array}{c}-0.17^{* * *} \\
(0.04)\end{array}$ \\
\hline Constant & $\begin{array}{c}0.80^{* * *} \\
(0.02)\end{array}$ & $\begin{array}{c}0.80^{* * *} \\
(0.02)\end{array}$ & $\begin{array}{c}0.80^{* * *} \\
(0.02)\end{array}$ & $\begin{array}{c}0.80^{* * *} \\
(0.02)\end{array}$ & $\begin{array}{c}0.89^{* * *} \\
(0.02)\end{array}$ & $\begin{array}{c}0.81^{* * *} \\
(0.03)\end{array}$ \\
\hline $\mathrm{N}$ & 456 & 455 & 453 & 754 & 551 & 569 \\
\hline \multicolumn{7}{|c|}{ Panel B: Charity/Charity versions } \\
\hline Complex & $\begin{array}{l}-0.00 \\
(0.03)\end{array}$ & $\begin{array}{c}0.01 \\
(0.02)\end{array}$ & $\begin{array}{c}-0.05^{*} \\
(0.03)\end{array}$ & $\begin{array}{l}-0.01 \\
(0.02)\end{array}$ & $\begin{array}{l}-0.00 \\
(0.02)\end{array}$ & $\begin{array}{l}-0.01 \\
(0.02)\end{array}$ \\
\hline Constant & $\begin{array}{c}0.93^{* * *} \\
(0.01)\end{array}$ & $\begin{array}{c}0.93^{* * *} \\
(0.01)\end{array}$ & $\begin{array}{c}0.93^{* * *} \\
(0.01)\end{array}$ & $\begin{array}{l}0.93^{* * *} \\
(0.01)\end{array}$ & $\begin{array}{c}0.94^{* * *} \\
(0.02)\end{array}$ & $\begin{array}{c}0.95^{* * *} \\
(0.01)\end{array}$ \\
\hline $\mathrm{N}$ & 452 & 450 & 453 & 751 & 559 & 590 \\
\hline \multicolumn{7}{|c|}{$\begin{array}{l}{ }^{*} p<0.10,{ }^{* *} p<0.05,{ }^{* * *} p<0.01 \text {. Standard errors are robust and shown in parentheses. The results } \\
\text { are from a linear probability model of the likelihood of choosing the } 200-\text { cent donation in the Self/Charity } \\
\text { version of Study } 3 \text { in Panel A and in the Charity/Charity version of Study } 3 \text { in Panel B, where Complex is } \\
\text { an indicator for one of the non-baseline versions. All columns include results from the Baseline version. The } \\
\text { non-baseline versions included are the Anchor- } 1 \text { version in Column } 1 \text {, the Anchor- } 2 \text { version in Column } 2 \\
\text { the Addition version in Column } 3 \text {, and all of these versions in Columns } 4-6 \text {. Column } 5 \text { involves a restricted } \\
\text { sample of participants with outside option } X \text { set to the lower bound of their indifference range (and thus } \\
\text { excludes participants with a zero lower bound). Column } 6 \text { involves a restricted sample of participants who } \\
\text { are monotonic in their calibration decisions. }\end{array}$} \\
\hline
\end{tabular}

\section{Conclusion}

Across three studies involving more than 4,200 participants and more than 100,000 main decisions, we show that payoff-irrelevant information influences decisions over payoffs, clear evidence of decision errors. These errors are eliminated — or dramatically reduced — when self-serving motives are removed (i.e., when agents are no longer motivated to make selfish decisions). This leads us to call them "motivated errors." Table 5 presents a summary of our results across the three studies. For each study, the table lists the versions with self-serving motives first (the first four rows for Study 1 and 2 and the first three rows for Study 3) followed by the versions without self-serving motives.

In light of our results, we have several observations that may be informative for future work. 
Table 5: The impact of irrelevant information in each study version

\begin{tabular}{|c|c|c|c|c|c|}
\hline & & & & $\begin{array}{r}\operatorname{Imp} \\
\text { irrelevant }\end{array}$ & $\begin{array}{l}\text { of } \\
\text { ormation }\end{array}$ \\
\hline & $\mathrm{N}$ & $\begin{array}{l}\text { Self-serving } \\
\text { motives? }\end{array}$ & $\begin{array}{l}\text { Baseline } \\
\text { Average }\end{array}$ & $\begin{array}{l}\text { Change in } \\
\text { Average }\end{array}$ & $\begin{array}{l}\text { Percent } \\
\text { Change }\end{array}$ \\
\hline \multicolumn{6}{|l|}{ Study 1} \\
\hline Self/Charity & 198 & Yes & 0.58 & $-0.06^{* * *}$ & $-10 \%$ \\
\hline Self/Charity-Choice & 195 & Yes & 0.52 & $-0.04^{* * *}$ & $-8 \%$ \\
\hline Self/Charity-Sum & 206 & Yes & 0.54 & $-0.03^{* * *}$ & $-6 \%$ \\
\hline Self/Charity-Unavoidable Sum & 168 & Yes & 0.51 & -0.02 & $-4 \%$ \\
\hline Charity/Charity & 199 & No & 0.62 & 0.01 & $2 \%$ \\
\hline Self $(150) /$ Self & 202 & No & 0.63 & -0.00 & $0 \%$ \\
\hline \multicolumn{6}{|l|}{ Study 2} \\
\hline Self/Charity & 203 & Yes & 0.42 & $-0.09^{* * *}$ & $-21 \%$ \\
\hline Self/Charity-Choice & 190 & Yes & 0.38 & $-0.06^{* * *}$ & $-16 \%$ \\
\hline Self/Charity-Sum & 195 & Yes & 0.42 & $-0.08^{* * *}$ & $-19 \%$ \\
\hline Self(150)/Charity & 200 & Yes & 0.24 & $-0.05^{* * *}$ & $-21 \%$ \\
\hline Charity/Charity & 191 & No & 0.58 & $-0.04^{* * *}$ & $-7 \%$ \\
\hline Charity/Charity-Choice & 215 & No & 0.50 & -0.01 & $-2 \%$ \\
\hline Charity/Charity-Sum & 202 & No & 0.56 & $-0.03^{* * *}$ & $-5 \%$ \\
\hline Charity $(A R C) /$ Charity & 200 & No & 0.57 & -0.01 & $-2 \%$ \\
\hline \multicolumn{6}{|l|}{ Study 3} \\
\hline Self/Charity-Anchor 1 & $456(151)$ & Yes & 0.80 & $-0.11^{* *}$ & $-14 \%$ \\
\hline Self/Charity-Anchor 2 & $455(150)$ & Yes & 0.80 & $-0.10^{* *}$ & $-13 \%$ \\
\hline Self/Charity-Addition & $453(148)$ & Yes & 0.80 & $-0.20^{* * *}$ & $-25 \%$ \\
\hline Charity/Charity-Anchor 1 & $452(150)$ & No & 0.93 & -0.00 & $0 \%$ \\
\hline Charity/Charity-Anchor 2 & $450(148)$ & No & 0.93 & 0.01 & $1 \%$ \\
\hline Charity/Charity-Addition & $453(151)$ & No & 0.93 & $-0.05^{*}$ & $-5 \%$ \\
\hline
\end{tabular}

$p<0.10,{ }^{* *} p<0.05,{ }^{* * *} p<0.01$. For Study 1 and Study 2, the baseline average is the fraction of baseline $n / 4$-bundles chosen, and the change in average is the estimated coefficient on $\left({ }^{+} 0\right)$ from the regression specification detailed for Column 1 of Table 2, run separately for each study version. For Study 3, the baseline average is the fraction choosing the 200-cent donation, and the change in the average is the estimated coefficient on Complex from the regression specifications in Table 4. Also, since Study 3 does not involve a within-subject design, note that results from two Baseline versions - one for the Charity/Self versions and one for the Charity/Charity versions - are used to determine these estimates. Thus, to make the sample sizes in Study 3 clear, the sample size shown in parentheses excludes participants from the Baseline versions.

First, while motivated reasoning is often facilitated by inattention or some level of unawareness, the motivated errors we document persist - and, if anything, are stronger - among the "attentive decisions" in the Self/Charity-Choice versions of Study 1 and Study 2. That attentiveness does not mitigate motivated errors suggests that conscious rationales may be at play (i.e., that agents may know they are making errors). Previous research has shown evidence of conscious rationales justifying behavior to others (see, e.g., Foerster and van der Weele (2018b)). A desire to consciously justify behavior to others may also relate to the rich literature on more self-serving outcomes that result from delegating one's decisions to others (Fershtman and Gneezy, 2001; Hamman, Loewenstein and Weber, 2010; Coffman, 2011; Bartling and Fischbacher, 2012; Oexl and Grossman, 2013), 
from obscuring the degree to which others can observe one's decisions (Dana, Cain and Dawes, 2006; Broberg, Ellingsen and Johannesson, 2007; Andreoni and Bernheim, 2009; Linardi and McConnell, 2011; Shaw et al., 2014), and from deceiving others (Gneezy, 2005; Shalvi et al., 2011; Shalvi, Eldar and Bereby-Meyer, 2012; Gino and Ariely, 2012; Gino, Ayal and Ariely, 2013; Pittarello et al., 2015; Bicchieri and Dimant, 2018). ${ }^{38}$ Given our results, an open question is whether conscious rationales may even help to justify behavior to oneself, for instance, because agents may desire for their decisions to appear justifiable to others even when they are not observed by others.

Second, we document motivated errors in decisions that require little to no calculation. An interesting avenue for future work is to consider settings that require more complex calculations, such as those that relate to base-rate neglect, correlation neglect, confirmation bias, and the gambler's fallacy. Such work could employ an identification strategy similar to the one in our studies varying the relevance of self-serving motives while ensuring stakes remain comparable — and observe whether biases are exacerbated when self-serving motives are relevant. Such work could also examine if — as proposed in Bénabou (2015) and Bénabou and Tirole (2016), and indeed consistent with the empirical findings from our experiments - the biased behavior: (i) occurs in a predictably selfserving direction, (ii) persists even as agents gain experience and when agents pay attention, and (iii) is pronounced when motives are about one's "religion, identity, morality, or politics." Indeed, we view such work as important because we agree with the speculation put forth in Bénabou and Tirole (2016) that self-serving motives may contribute to behavior and beliefs that seem to be indicative of agents "displaying limited cognitive abilities due to some the biases discussed in the large behavioral-economics and bounded-rationality literatures."

Our caveat to such future work, however, is that motivated errors can only be observed if there is room for individuals to act more confused than they actually are. As an example, let us turn to the results from an additional study that we ran ("Study 4") that follows a similar design as detailed in Study 3 (see Appendix C for full study details). Participants choose between a 200-cent donation to Make-A-Wish Foundation national chapter and $X$ cents for themselves in the Charity/Self versions of Study 4. When the 200-cent donation is presented directly, $79 \%$ of participants choose it. When information about the 200-cent donation is presented in a correlated way, only $49 \%$ of participants choose it. This 30 percentage point decrease is substantially larger than all of the effects we observe in our other studies. However, when participants choose between a 200-cent donation and a 150-cent donation to the national chapter in the Charity/Charity versions, the same change in how information about the 200-cent donation is presented results in a 68 percentage point decrease (from

\footnotetext{
${ }^{38}$ In the literature on deceiving others, participants are often described as making "errors" to achieve more selfserving outcomes (e.g., by misreporting the state of the world to others or to the experimenter). In these experiments, however, such "errors" are necessary to achieve certain self-serving outcomes (e.g., I have to tell the experimenter the die landed on 6 to get the highest possible payoff). Our experiments are notably different since self-serving outcomes can be achieved without making errors (indeed, the most self-serving outcomes would involve always choosing payoffs that benefit oneself and thus would not be indicative of errors). Put differently, rather that examining whether agents make errors to achieve the most self-serving outcome, we examine whether agents make errors to rationalize more self-serving outcomes.
} 
93\% to 25\%). This massive effect when participants are not motivated means we cannot conclude that individuals exploit correlation neglect as an excuse not to give. Note that the extent to which participants suffer from correlation neglect when self-serving motives are not relevant ensures this result. To find evidence of motivated errors in this experiment, the correlated information structure would have had to cause a decrease statistically significantly larger than the 68 percentage point decrease observed in the Charity/Charity versions (off of a base of 79\%). Rather than concluding that individuals are unlikely to exploit correlation neglect as an excuse, however, we simply note that in decision environments in which unmotivated errors are pervasive it may be infeasible to identify more errors arising due to self-serving motives. Put differently, we can only identify an individual making a motivated error if that individual does not make the same error when motives are removed. More empirical work is clearly needed to map out the space in which the complexity is sufficient enough to facilitate excuses but not so great as to prevent the identification of motived errors.

Third, that standard debiasing techniques used to eliminate errors due to cognitive limitations prove ineffective at countering motivated errors suggests the need for more work on debiasing techniques and highlight the value in determining whether an error is motivated before determining which debiasing strategies should be used. Related to work on the role of cognitive dissonance (Babcock et al., 1995; Haisley and Weber, 2010; Gneezy et al., 2015; Gneezy, Saccardo and van Veldhuizen, 2018), one approach may be to make motivated errors more salient to individuals by juxtaposing them with the lack of errors when agents are not motivated.

Fourth and finally, we speculate that motivated errors may be particularly difficult to mitigate because agents want to make these errors. If future work finds this to indeed be the case, another important question is whether trying to debias agents who display motivated errors makes them worse off. 


\section{References}

Andreoni, James, and B. Douglas Bernheim. 2009. "Social Image and the 50-50 Norm: A Theoretical and Experimental Analysis of Audience Effects." Econometrica, 77(5): 1607-1636.

Andreoni, James, Justin M. Rao, and Hannah Trachtman. 2016. "Avoiding the ask: A field experiment on altruism, empathy, and charitable giving." Journal of Political Economy.

Ashraf, Nava, Oriana Bandiera, and Scott S. Lee. 2014. "Awards Unbundled: Evidence from a Natural Field Experiment." Journal of Economic Behavior 85 Organization, 100: 44-63.

Babcock, Linda, George Loewenstein, Samuel Issacharoff, and Colin Camerer. 1995. "Biased Judgments of Fairness in Bargaining." The American Economic Review, 85(5): 1337-1343.

Barberis, Nicholas, Ming Huang, and Richard H Thaler. 2006. "Individual preferences, monetary gambles, and stock market participation: A case for narrow framing." The American economic review, 96(4): 1069-1090.

Bartling, Björn, and Urs Fischbacher. 2012. "Shifting the Blame: On Delegation and Responsibility." Review of Economic Studies, 79(1): 67-87.

Bartling, Björn, and Yagiz Özdemir. 2017. "The Limits to Moral Erosion in Markets: Social Norms and the Replacement Excuse." Working Paper.

Bartling, Björn, Florian Engl, and Roberto A. Weber. 2014. "Does willful ignorance deflect punishment? - An experimental study." European Economic Review, 70(0): 512 - 524.

Bartoš, Vojtěch, Michal Bauer, Julie Chytilová, and Filip Matějka. 2016. "Attention Discrimination: Theory and Field Experiments with Monitoring Information Acquisition." American Economic Review, 106(6): 1437-1475.

Batson, C Daniel, Diane Kobrynowicz, Jessica L Dinnerstein, Hannah C Kampf, and Angela D Wilson. 1997. "In a very different voice: unmasking moral hypocrisy." Journal of personality and social psychology, 72(6): 1997.

Batson, C Daniel, Elizabeth R Thompson, Greg Seuferling, Heather Whitney, and Jon A Strongman. 1999. "Moral hypocrisy: appearing moral to oneself without being so." Journal of personality and social psychology, 77(3).

Bazerman, Max H, George F Loewenstein, and Sally Blount White. 1992. "Reversals of preference in allocation decisions: Judging an alternative versus choosing among alternatives." Administrative Science Quarterly, 37(2): 220-240.

Bénabou, Roland. 2015. "The economics of motivated beliefs." Revue d'économie politique, 125(5): 665685. 
Bénabou, Roland, and Jean Tirole. 2002. "Self-confidence and personal motivation." The Quarterly Journal of Economics, 117(3): 871-915.

Bénabou, Roland, and Jean Tirole. 2004. "Willpower and personal rules." Journal of Political Economy, 112(4): 848-886.

Bénabou, Roland, and Jean Tirole. 2006. "Incentives and Prosocial Behavior." American Economic Review, 96(5): 1652-1678.

Bénabou, Roland, and Jean Tirole. 2011. "Identity, Morals, and Taboos: Beliefs as Assets." Quarterly Journal of Economics, 126: 805-855.

Bénabou, Roland, and Jean Tirole. 2016. "Mindful Economics: The Production, Consumption, and Value of Beliefs." Journal of Economic Perspectives, 30(3): 141-164.

Bénabou, Roland, Armin Falk, and Jean Tirole. 2018. "Narratives, Imperatives and Moral Reasoning." Working Paper.

Bicchieri, Cristina, and Eugen Dimant. 2018. "It's Not A Lie If You Believe It. Lying and Belief Distortion Under Norm-Uncertainty." Working Paper.

Bodner, Ronit, and Drazen Prelec. 2003. "Self-signaling and diagnostic utility in everyday decision making." The psychology of economic decisions, 1: 105-26.

Bohnet, Iris, Alexandra van Geen, and Max Bazerman. 2016. "When Performance Trumps Gender Bias: Joint Versus Separate Evaluation.” Management Science, 62(5): 1225-1234.

Bordalo, Pedro, Nicola Gennaioli, and Andrei Shleifer. 2012. "Salience theory of choice under risk." The Quarterly Journal of Economics, 127(3): 1243-1285.

Bordalo, Pedro, Nicola Gennaioli, and Andrei Shleifer. 2013. "Salience and consumer choice." Journal of Political Economy, 121(5): 803-843.

Broberg, Tomas, Tore Ellingsen, and Magnus Johannesson. 2007. "Is generosity involuntary?" Economics Letters, 94(1): 32-37.

Brocas, Isabelle, Juan D Carrillo, Stephanie W Wang, and Colin F Camerer. 2014. "Imperfect choice or imperfect attention? Understanding strategic thinking in private information games." Review of Economic Studies, 81(3): 944-970.

Buser, Thomas, Leonie Gerhards, and Joël J Van der Weele. 2018. "Measuring responsiveness to feedback as a personal trait." Journal of Risk and Uncertainty, 56(2): 165-192.

Bushong, Benjamin, Matthew Rabin, and Josh Schwartzstein. 2017. "A Model of Relative Thinking." Working Paper.

Caplin, Andrew. 2016. "Measuring and Modeling Attention." Annual Review of Economics, 8: 379-403. 
Caplin, Andrew, Mark Dean, and John Leahy. 2018. "Rational Inattention, Optimal consideration sets and stochastic choice." Review of Economic Studies.

Chadd, Ian, Emel Filiz-Ozbay, and Erkut Y. Ozbay. 2019. "The Relevance of Irrelevant Information." Working Paper.

Chance, Zoe, and Michael I Norton. 2015. "The what and why of self-deception." Current Opinion in Psychology, 6: 104-107.

Chetty, Raj, Adam Looney, and Kory Kroft. 2009. "Salience and taxation: Theory and evidence." The American Economic Review, 99(4): 1145-1177.

Chew, Soo Hong, Wei Huang, and Xiaojian Zhao. 2018. "Motivated False Memory." Working Paper.

Cialdini, Robert. 1984. Influence, the Psychology of Persuasion. New York:Harper Collins.

Coffman, Lucas C. 2011. "Intermediation Reduces Punishment (and Reward)." American Economic Journal: Microeconomics, 3(4): 1-30.

Conlisk, John. 1996. "Why bounded rationality?" Journal of economic literature, 34(2): 669-700.

Conrads, Julian, and Bernd Irlenbusch. 2013. "Strategic ignorance in ultimatum bargaining." Journal of Economic Behavior and Organization, 92(C): 104-115.

Coutts, Alexander. 2018. "Good news and bad news are still news: Experimental evidence on belief updating." Experimental Economics, 1-27.

Dana, Jason, Daylian M. Cain, and Robyn M. Dawes. 2006. "What you don't know won't hurt me: Costly (but quiet) exit in dictator games." Organizational Behavior and Human Decision Processes, 100: 193-201.

Dana, Jason, Roberto A. Weber, and Jason Xi Kuang. 2007. "Exploiting moral wiggle room: experiments demonstrating an illusory preference for fairness." Economic Theory, 33: 67-80.

Danilov, Anastasia, and Silvia Saccardo. 2016. "Disguised Discrimination." Working Paper.

DellaVigna, Stefano. 2009. "Psychology and economics: Evidence from the field." Journal of Economic literature, $47(2): 315-72$.

DellaVigna, Stefano, John List, and Ulrike Malmendier. 2012. "Testing for Altruism and Social Pressure in Charitable Giving." Quarterly Journal of Economics, 127(1): 1-56.

De Quidt, Jonathan, Johannes Haushofer, and Christopher Roth. 2017. "Measuring and Bounding Experimenter Demand." National Bureau of Economic Research.

Di Tella, Rafael, Ricardo Perez-Truglia, Andres Babino, and Mariano Sigman. 2015. "Conveniently Upset: Avoiding Altruism by Distorting Beliefs about Others' Altruism." American Economic Review, 105(11): 3416-42. 
Eil, David, and Justin M. Rao. 2011. "The Good News-Bad News Effect: Asymmetric Processing of Objective Information about Yourself." American Economic Journal: Microeconomics, 3(2): 114-138.

Enke, Benjamin. 2017. "What You See Is All There Is." Working Paper.

Enke, Benjamin, and Florian Zimmermann. 2019. "Correlation Neglect in Belief Formation." Review of Economic Studies, 88(1): 313-332.

Ertac, Seda. 2011. "Does self-relevance affect information processing? Experimental evidence on the response to performance and non-performance feedback." Journal of Economic Behavior E Organization, 80(3): 532-545.

Exley, Christine L. 2015. "Excusing Selfishness in Charitable Giving: The Role of Risk." Review of Economic Studies, 83(2): 587-628.

Exley, Christine L. Forthcoming. "Using Charity Performance Metrics as an Excuse Not To Give." Management Science.

Exley, Christine L., and Judd B. Kessler. 2019. "Equity Concerns are Narrowly Framed." Working paper.

Exley, Christine L., and Ragan Petrie. 2018. "The Impact of a Surprise Donation Ask." Journal of Public Economics, 158(152-167).

Falk, Armin, and Florian Zimmermann. 2016. "Consistency as a Signal of Skills." Management Science, 63(7): 2197-2210.

Falk, Armin, and Florian Zimmermann. Forthcoming. "Information Processing and Commitment." The Economic Journal.

Falk, Armin, and Nora Szech. 2013. "Morals and markets." Science, 340(6133): 707-711.

Falk, Armin, and Nora Szech. 2017. "Diffusion of Being Pivotal and Immoral Outcomes." Working Paper.

Feiler, Lauren. 2014. "Testing Models of Information Avoidance with Binary Choice Dictator Games." Journal of Economic Psychology.

Fershtman, Chaim, and Uri Gneezy. 2001. "Strategic delegation: An experiment." RAND Journal of Economics, 352-368.

Finkelstein, Amy. 2009. "E-ztax: Tax salience and tax rates." The Quarterly Journal of Economics, 124(3): 969-1010.

Foerster, Manuel, and Joel J van der Weele. 2018a. "Denial and Alarmism in Collective Action Problems." Working Paper. 
Foerster, Manuel, and Joël van der Weele. 2018b. "Persuasion, justification and the communication of social impact." Working Paper.

Freddi, Eleonora. 2018. "Do People Avoid Morally Relevant Information? Evidence from the Refugee Crisis." Working Paper.

Gabaix, Xavier. 2014. "A sparsity-based model of bounded rationality." The Quarterly Journal of Economics, 129(4): 1661-1710.

Gabaix, Xavier. 2017. "Behavioral Inattention." NBER Working Paper No. 24096.

Garcia, Thomas, Sébastien Massoni, and Marie Claire Villeval. 2018. "Ambiguity and excusedriven behavior in charitable giving." Working Paper.

Gauriot, Romain, Stephanie A. Heger, and Robert Slonim. 2019. "Altruism or Diminishing Marginal Utility?" Working Paper.

Gilovich, T., D. Griffin, and D. Kahneman. 2002. "The Affect Heuris." In Heuristics and biases: The psychology of intuitive judgment. 397-420. New York:Cambridge University Press.

Gino, Francesca, and Dan Ariely. 2012. "The dark side of creativity: original thinkers can be more dishonest." Journal of personality and social psychology, 102(3): 445.

Gino, Francesca, Michael I. Norton, and Roberto A. Weber. 2016. "Motivated Bayesians: Feeling Moral While Acting Egoistically." Journal of Economic Perspectives, 30(3): 189-212.

Gino, Francesca, Shahar Ayal, and Dan Ariely. 2013. "Self-serving altruism? The lure of unethical actions that benefit others." Journal of economic behavior $\&$ organization, 93(285-292).

Gneezy, Ayelet, Alex Imas, Amber Brown, Leif D Nelson, and Michael I Norton. 2012. "Paying to be nice: Consistency and costly prosocial behavior." Management Science, 58(1): 179-187.

Gneezy, Uri. 2005. "Deception: The Role of Consequences." The American Economic Review, 95(1): pp. 384-394.

Gneezy, Uri, Elizabeth A. Keenan, and Ayelet Gneezy. 2014. "Avoiding overhead aversion in charity." Science, 346(6209): 632-635.

Gneezy, Uri, Silvia Saccardo, and Roel van Veldhuizen. 2018. "Bribery: Behavioral Drivers of Distorted Decisions." Journal of the European Economic Association.

Gneezy, Uri, Silvia Saccardo, Marta Serra-Garcia, and Roel van Veldhuizen. 2015. "Bribing the Self." Working paper.

Golman, Russell, David Hagmann, and George Loewenstein. 2017. "Information Avoidance." Journal of Economic Literature, 55(1): 1-40. 
Golman, Russell, George Loewenstein, Karl Ove Moene, and Luca Zarri. 2016. "The Preference for Belief Consonance." Journal of Economic Perspectives, 30(3): 165-188.

Gotthard-Real, Alexander. 2017. "Desirability and information processing: An experimental study." Economics Letters, 152: 96-99.

Grossman, Zachary. 2014. "Strategic ignorance and the robustness of social preferences." Management Science, 60(11): 2659-2665.

Grossman, Zachary. 2015. "Self-signaling and social-signaling in giving." Journal of Economic Behavior \& Organization, 117(0): 26-39.

Grossman, Zachary, and David Owens. 2012. "An unlucky feeling: Overconfidence and noisy feedback." Journal of Economic Behavior \& Organization, 84(2): 510-524.

Grossman, Zachary, and Joël J van der Weele. 2017. "Self-image and willful ignorance in social decisions." Journal of the European Economic Association, 15(1).

Haisley, Emily C., and Roberto A. Weber. 2010. "Self-serving interpretations of ambiguity in otherregarding behavior." Games and Economic Behavior, 68: 614-625.

Hamman, John R., George Loewenstein, and Roberto A. Weber. 2010. "Self-Interest through Delegation: An Additional Rationale for the Principal-Agent Relationship." American Economic Review, 100(4): $1826-1846$.

Hanna, Rema, Sendhil Mullainathan, and Joshua Schwartzstein. 2014. "Learning through noticing: Theory and evidence from a field experiment." The Quarterly Journal of Economics, 129(3): 13111353.

Heger, Stephanie A, and Nicholas W Papageorge. 2018. "We should totally open a restaurant: How optimism and overconfidence affect beliefs." Journal of Economic Psychology, 67: 177-190.

Hsee, Christopher K. 1996. "Elastic justification: How unjustifiable factors influence judgments." Organizational Behavior and Human Decision Processes, , (1).

Hsee, Christopher K. 1998. "Less is better: When low-value options are valued more highly than high-value options." Journal of Behavioral Decision Making, 11(107-121).

Imas, Alex. 2016. "The realization effect: Risk-taking after realized versus paper losses." The American Economic Review, 106(8): 2086-2109.

Jacobsen, Karin J, Kari H Eika, Leif Helland, Jo Thori Lind, and Karine Nyborg. 2011. "Are nurses more altruistic than real estate brokers?" Journal of Economic Psychology, 32(5): 818-831.

Kahneman, Daniel. 2011. Thinking, fast and slow. Macmillan. 
Kamdar, Amee, Steven D. Levitt, John A. List, Brian Mullaney, and Chad Syverson. 2015. "Once and Done: Leveraging Behavioral Economics to Increase Charitable Contributions."

Konow, James. 2000. "Fair Shares: Accountability and Cognitive Dissonance in Allocation Decisions." The American Economic Review, 90(4): 1072-1092.

Köszegi, Botond. 2006. "Ego utility, overconfidence, and task choice." Journal of the European Economic Association, 4(4): 673-707.

Kőszegi, Botond, and Adam Szeidl. 2013. "A model of focusing in economic choice." Quarterly Journal of Economics, 128(1): 53-104.

Kuhnen, Camelia M. 2015. "Asymmetric learning from financial information." The Journal of Finance, 70(5): 2029-2062.

Kunda, Ziva. 1990. "The Case for Motivated Reasoning." Psychological Bulletin, 108(3): 480-498.

Larson, Tara, and Monica C. Capra. 2009. "Exploiting moral wiggle room: Illusory preference for fairness? A comment." Judgment and Decision Making, 4(6): 467-474.

Lazear, Edward P., Ulrike Malmendier, and Roberto A. Weber. 2012. "Sorting in experiments with application to social preferences." American Economic Journal: Applied Economics, 4(1): 136-163.

Leszczyc, Peter TL Popkowski, John W Pracejus, and Yingtao Shen. 2008. "Why more can be less: An inference-based explanation for hyper-subadditivity in bundle valuation." Organizational Behavior and Human Decision Processes, 105(2): 233-246.

Linardi, Sera, and Margaret A. McConnell. 2011. "No excuses for good behavior: Volunteering and the social environment." Journal of Public Economics, 95: 445-454.

Lin, Stephanie C., Rebecca L. Schaumberg, and Taly Reich. 2016. "Sidestepping the rock and the hard place: The private avoidance of prosocial requests." Journal of Experimental Social Psychology, $35-40$.

List, John A. 2002. "Preference reversals of a different kind: The "More is less" Phenomenon." American Economic Review, 92(5): 1636-1643.

List, John A. 2003. "Does Market Experience Eliminate Market Anomalies?" Quarterly Journal of Economics, 118(1): 41-71.

Liu, Peggy J, and Stephanie C Lin. 2018. "Projecting lower competence to maintain moral warmth in the avoidance of prosocial requests." Journal of Consumer Psychology, 28(1): 23-39.

Madrian, Brigitte C. 2014. "Applying insights from behavioral economics to policy design." Annual Review of Economics, 6(1): 663-688. 
Magen, Eran, Carol S Dweck, and James J Gross. 2008. "The hidden-zero effect representing a single choice as an extended sequence reduces impulsive choice." Psychological Science, '9(7): 648-649.

Matthey, Astrid, and Tobias Regner. 2011. "Do I really want to know? A cognitive dissonance-based explanation of other-regarding behavior." Game, 2(1): 114-135.

Mijović-Prelec, Danica, and Drazen Prelec. 2010. "Self-deception as self-signalling: a model and experimental evidence." Philosophical Transactions of the Royal Society B: Biological Sciences, 365(1538): 227-240.

Mobius, Markus M., Muriel Niederle, Paul Niehaus, and Tanya S. Rosenblat. 2014. "Managing Self-Confidence: Theory and Experimental Evidence." Working Paper.

Nyborg, Karine. 2011. "I don't want to hear about it: Rational ignorance among duty-oriented consumers." Journal of Economic Behavior \& Organization, 79(3): 263-274.

Oberholzer-Gee, Felix, and Reiner Eichenberger. 2008. "Fairness in Extended Dictator Game Experiments." The B.E. Journal of Economic Analysis 8 Policy, 8(1).

Oexl, Regine, and Zachary J Grossman. 2013. "Shifting the blame to a powerless intermediary." Experimental Economics, 16(3): 306-312.

Olschewski, Sebastian, Marius Dietsch, Elliot A Ludvig, et al. 2019. "Anti-social motives explain increased risk aversion for others in decisions from experience." Judgment and Decision Making, 14(1): 58-71.

Palma, Marco A, and Zhicheng Phil Xu. 2019. "Shadow of a Doubt: Moral Excuse in Charitable Giving." Review of Behavioral Economics, 6(2): 133-146.

Pittarello, Andrea, Margarita Leib, Tom Gordon-Hecker, and Shaul Shalvi. 2015. "Justifications shape ethical blind spots." Psychological Science.

Rabin, M. 1995. "Moral preferences, moral constraints, and self-serving biases." Working paper.

Rabin, Matthew. 1998. "Psychology and economics." Journal of Economic Literature, 36(1): 11-46.

Rabin, Matthew, and Georg Weizsäcker. 2009. "Narrow bracketing and dominated choices." The American Economic Review, 1508-1543.

Read, Daniel, Christopher Y Olivola, and David J Hardisty. 2016. "The value of nothing: Asymmetric attention to opportunity costs drives intertemporal decision making." Management Science.

Regner, Tobias. 2018. "Reciprocity under moral wiggle room: Is it a preference or a constraint?" $E x$ perimental Economics, 1-18.

Saucet, Charlotte, and Marie Claire Villeval. 2019. "Motivated memory in dictator games." Games and Economic Behavior, 117: 250-275. 
Schwardmann, Peter, and Joël van der Weele. 2017. "Deception and Self-Deception." Working Paper.

Schwardmann, Peter, Egon Tripodi, and Joël J. van der Weele. 2019. "Self-Persuasion: Evidence from Field Experiments at Two International Debating Competitions." Working Paper.

Schwartzstein, Joshua. 2014. "Selective attention and learning." Journal of the European Economic Association, 12(6): 1423-1452.

Serra-Garcia, Marta, and Nora Szech. 2019. "The (in)elasticity of moral ignorance." Working Paper.

Shalvi, Shaul, Jason Dana, Michel JJ Handgraaf, and Carsten KW De Dreu. 2011. "Justified ethicality: Observing desired counterfactuals modifies ethical perceptions and behavior." Organizational Behavior and Human Decision Processes, 115(2): 181-190.

Shalvi, Shaul, Ori Eldar, and Yoella Bereby-Meyer. 2012. "Honesty requires time (and lack of justifications)." Psychological science, 10(1264-1270).

Shaw, Alex, Natalia Montinari, Marco Piovesan, Kristina R Olson, Francesca Gino, and Michael I Norton. 2014. "Children develop a veil of fairness." Journal of Experimental Psychology: General, 143(1).

Simon, Herbert A. 1955. "A behavioral model of rational choice." The quarterly journal of economics, 69(1): 99-118.

Sims, Christopher A. 2003. "Implications of rational inattention." Journal of Monetary Economics, 50(3): 665-690.

Snyder, Melvin L, Robert E Kleck, Angelo Strenta, and Steven J Mentzer. 1979. "Avoidance of the handicapped: an attributional ambiguity analysis." Journal of personality and social psychology, 37(12): 2297-2306.

Spiekermann, Kai, and Arne Weiss. 2016. "Objective and subjective compliance: A norm-based explanation of 'moral wiggle room'." Games and Economic Behavior, 96: 170-183.

Taubinsky, Dmitry, and Alex Rees-Jones. Forthcoming. "Attention variation and welfare: theory and evidence from a tax salience experiment." Review of Economic Studies.

Thaler, Michael. 2019. "“The "Fake News" Effect: An Experiment on Motivated Reasoning and Trust in News".Abstract." Working Paper.

Trachtman, Hannah, Andrew Steinkruger, Mackenzie Wood, Adam Wooster, James Andreoni, James J. Murphy, and Justin M. Rao. 2015. "Fair weather avoidance: unpacking the costs and benefits of "Avoiding the Ask"." Journal of the Economic Science Association, 1-7.

Tversky, Amos, and Daniel Kahneman. 1973. "Availability: A heuristic for judging frequency and probability." Cognitive psychology, 5(2): 207-232. 
Tversky, Amos, and Daniel Kahneman. 1974. "Judgment under uncertainty: Heuristics and biases." Science, 185(4157): 1124-1131.

Tversky, Amos, and Daniel Kahneman. 1981. "The framing of decisions and the psychology of choice." Science, 211(4481): 453-458.

Tversky, Amos, and Daniel Kahneman. 1986. "Rational choice and the framing of decisions." Journal of business, S251-S278.

van der Weele, Joël J., Julija Kulisa, Michael Kosfeld, and Guido Friebel. 2014. "Resisting Moral Wiggle Room: How Robust Is Reciprocal Behavior?" American Economic Journal: Microeconomics, 6(3): 256-264.

Wang, Stephanie W., Michelle Filiba, and Colin F. Camerer. 2010. "Dynamically Optimized Sequential Experimentation (DOSE) for Estimating Economic Preference Parameters." Working Paper.

Zimmermann, Florian. 2018. "The Dynamics of Motivated Beliefs." Working Paper. 


\section{Appendixes (For Online Publication Only)}

\section{A Additional Tables and Results Mentioned in Main Text}

Table A.1: The 36 main bundles

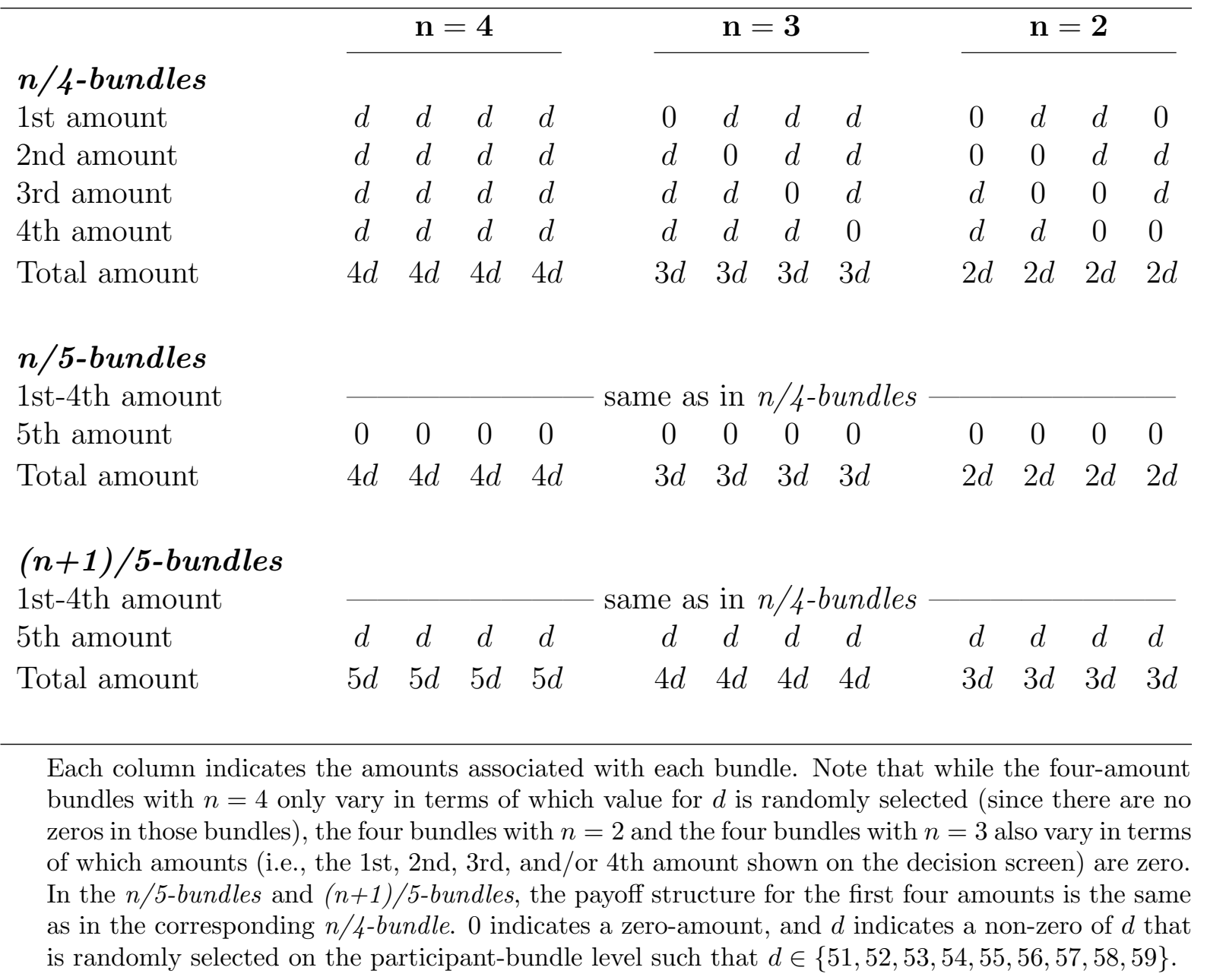

Table A.2: The 12 non-main bundles

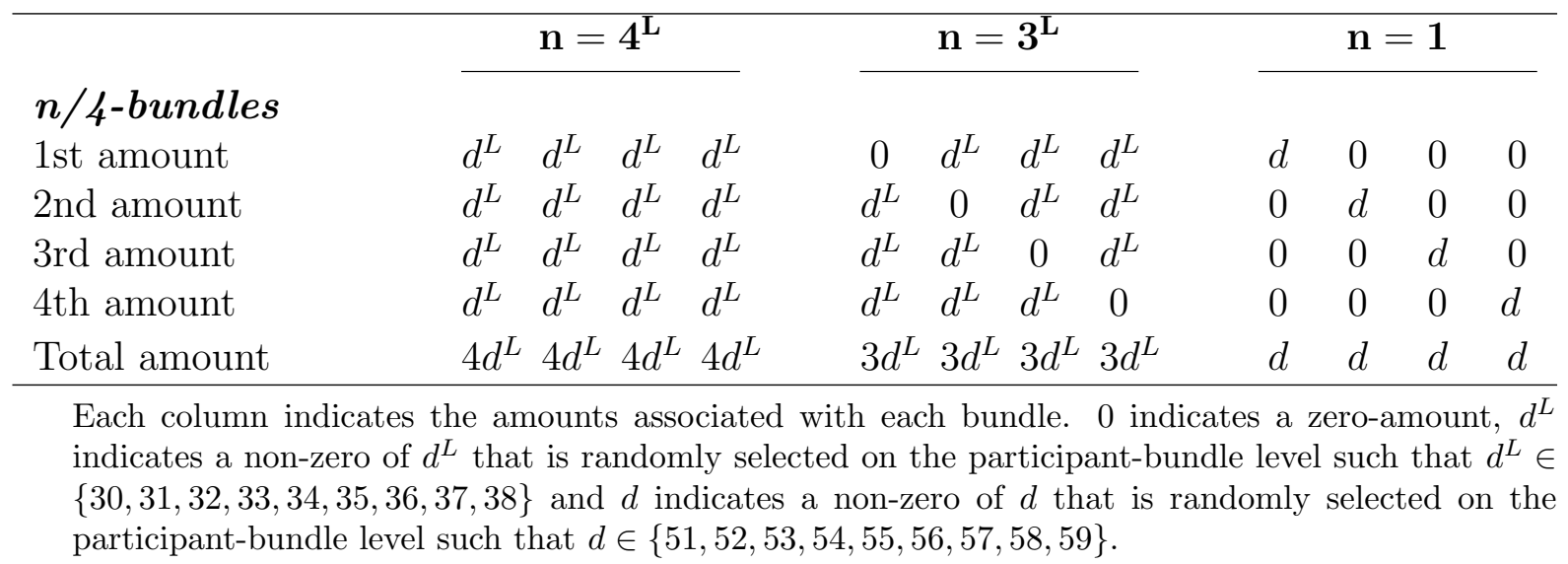


Figure A.1: Distribution of $X$ values

(a) Study 1

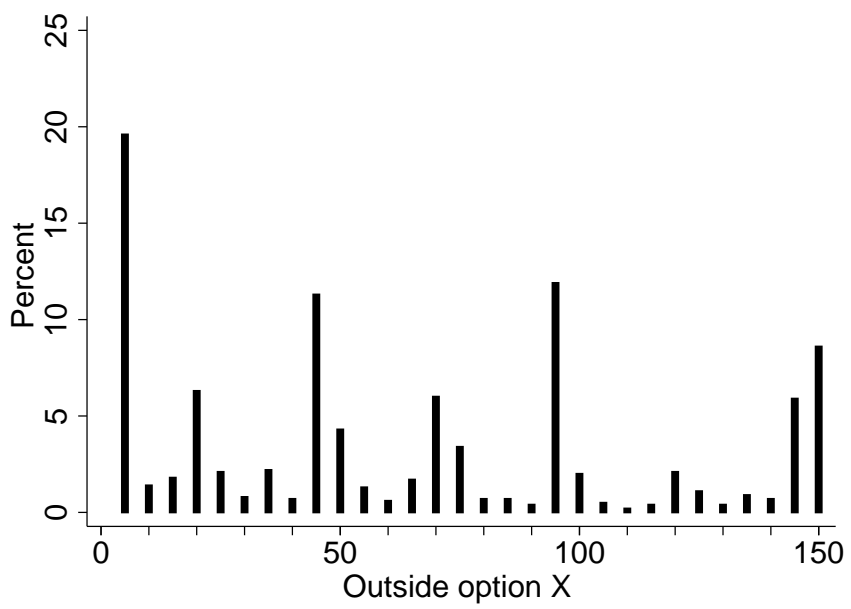

(b) Study 2

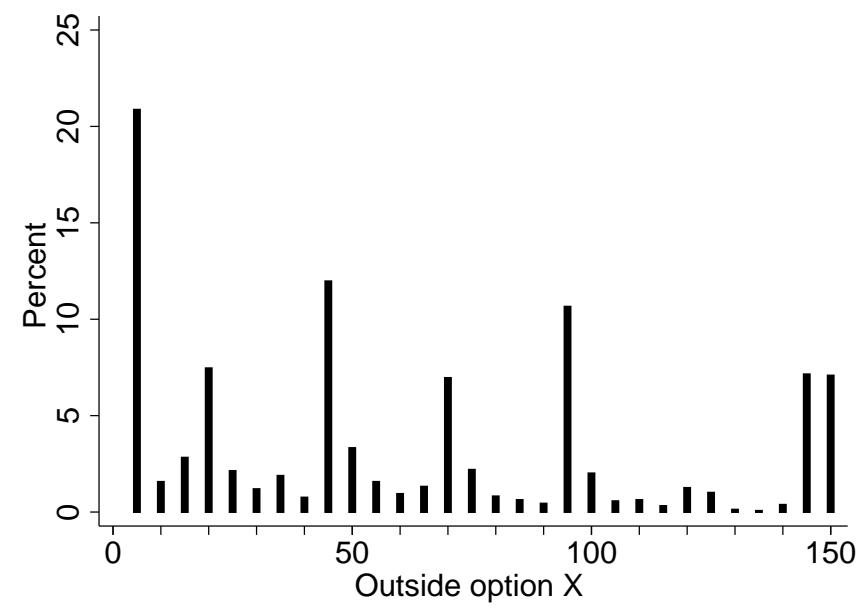

(c) Study 3

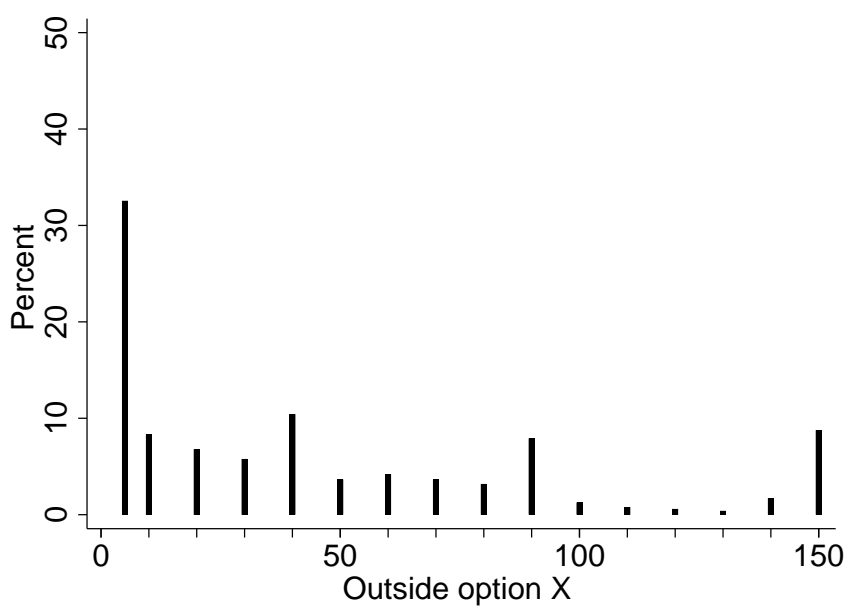

Data include all participants' decisions in the calibration procedure across all versions of Study 1 in Panel A, across all versions of Study 2 in Panel B, and across all versions of Study 3 in Panel C. $X$ is set to the lower bound of participants' implied indifference range from the calibration procedure except for when there is a zero lower bound and so $X$ is set to 5 cents. There is a zero lower bound for $12 \%$ of the 1000 participants in Study 1, for $13 \%$ of the 1596 participants in Study 2, and for $26 \%$ of the 1505 participants in Study 3. 
Table A.3: In the Self/Charity and the Charity/Charity version of Study 1, regression of choosing a main bundle

\begin{tabular}{|c|c|c|c|c|c|}
\hline Sample: & $\begin{array}{l}\text { main } \\
\text { bundles } \\
(1)\end{array}$ & $\begin{array}{r}\text { full } \\
\text { if } 4 / 4 \\
\text { baseline } \\
(2)\end{array}$ & $\begin{array}{c}\text { if } 2 / 4 \text { or } 3 / 4 \\
\text { baseline } \\
(3)\end{array}$ & $\begin{array}{c}\text { choice varies } \\
\text { main } \\
\text { bundles } \\
(4)\end{array}$ & $\begin{array}{c}X \text { is lower bound } \\
\text { main } \\
\text { bundles } \\
(5)\end{array}$ \\
\hline$\left({ }^{+} 0\right)$ & $\begin{array}{c}-0.06^{* * *} \\
(0.01)\end{array}$ & $\begin{array}{c}-0.04^{* * *} \\
(0.02)\end{array}$ & $\begin{array}{c}-0.07^{* * *} \\
(0.01)\end{array}$ & $\begin{array}{c}-0.08^{* * *} \\
(0.01)\end{array}$ & $\begin{array}{c}-0.07^{* * *} \\
(0.01)\end{array}$ \\
\hline$\left({ }^{+} 1\right)$ & $\begin{array}{c}0.11^{* * *} \\
(0.01)\end{array}$ & $\begin{array}{l}0.03^{* *} \\
(0.02)\end{array}$ & $\begin{array}{c}0.15^{* * *} \\
(0.02)\end{array}$ & $\begin{array}{c}0.14^{* * *} \\
(0.02)\end{array}$ & $\begin{array}{c}0.12^{* * *} \\
(0.01)\end{array}$ \\
\hline Charity/Charity* $\left(^{+} 0\right)$ & $\begin{array}{c}0.07^{* * *} \\
(0.02)\end{array}$ & $\begin{array}{c}0.06^{* * *} \\
(0.02)\end{array}$ & $\begin{array}{c}0.08^{* * *} \\
(0.02)\end{array}$ & $\begin{array}{c}0.09^{* * *} \\
(0.02)\end{array}$ & $\begin{array}{c}0.08^{* * *} \\
(0.02)\end{array}$ \\
\hline Charity/Charity* $\left.{ }^{+}{ }^{+} 1\right)$ & $\begin{array}{c}0.17^{* * *} \\
(0.02)\end{array}$ & $\begin{array}{l}-0.02 \\
(0.02)\end{array}$ & $\begin{array}{c}0.27^{* * *} \\
(0.02)\end{array}$ & $\begin{array}{c}0.15^{* * *} \\
(0.02)\end{array}$ & $\begin{array}{c}0.16^{* * *} \\
(0.02)\end{array}$ \\
\hline Charity/Charity & $\begin{array}{c}0.03 \\
(0.03)\end{array}$ & $\begin{array}{c}0.15^{* * *} \\
(0.03)\end{array}$ & $\begin{array}{l}-0.03 \\
(0.03)\end{array}$ & $\begin{array}{c}0.00 \\
(0.02)\end{array}$ & $\begin{array}{c}0.01 \\
(0.03)\end{array}$ \\
\hline $\begin{array}{l}\mathrm{N} \\
k_{n} * l_{d} \mathrm{FEs}\end{array}$ & $\begin{array}{c}14292 \\
\text { yes }\end{array}$ & $\begin{array}{c}4764 \\
\text { yes }\end{array}$ & $\begin{array}{c}9528 \\
\text { yes }\end{array}$ & $\begin{array}{c}12708 \\
\text { yes }\end{array}$ & $\begin{array}{c}12492 \\
\text { yes }\end{array}$ \\
\hline
\end{tabular}

${ }^{*} p<0.10,{ }^{* *} p<0.05,{ }^{* * *} p<0.01$. Standard errors are clustered at the participant-level and shown in parentheses. The results are from a linear probability model of the likelihood to choose a main bundle in the Self/Charity version or in the Charity/Charity version of of Study 1, where $\left({ }^{+} 0\right)$ is an indicator for an $n / 5$-bundle that is constructed by adding a fifth amount that is equal to zero to a baseline $n / 4$-bundle, $\left({ }^{+} 1\right)$ is an indicator for an $(n+1) / 5$-bundle that is constructed by adding a fifth amount that is non-zero to a baseline $n / 4$-bundle, Charity is an indicator for the Charity/Charity version, $k_{n} * l_{d}$ FEs include all possible interactions of dummies for the number of non-zero amounts within the underlying baseline n/4-bundle (see Table A.1) and dummies for the value of the non-zero amount $d$ in the bundle to fully control for the sum of the amounts in the baseline bundle. Columns 1-3 analyze all participants' decisions: in all main bundles in Column 1, involving the baseline 4/4-bundles in Column 2, and involving the baseline 2/4- and 3/4-bundles in Column 3. Column 4 analyzes all main bundles but among a restricted sample of participants who choose the bundle at least once and choose their outside option at least once across all 48 decisions. Column 5 analyzes all main bundles but among a restricted sample of participants with outside option $X$ set to the lower bound of their indifference range (and thus excludes participants with a zero lower bound). 
Table A.4: Considering the role of experience in the Self/Charity version of Study 1 , regression of choosing a main bundle

\begin{tabular}{|c|c|c|c|c|}
\hline & $\begin{array}{l}5 \text {-bundles first } \\
\text { (1) }\end{array}$ & $\begin{array}{l}\text { 4-bundles first } \\
\text { (2) }\end{array}$ & $\begin{array}{l}\text { early bundles } \\
\text { (3) }\end{array}$ & $\begin{array}{c}\text { late bundles } \\
\text { (4) }\end{array}$ \\
\hline$\left({ }^{+} 0\right)$ & $\begin{array}{c}-0.06^{* * *} \\
(0.02)\end{array}$ & $\begin{array}{c}-0.06^{* * *} \\
(0.02)\end{array}$ & $\begin{array}{l}-0.04^{* *} \\
(0.02)\end{array}$ & $\begin{array}{c}-0.08^{* * *} \\
(0.02)\end{array}$ \\
\hline $\mathrm{N}$ & 3744 & 3384 & 3568 & 3560 \\
\hline$\left({ }^{+} 1\right)$ controls & yes & yes & yes & yes \\
\hline$k_{n} * l_{d} \mathrm{FEs}$ & yes & yes & yes & yes \\
\hline
\end{tabular}

${ }^{*} p<0.10,{ }^{* *} p<0.05,{ }^{* * *} p<0.01$. Standard errors are clustered at the participant-level and shown in parentheses. The results are from a linear probability model of the likelihood to choose a main bundle in the Self/Charity version of Study 1 , where $\left({ }^{+} 0\right)$ is an indicator for an $n / 5$-bundle that is constructed by adding a fifth amount that is equal to zero to a baseline $n / 4$-bundle, $\left({ }^{+} 1\right)$ controls involve an indicator for an $(n+1) / 5$-bundle that is constructed by adding a fifth amount that is non-zero to a baseline $n / 4$-bundle, $k_{n} * l_{d}$ FEs include all possible interactions of dummies for the number of non-zero amounts within the underlying baseline $n / 4$-bundle (see Table A.1) and dummies for the value of the non-zero amount $d$ in the bundle to fully control for the sum of the amounts in the baseline bundle. Columns 1-2 analyze decisions in all main bundles by participants who first view the set of five-amount bundles then the set of four-amount bundles in Column 1 and instead by participants who first view the set of four-amount bundles then the set of five-amount in Column 2. Columns 3-4 analyze all participants' decisions in main bundles that occur "early" within each set of bundles (i.e., decisions 1-12 and 25-36) in Column 3 and that instead occur "late" within the set of bundles (i.e., decisions 13-24 and 37-48) in Column 4. 
Table A.5: Considering the role of inattention and simplifying the decision environment in Study 1, regression of choosing a main bundle

\begin{tabular}{|c|c|c|c|}
\hline & \multicolumn{3}{|c|}{ Self/Charity and } \\
\hline & $\begin{array}{c}\text { attentive } \\
\text { decisions from } \\
\text { Self/Charity-Choice } \\
\text { (1) }\end{array}$ & $\begin{array}{c}\text { Self/Charity } \\
\text {-Sum } \\
\\
(2)\end{array}$ & $\begin{array}{c}\text { Self/Charity } \\
\text {-Unavoidable Sum } \\
(3)\end{array}$ \\
\hline$\left({ }^{+} 0\right)$ & $\begin{array}{c}-0.11^{* * *} \\
(0.02)\end{array}$ & $\begin{array}{c}-0.03^{* * *} \\
(0.01)\end{array}$ & $\begin{array}{l}-0.02 \\
(0.01)\end{array}$ \\
\hline Self/Charity* $\left.{ }^{*}{ }^{+} 0\right)$ & $\begin{array}{l}0.05^{* *} \\
(0.02)\end{array}$ & $\begin{array}{l}-0.03^{*} \\
(0.02)\end{array}$ & $\begin{array}{c}-0.04^{* *} \\
(0.02)\end{array}$ \\
\hline Self/Charity & $\begin{array}{c}-0.12^{* * *} \\
(0.03) \\
\end{array}$ & $\begin{array}{c}0.04 \\
(0.03)\end{array}$ & $\begin{array}{l}0.08^{*} \\
(0.04)\end{array}$ \\
\hline $\mathrm{N}$ & 10209 & 14544 & 13176 \\
\hline$\left({ }^{+} 1\right)$ controls & yes & yes & yes \\
\hline$k_{n} * l_{d} \mathrm{FEs}$ & yes & yes & yes \\
\hline
\end{tabular}

${ }^{*} p<0.10,{ }^{* *} p<0.05,{ }^{* * *} p<0.01$. Standard errors are clustered at the participant-level and shown in parentheses. The results are from a linear probability model of the likelihood to choose a main bundle, where $\left({ }^{+} 0\right)$ is an indicator for an $n / 5$-bundle that is constructed by adding a fifth amount that is equal to zero to a baseline $n / 4$-bundle, Self/Charity is an indicator for being in the Self/Charity version, $\left({ }^{+} 1\right)$ controls involve an indicator for an $(n+1) / 5$-bundle that is constructed by adding a fifth amount that is non-zero to a baseline $n / 4$-bundle as well as an interaction of that indicator with the Self/Charity indicator, $k_{n} * l_{d}$ FEs include all possible interactions of dummies for the number of non-zero amounts within the underlying baseline $n / 4$-bundle (see Table A.1) and dummies for the value of the nonzero amount $d$ in the bundle to fully control for the sum of the amounts in the baseline bundle. Column 1 analyzes all participants' decisions in all main bundles in the Self/Charity version of Study 1 and all participants' decisions that are "attentive" (as indicated by them fully revealing information in that decision) in all main bundles in the Self/Charity-Choice version of Study 1. Column 2 analyzes all participants' decisions in all main bundles in the Self/Charity version of Study 1 and all participants' decisions in all main bundles in the Self/Charity-Sum version of Study 1. Column 3 analyzes all participants' decisions in all main bundles in the Self/Charity version of Study 1 and all participants' decisions in all main bundles in the Self/Charity-Unavoidable Sum version of Study 1. 
Table A.6: In the Self/Charity and Charity/Charity versions of Study 2, regression of choosing a main bundle

\begin{tabular}{|c|c|c|c|c|c|}
\hline Sample: & $\begin{array}{c}\text { main } \\
\text { bundles } \\
(1)\end{array}$ & $\begin{array}{c}\text { full } \\
\text { if } 4 / 4 \\
\text { baseline } \\
(2)\end{array}$ & $\begin{array}{c}\text { if } 2 / 4 \text { or } 3 / 4 \\
\text { baseline } \\
(3)\end{array}$ & $\begin{array}{c}\text { choice varies } \\
\text { main } \\
\text { bundles } \\
(4)\end{array}$ & $\begin{array}{c}X \text { is lower bound } \\
\text { main } \\
\text { bundles } \\
(5)\end{array}$ \\
\hline \multicolumn{6}{|c|}{ Panel A: Self/Charity version } \\
\hline$\left({ }^{+} 0\right)$ & $\begin{array}{c}-0.09^{* * *} \\
(0.01)\end{array}$ & $\begin{array}{c}-0.10^{* * *} \\
(0.02)\end{array}$ & $\begin{array}{c}-0.08^{* * *} \\
(0.01)\end{array}$ & $\begin{array}{c}-0.13^{* * *} \\
(0.02)\end{array}$ & $\begin{array}{c}-0.10^{* * *} \\
(0.01)\end{array}$ \\
\hline$\left({ }^{+} 1\right)$ & $\begin{array}{c}0.07^{* * *} \\
(0.01)\end{array}$ & $\begin{array}{c}0.01 \\
(0.01)\end{array}$ & $\begin{array}{c}0.10^{* * *} \\
(0.02)\end{array}$ & $\begin{array}{c}0.10^{* * *} \\
(0.02)\end{array}$ & $\begin{array}{l}0.08^{* * *} \\
(0.01)\end{array}$ \\
\hline $\mathrm{N}$ & 7308 & 2436 & 4872 & 5148 & 6048 \\
\hline$k_{n} * l_{d} \mathrm{FEs}$ & yes & yes & yes & yes & yes \\
\hline \multicolumn{6}{|c|}{ Panel B: Charity/Charity version } \\
\hline$\left({ }^{+} 0\right)$ & $\begin{array}{c}-0.04^{* * *} \\
(0.01)\end{array}$ & $\begin{array}{c}-0.03^{*} \\
(0.02)\end{array}$ & $\begin{array}{c}-0.05^{* * *} \\
(0.01)\end{array}$ & $\begin{array}{c}-0.05^{* * *} \\
(0.01)\end{array}$ & $\begin{array}{c}-0.04^{* * *} \\
(0.01)\end{array}$ \\
\hline$\left({ }^{+} 1\right)$ & $\begin{array}{c}0.17^{* * *} \\
(0.02)\end{array}$ & $\begin{array}{c}0.00 \\
(0.02)\end{array}$ & $\begin{array}{c}0.26^{* * *} \\
(0.02)\end{array}$ & $\begin{array}{c}0.19^{* * *} \\
(0.02)\end{array}$ & $\begin{array}{l}0.18^{* * *} \\
(0.02)\end{array}$ \\
\hline $\mathrm{N}$ & 6876 & 2292 & 4584 & 6192 & 5940 \\
\hline$k_{n} * l_{d} \mathrm{FEs}$ & yes & yes & yes & yes & yes \\
\hline
\end{tabular}

${ }^{*} p<0.10,{ }^{* *} p<0.05,{ }^{* * *} p<0.01$. Standard errors are clustered at the participant-level and shown in parentheses. The results are from a linear probability model of the likelihood to choose a main bundle in the Self/Charity version of Study 2 in Panel A and in the Charity/Charity version of Study 2 in Panel B, where $\left({ }^{+} 0\right)$ is an indicator for an $n / 5$-bundle that is constructed by adding a fifth amount that is equal to zero to a baseline $n / 4$-bundle, $\left({ }^{+} 1\right)$ is an indicator for an $(n+1) / 5$-bundle that is constructed by adding a fifth amount that is non-zero to a baseline $n / 4$-bundle, $k_{n} * l_{d}$ FEs include all possible interactions of dummies for the number of non-zero amounts within the underlying baseline $n / 4$-bundle (see Table A.1) and dummies for the value of the non-zero amount $d$ in the bundle to fully control for the sum of the amounts in the baseline bundle. Columns 1-3 analyze all participants' decisions: in all main bundles in Column 1, involving the baseline 4/4-bundles in Column 2, and involving the baseline 2/4- and 3/4-bundles in Column 3. Column 4 analyzes all main bundles but among a restricted sample of participants who choose the bundle at least once and choose their outside option at least once across all 48 decisions. Column 5 analyzes all main bundles but among a restricted sample of participants with outside option $X$ set to the lower bound of their indifference range (and thus excludes participants with a zero lower bound). 
Table A.7: In the Self/Charity and the Charity/Charity version of Study 2, regression of choosing a main bundle

\begin{tabular}{|c|c|c|c|c|c|}
\hline Sample: & $\begin{array}{l}\text { main } \\
\text { bundles } \\
(1)\end{array}$ & $\begin{array}{r}\text { full } \\
\text { if } 4 / 4 \\
\text { baseline } \\
(2)\end{array}$ & $\begin{array}{c}\text { if } 2 / 4 \text { or } 3 / 4 \\
\text { baseline } \\
(3)\end{array}$ & $\begin{array}{c}\text { choice varies } \\
\text { main } \\
\text { bundles } \\
(4)\end{array}$ & $\begin{array}{c}X \text { is lower bound } \\
\text { main } \\
\text { bundles } \\
(5)\end{array}$ \\
\hline$\left({ }^{+} 0\right)$ & $\begin{array}{c}-0.09^{* * *} \\
(0.01)\end{array}$ & $\begin{array}{c}-0.10^{* * *} \\
(0.02)\end{array}$ & $\begin{array}{c}-0.08^{* * *} \\
(0.01)\end{array}$ & $\begin{array}{c}-0.13^{* * *} \\
(0.02)\end{array}$ & $\begin{array}{c}-0.10^{* * *} \\
(0.01)\end{array}$ \\
\hline$\left({ }^{+} 1\right)$ & $\begin{array}{c}0.07^{* * *} \\
(0.01)\end{array}$ & $\begin{array}{c}0.01 \\
(0.01)\end{array}$ & $\begin{array}{c}0.10^{* * *} \\
(0.02)\end{array}$ & $\begin{array}{c}0.10^{* * *} \\
(0.02)\end{array}$ & $\begin{array}{c}0.08^{* * *} \\
(0.01)\end{array}$ \\
\hline Charity/Charity* $\left(^{+} 0\right)$ & $\begin{array}{c}0.05^{* * *} \\
(0.02)\end{array}$ & $\begin{array}{l}0.07^{* *} \\
(0.03)\end{array}$ & $\begin{array}{l}0.04^{*} \\
(0.02)\end{array}$ & $\begin{array}{c}0.08^{* * *} \\
(0.02)\end{array}$ & $\begin{array}{c}0.06^{* * *} \\
(0.02)\end{array}$ \\
\hline Charity/Charity* $\left.{ }^{+}{ }^{+} 1\right)$ & $\begin{array}{c}0.10^{* * *} \\
(0.02)\end{array}$ & $\begin{array}{l}-0.01 \\
(0.02)\end{array}$ & $\begin{array}{c}0.16^{* * *} \\
(0.03)\end{array}$ & $\begin{array}{c}0.09^{* * *} \\
(0.02)\end{array}$ & $\begin{array}{c}0.10^{* * *} \\
(0.02)\end{array}$ \\
\hline Charity/Charity & $\begin{array}{c}0.16^{* * *} \\
(0.03)\end{array}$ & $\begin{array}{c}0.21^{* * *} \\
(0.04)\end{array}$ & $\begin{array}{c}0.13^{* * *} \\
(0.03)\end{array}$ & $\begin{array}{l}0.06^{* *} \\
(0.03)\end{array}$ & $\begin{array}{c}0.13^{* * *} \\
(0.03)\end{array}$ \\
\hline $\begin{array}{l}\mathrm{N} \\
k_{n} * l_{d} \mathrm{FEs}\end{array}$ & $\begin{array}{c}14184 \\
\text { yes }\end{array}$ & $\begin{array}{c}4728 \\
\text { yes }\end{array}$ & $\begin{array}{c}9456 \\
\text { yes }\end{array}$ & $\begin{array}{c}11340 \\
\text { yes }\end{array}$ & $\begin{array}{c}11988 \\
\text { yes }\end{array}$ \\
\hline
\end{tabular}

${ }^{*} p<0.10,{ }^{* *} p<0.05,{ }^{* * *} p<0.01$. Standard errors are clustered at the participant-level and shown in parentheses. The results are from a linear probability model of the likelihood to choose a main bundle in the Self/Charity version or in the Charity/Charity version of Study 1, where $\left({ }^{+} 0\right)$ is an indicator for an $n / 5$-bundle that is constructed by adding a fifth amount that is equal to zero to a baseline $n / 4$-bundle, $\left({ }^{+} 1\right)$ is an indicator for an $(n+1) / 5$-bundle that is constructed by adding a fifth amount that is non-zero to a baseline $n / 4$-bundle, Charity/Charity is an indicator for the Charity/Charity version, $k_{n} * l_{d}$ FEs include all possible interactions of dummies for the number of non-zero amounts within the underlying baseline $n / 4$-bundle (see Table A.1) and dummies for the value of the non-zero amount $d$ in the bundle to fully control for the sum of the amounts in the baseline bundle. Columns 1-3 analyze all participants' decisions: in all main bundles in Column 1, involving the baseline 4/4-bundles in Column 2, and involving the baseline 2/4- and 3/4-bundles in Column 3. Column 4 analyzes all main bundles but among a restricted sample of participants who choose the bundle at least once and choose their outside option at least once across all 48 decisions. Column 5 analyzes all main bundles but among a restricted sample of participants with outside option $X$ set to the lower bound of their indifference range (and thus excludes participants with a zero lower bound). 
Table A.8: Considering the role of inexperience in the Self/Charity and Charity/Charity versions of Study 2, regression of choosing a main bundle

\begin{tabular}{|c|c|c|c|c|}
\hline & $\begin{array}{c}\text { 5-bundles first } \\
\text { (1) }\end{array}$ & $\begin{array}{c}\text { 4-bundles first } \\
\text { (2) }\end{array}$ & $\begin{array}{c}\text { early bundles } \\
(3)\end{array}$ & $\begin{array}{l}\text { late bundles } \\
(4)\end{array}$ \\
\hline $\begin{array}{l}\text { Panel A: Sel } \\
\left({ }^{+} 0\right)\end{array}$ & $\begin{array}{l}\text { Charity } \\
\qquad-0.09^{* * *} \\
(0.02)\end{array}$ & $\begin{array}{c}-0.09^{* * *} \\
(0.02)\end{array}$ & $\begin{array}{c}-0.07^{* * *} \\
(0.02)\end{array}$ & $\begin{array}{c}-0.11^{* * *} \\
(0.02)\end{array}$ \\
\hline $\begin{array}{l}\mathrm{N} \\
\left({ }^{+} 1\right) \text { controls } \\
k_{n} * l_{d} \mathrm{FEs}\end{array}$ & $\begin{array}{c}3744 \\
\text { yes } \\
\text { yes }\end{array}$ & $\begin{array}{c}3564 \\
\text { yes } \\
\text { yes }\end{array}$ & $\begin{array}{c}3665 \\
\text { yes } \\
\text { yes }\end{array}$ & $\begin{array}{c}3643 \\
\text { yes } \\
\text { yes }\end{array}$ \\
\hline $\begin{array}{l}\text { Panel B: } \boldsymbol{C h} \\
\left({ }^{+} 0\right)\end{array}$ & $\begin{array}{c}\text { ty/Charity } \\
-0.03 \\
(0.02)\end{array}$ & $\begin{array}{c}-0.05^{* * *} \\
(0.02)\end{array}$ & $\begin{array}{l}-0.02 \\
(0.02)\end{array}$ & $\begin{array}{c}-0.06^{* * *} \\
(0.02)\end{array}$ \\
\hline $\begin{array}{l}\mathrm{N} \\
\left({ }^{+} 1\right) \text { controls } \\
k_{n} * l_{d} \mathrm{FEs} \\
\end{array}$ & $\begin{array}{c}3060 \\
\text { yes } \\
\text { yes }\end{array}$ & $\begin{array}{c}3816 \\
\text { yes } \\
\text { yes }\end{array}$ & $\begin{array}{c}3462 \\
\text { yes } \\
\text { yes }\end{array}$ & $\begin{array}{c}3414 \\
\text { yes } \\
\text { yes }\end{array}$ \\
\hline
\end{tabular}

${ }^{*} p<0.10,{ }^{* *} p<0.05,{ }^{* * *} p<0.01$. Standard errors are clustered at the participant-level and shown in parentheses. The results are from a linear probability model of the likelihood to choose a main bundle in in the Self/Charity version of Study 2 in Panel A and in the Charity/Charity version of Study 2 in Panel B, where $\left({ }^{+} 0\right)$ is an indicator for an $n / 5$-bundle that is constructed by adding a fifth amount that is equal to zero to a baseline $n / 4$-bundle, $\left({ }^{+} 1\right)$ controls involve an indicator for an $(n+1) / 5$-bundle that is constructed by adding a fifth amount that is non-zero to a baseline $n / 4$-bundle, $k_{n} * l_{d}$ FEs include all possible interactions of dummies for the number of non-zero amounts within the underlying baseline $n / 4$-bundle (see Table A.1) and dummies for the value of the non-zero amount $d$ in the bundle to fully control for the sum of the amounts in the baseline bundle. Columns 1-2 analyze decisions in all main bundles by participants who first view the set of five-amount bundles then the set of four-amount bundles in Column 1 and instead by participants who first view the set of four-amount bundles then the set of five-amount in Column 2. Columns 3-4 analyze all participants' decisions in main bundles that occur "early" within each set of bundles (i.e., decisions 1-12 and 25-36) in Column 3 and that instead occur "late" within the set of bundles (i.e., decisions 13-24 and 37-48) in Column 4. 
Table A.9: Considering the role of inattention and simplifying the decision environment in Study 2, regression of choosing a main bundle

\begin{tabular}{lcc}
\hline \hline Panel A: Self/Charity versions & \multicolumn{2}{c}{ Self/Charity \begin{tabular}{c} 
and \\
\multicolumn{1}{c}{ attentive decisions from } \\
Self/Charity-Choice
\end{tabular}} \\
& $(1)$ & $(2)$ \\
\cline { 2 - 3 }$\left({ }^{+} 0\right)$ & $-0.16^{* * *}$ & $-0.08^{* * *}$ \\
& $(0.03)$ & $(0.01)$ \\
Self/Charity ${ }^{*}\left({ }^{+} 0\right)$ & $0.07^{* *}$ & -0.01 \\
& $(0.03)$ & $(0.02)$ \\
Self/Charity & $-0.20^{* * *}$ & -0.00 \\
& $(0.04)$ & $(0.04)$ \\
\hline $\mathrm{N}$ & 9378 & 14328 \\
$\left.{ }^{+} 1\right)$ controls & yes & yes \\
$k_{n} * l_{d}$ FEs & yes & yes
\end{tabular}

Panel B: Charity/Charity versions

Charity/Charity and

attentive decisions from Charity/Charity-Sum

Charity/Charity-Choice

(1)

$-0.06^{* * *}$

$(0.01)$

$-0.03^{* * *}$

Charity/Charity* $\left.{ }^{+}{ }^{+}\right)$

0.02

$(0.02)$

$-0.01$

Charity/Charity

$-0.04^{*}$

$(0.02)$

$(0.02)$

\begin{tabular}{lcc}
\hline $\mathrm{N}$ & 10767 & 14148 \\
$\left({ }^{+} 1\right)$ controls & yes & yes \\
$k_{n} * l_{d}$ FEs & yes & yes \\
\hline \hline
\end{tabular}

${ }^{*} p<0.10,{ }^{* *} p<0.05,{ }^{* * *} p<0.01$. Standard errors are clustered at the participant-level and shown in parentheses. The results are from a linear probability model of the likelihood to choose a main bundle in the Self/Charity or Self/Charity-Choice versions of Study 2 in Column 1 and in the Self/Charity or Self/Charity-Sum versions of Study 2 in Column 2, where $\left({ }^{+} 0\right)$ is an indicator for an $n / 5$-bundle that is constructed by adding a fifth amount that is equal to zero to a baseline $n / 4$-bundle, Self/Charity is an indicator for being in the Self/Charity version, $\left({ }^{+} 1\right)$ controls involve an indicator for an $(n+1) / 5$-bundle that is constructed by adding a fifth amount that is non-zero to a baseline $n / 4$-bundle as well as an interaction of that indicator with the Self/Charity indicator, $k_{n} * l_{d}$ FEs include all possible interactions of dummies for the number of non-zero amounts within the underlying baseline $n / 4$-bundle (see Table A.1) and dummies for the value of the non-zero amount $d$ in the bundle to fully control for the sum of the amounts in the baseline bundle. Column 1 analyzes all participants' decisions in all main bundles in the Self/Charity version of Study 2 and all participants' decisions that are "attentive" (as indicated by them fully revealing information in that decision) in all main bundles in the Self/Charity-Choice version of Study 2. Column 2 analyzes all participants' decisions in all main bundles in the Self/Charity version of Study 2 and all participants' decisions in all main bundles in the Self/Charity-Sum version of Study 2. 
Table A.10: In the Self/Charity and the Charity/Charity version of Study 3, regression of choosing the 200-cent donation

\begin{tabular}{|c|c|c|c|c|c|c|}
\hline \multirow{2}{*}{$\begin{array}{l}\text { Sample: } \\
\text { Version: }\end{array}$} & \multicolumn{4}{|c|}{ full } & \multirow{2}{*}{$\begin{array}{c}X \text { is lower } \\
\text { bound } \\
\text { All } \\
(5)\end{array}$} & \multirow{2}{*}{$\begin{array}{c}\text { monotonic } \\
\text { calibration } \\
\text { All } \\
(6)\end{array}$} \\
\hline & $\begin{array}{c}\text { Anchor-1 } \\
\text { (1) }\end{array}$ & $\begin{array}{c}\text { Anchor-2 } \\
(2)\end{array}$ & $\begin{array}{c}\text { Addition } \\
\quad(3)\end{array}$ & $\begin{array}{l}\text { All } \\
(4)\end{array}$ & & \\
\hline Complex & $\begin{array}{c}-0.11^{* *} \\
(0.04)\end{array}$ & $\begin{array}{c}-0.10^{* *} \\
(0.04)\end{array}$ & $\begin{array}{c}-0.20^{* * *} \\
(0.05)\end{array}$ & $\begin{array}{c}-0.13^{* * *} \\
(0.03)\end{array}$ & $\begin{array}{c}-0.09^{* * *} \\
(0.03)\end{array}$ & $\begin{array}{c}-0.17^{* * *} \\
(0.04)\end{array}$ \\
\hline Charity/Charity & $\begin{array}{c}0.12^{* * *} \\
(0.03)\end{array}$ & $\begin{array}{c}0.12^{* * *} \\
(0.03)\end{array}$ & $\begin{array}{c}0.12^{* * *} \\
(0.03)\end{array}$ & $\begin{array}{c}0.12^{* * *} \\
(0.03)\end{array}$ & $\begin{array}{l}0.05^{* *} \\
(0.03)\end{array}$ & $\begin{array}{c}0.14^{* * *} \\
(0.03)\end{array}$ \\
\hline $\begin{array}{l}\text { Charity/Charity } \\
{ }^{*} \text { Complex }\end{array}$ & $\begin{array}{l}0.11^{* *} \\
(0.05)\end{array}$ & $\begin{array}{l}0.11^{* *} \\
(0.05)\end{array}$ & $\begin{array}{l}0.14^{* *} \\
(0.06)\end{array}$ & $\begin{array}{c}0.12^{* * *} \\
(0.04)\end{array}$ & $\begin{array}{l}0.09^{* *} \\
(0.04)\end{array}$ & $\begin{array}{l}0.16^{* * *} \\
(0.04)\end{array}$ \\
\hline Constant & $\begin{array}{c}0.80^{* * *} \\
(0.02)\end{array}$ & $\begin{array}{c}0.80^{* * *} \\
(0.02)\end{array}$ & $\begin{array}{c}0.80^{* * *} \\
(0.02) \\
\end{array}$ & $\begin{array}{c}0.80^{* * *} \\
(0.02)\end{array}$ & $\begin{array}{c}0.89^{* * *} \\
(0.02) \\
\end{array}$ & $\begin{array}{c}0.81^{* * *} \\
(0.03) \\
\end{array}$ \\
\hline $\mathrm{N}$ & 908 & 905 & 906 & 1505 & 1110 & 1159 \\
\hline $\begin{array}{l}{ }^{*} p<0.10,{ }^{* *} p \\
\text { from a linear pro } \\
\text { or in the Charit } \\
\text { versions and Ch } \\
\text { from the Baselir } \\
\text { Anchor-2 versio } \\
\text { Column } 5 \text { involv } \\
\text { indifference rang } \\
\text { sample of partic }\end{array}$ & $\begin{array}{l}\text { arity/Charit } \\
\text { e version. I } \\
\text { es Column } \\
\text { in a restricte }\end{array}$ & $\begin{array}{l}\text { rsion of Stu } \\
\text { is an indica } \\
\text { he the Additi } \\
\text { d sample of }\end{array}$ & $\begin{array}{l}\text { lard errors a } \\
\text { hood to choc } \\
\text { y } 3 \text {, where } \\
\text { or for the } \\
\text { ne versions } \\
n \text { version in } \\
\text { articipants }\end{array}$ & $\begin{array}{l}\text { robust an } \\
\text { the } 200-\mathrm{c} \\
\text { mplex is } \\
\text { arity/Char } \\
\text { cluded are } \\
\text { olumn } 3 \text {, a } \\
\text { h outside }\end{array}$ & $\begin{array}{l}\text { own in paren } \\
\text { lonation in th } \\
\text { dicator for o } \\
\text { ersion. All c } \\
\text { Anchor-1 ver } \\
\text { ll of these ve } \\
\text { on } X \text { set to th } \\
\text { nd). Column }\end{array}$ & $\begin{array}{l}\text { The results } \\
\text { Charity versi } \\
\text { the non-basel } \\
\text { s include resu } \\
\text { n Column 1, } \\
\text { in Columns } 4 \\
\text { ar bound of th }\end{array}$ \\
\hline
\end{tabular}




\section{B Additional Information about Study 2}

\section{B.1 Additional Experimental Design Information about Study 2}

\section{Implementation details}

From October 10-13, 2016, we recruited and randomized 1200 participants from Amazon's Mechanical Turk (MTurk) into one of six study versions in a $2 \times 3$ design: $\{$ Self/, Charity $/\} \times\{$ Charity, Charity-Choice, Charity-Sum\}, and 1196 participants completed the study. On March 13, 2017, we recruited and randomized 400 participants into one of two study versions: Self(150)/Charity and Charity $(A R C) /$ Charity, and all 400 participants completed the study. To be eligible for any of our study versions, workers must have previously completed at least 100 HITs with a $95 \%$ or better approval rating and must be working from a United States IP address. Overall, 50\% of participants are female, the median age is 33 years old, and the median educational attainment is an Associate's Degree. There are not significant differences across the Self/ version and the Charity/ version for any of \{Charity, Charity-Choice, Charity-Sum $\}$ or between Self(150)/Charity and Charity $(A R C) /$ Charity, demonstrating successful randomization. Full instructions for Study 2 can be found in Appendix D.2.

\section{State Chapters}

Due to constraints (related to which chapters were approved by the IRB to receive donations and related to how some states shared chapters), we randomly drew states from a list of 28 states that we matched with corresponding Make-A-Wish Foundation chapters. This list of states was: Alaska, California, Colorado, Connecticut, Florida, Georgia, Illinois, Indiana, Iowa, Kentucky, Louisiana, Maine, Michigan, Missouri, Nebraska, Nevada, New Hampshire, New York, North Carolina, Ohio, Oklahoma, South Carolina, Tennessee, Texas, Utah, Virginia, Washington, and Wisconsin.

\section{Study Versions}

The eight versions of Study 2 vary along two dimensions: (1) the recipient and level of the outside option and (2) what information about the bundle participants must learn before making each choice. The differences across the eight versions of Study 2 are best visualized in Appendix Table B.1. 
Table B.1: Study 2 Versions

\begin{tabular}{|c|c|c|c|c|c|}
\hline \multicolumn{2}{|c|}{ Outside Option to... } & \multicolumn{2}{|c|}{...Charity } & \multicolumn{2}{|c|}{...Self } \\
\hline \multirow[t]{3}{*}{ Information } & Optional & & $\begin{array}{c}\text { Charity/ } \\
\text { Charity-Choice } \\
(\mathrm{n}=215)\end{array}$ & $\begin{array}{c}\text { Self / } \\
\text { Charity-Choice } \\
(\mathrm{n}=190)\end{array}$ & \\
\hline & Required & $\begin{array}{c}\text { Charity }(A R C) / \\
\text { Charity } \\
(\mathrm{n}=200)\end{array}$ & $\begin{array}{c}\text { Charity/ } \\
\text { Charity } \\
(\mathrm{n}=191)\end{array}$ & $\begin{array}{c}\text { Self } / \\
\text { Charity } \\
(\mathrm{n}=203)\end{array}$ & $\begin{array}{l}\text { Self(150)/ } \\
\text { Charity } \\
(\mathrm{n}=200)\end{array}$ \\
\hline & $\begin{array}{l}\text { Required } \\
\text { and Sum } \\
\text { Shown }\end{array}$ & & $\begin{array}{c}\text { Charity/ } \\
\text { Charity-Sum } \\
(\mathrm{n}=202)\end{array}$ & $\begin{array}{c}\text { Self } / \\
\text { Charity-Sum } \\
(\mathrm{n}=195)\end{array}$ & \\
\hline \multicolumn{2}{|l|}{ Bundle to... } & \multicolumn{4}{|c|}{...Charity } \\
\hline
\end{tabular}

\section{B.2 Additional Results from Study 2 to Address Additional Psycho- logical Explanations}

In this section, we present results from the final two versions of Study 2 to show the robustness of our results and to further confirm that observed differences between the Self/ and Charity/ versions of each study are due to self-serving motives.

The calibration procedure described in Section 2.1 ensures that each participant in Study 1 and Study 2 values their outside options roughly equivalently regardless of whether they are randomized into a Self/ or Charity/ version of the study. The calibration has a number of important advantages as described in Section 2.1. In that section, we emphasize that our identification strategy involves exploring decision errors within a person who faces a fixed outside option, and so we do not expect the calibration procedure to have an impact on our results.

Nevertheless, two concerns were raised to us: (i) errors might be more likely in the Self/Charity versions than the Charity/Charity versions because the calibration sets the nominal level of the outside option far from the sum of the donations in the bundle, which might make the amounts harder to compare; (ii) errors might be more likely in the Self/Charity versions than the Charity/Charity versions because the recipient of the bundle and the outside option were more similar in the Charity/Charity versions (the charities are alway the Make-A-Wish Foundation national chapter or state chapters and the self is a different recipient). ${ }^{39}$

Note that for such concerns to explain our results, they would need to make it easier to process the addition of a zero when the outside option is 150 cents for the Make-A-Wish Foundation national chapter and harder to process the addition of a zero when the outside option is a calibrated amount for oneself. That is, for a feature of the calibration or outside option to drive the differences across our versions it could not simply be that the calibration or outside option makes decisions "harder" in general in the Self/Charity versions, but rather it must be that this difficulty interacts with

\footnotetext{
${ }^{39}$ We are grateful to George Loewenstein for raising these concerns to us and inspiring the final two versions of Study 2, which are presented in this section.
} 
adding a zero in Study 1 and interacts with changing the salience of a state chapter in Study 2. While neither of the concerns raised above struck us as likely to interact with the ability to process the addition of a zero, we ran two additional study versions to address them. The Self(150)/Charity version of Study 2 was run to assuage concerns related to point (i). ${ }^{40}$ The Charity(ARC)/Charity version of Study 2 was run to assuage concerns related to point (ii).

In the Self(150)/Charity version, we still ask participants the calibration question (to keep procedures identical to the other treatments), but all participants make all decisions with 150 cents for themselves as the outside option, so the calibration does not affect their outside option. In this Self(150)/Charity version, the rate of choosing a baseline $n / 4$-bundle is only 0.24 . This is substantially and statistically significantly lower than the 0.42 rate of choosing a baseline $n / 4$-bundle in the Self/Charity version of Study 2. This difference suggests the need for the calibration in order to avoid censoring concerns from participants being too far from indifferent between the outside option and the bundles (an issue raised in Section 2.1). Indeed, while only $25 \%$ of participants in the Self/Charity version of Study 2 choose their outside option in all 48 decisions, this rate doubles to $51 \%$ in the Self(150)/Charity version. In spite of the lower rate of selecting bundles mechanically shrinking the effect in percentage point terms, Appendix Table B.2 shows that the response to making salient a charity that does not receive a donation is robust to the 150-cent outside option. Column 1 shows that participants are 5 percentage points less likely to choose a bundle when we add to it a charity that does not receive a donation. Given the lower rate of choosing the bundles in this version, the 5 percentage point reduction is the same percent effect (21\%) as the percent effect in the Self/Charity version of Study $2(21 \%)$. Columns 2 to 5 confirm the robustness of this result. Notably, in Column 4, when we focus on the restricted sample of participants who choose the bundle in at least one of the 48 decisions and choose the outside option in at least one of the 48 decisions, we see a coefficient that is similarly sized as in the Self/Charity version (10 percentage points here as compared to 9 percentage points in the Self/Charity version of Study 2). Thus, these results indicate that self-serving motives — rather than something about the calibration are driving the larger effects we observe the Self/ versions than in the Charity/ versions.

In the Charity $(A R C) / C h a r i t y$ version, the bundle continues to go to Make-A-Wish Foundation state chapters, but the outside option is now 150 cents for the American Red Cross, a charity that differs from the Make-A-Wish Foundation in both its mission and the types of people that it serves. If differences between recipients of the bundle and the outside option cause the errors that we see, then this difference should increase errors relative to the standard Charity/Charity version of Study 2, in which the recipients are more similar. As shown in Appendix Table B.2, the frequency of errors does not increase in the Charity $(A R C) /$ Charity and instead becomes statistically indistinguishable from 0. In fact, the estimated coefficient estimated on $\left({ }^{+} 0\right)$ in Charity $(A R C) /$ Charity is statistically

\footnotetext{
${ }^{40}$ It is worth noting that we observe motivated errors among participants with various $X$ values, including participants with $X$ that are close to, and exactly, 150 cents, which made it seem unlikely that concerns related to point (i) would be problematic.
} 
significantly smaller than that observed in the Charity/Charity version. This evidence directly counters the hypothesis that the difference between the recipient of the outside option and the recipient of the bundle is a key driver of the size of the bias. It should be noted, however that any variant of this difference-in-recipient argument that claims the differential effects across our Self/ and Charity/ versions arise due to particular difficulties associated with making self-other trade-offs will be isomorphic to our argument that self-serving motives (arising from a desire to keep money for oneself) are at play. We are thus happy to call any response particular to a self-other trade-off a result of self-serving motives.

Table B.2: In the Self(150)/Charity and Charity(ARC)/Charity versions of Study 2, regression of choosing a main bundle

\begin{tabular}{|c|c|c|c|c|c|}
\hline Sample: & $\begin{array}{l}\text { main } \\
\text { bundles } \\
\text { (1) }\end{array}$ & $\begin{array}{c}\text { full } \\
\text { if } 4 / 4 \\
\text { baseline } \\
(2)\end{array}$ & $\begin{array}{l}\text { if } 2 / 4 \text { or } 3 / 4 \\
\text { baseline } \\
(3)\end{array}$ & $\begin{array}{l}\text { choice varies } \\
\text { main } \\
\text { bundles } \\
(4)\end{array}$ & $\begin{array}{c}X \text { is lower bound } \\
\text { main } \\
\text { bundles } \\
(5)\end{array}$ \\
\hline \multicolumn{6}{|c|}{ Panel A: Self(150)/Charity version } \\
\hline$\left({ }^{+} 0\right)$ & $\begin{array}{c}-0.05^{* * *} \\
(0.01)\end{array}$ & $\begin{array}{c}-0.07^{* * *} \\
(0.02)\end{array}$ & $\begin{array}{c}-0.03^{* * *} \\
(0.01)\end{array}$ & $\begin{array}{c}-0.10^{* * *} \\
(0.02)\end{array}$ & $\begin{array}{c}-0.05^{* * *} \\
(0.01)\end{array}$ \\
\hline$\left({ }^{+} 1\right)$ & $\begin{array}{c}0.07^{* * *} \\
(0.01)\end{array}$ & $\begin{array}{c}0.01 \\
(0.01)\end{array}$ & $\begin{array}{c}0.10^{* * *} \\
(0.01)\end{array}$ & $\begin{array}{c}0.14^{* * *} \\
(0.02)\end{array}$ & $\begin{array}{l}0.07^{* * *} \\
(0.01)\end{array}$ \\
\hline $\mathrm{N}$ & 7200 & 2400 & 4800 & 3384 & 6372 \\
\hline$k_{n} * l_{d} \mathrm{FEs}$ & yes & yes & yes & yes & yes \\
\hline \multicolumn{6}{|c|}{ Panel B: Charity $(A R C) /$ Charity version } \\
\hline$\left({ }^{+} 0\right)$ & $\begin{array}{l}-0.01 \\
(0.01)\end{array}$ & $\begin{array}{l}-0.00 \\
(0.01)\end{array}$ & $\begin{array}{c}-0.02 \\
(0.01)\end{array}$ & $\begin{array}{l}-0.02 \\
(0.01)\end{array}$ & $\begin{array}{l}-0.02^{*} \\
(0.01)\end{array}$ \\
\hline$\left({ }^{+} 1\right)$ & $\begin{array}{c}0.21^{* * *} \\
(0.01)\end{array}$ & $\begin{array}{l}0.03^{* *} \\
(0.01)\end{array}$ & $\begin{array}{c}0.30^{* * *} \\
(0.02)\end{array}$ & $\begin{array}{c}0.23^{* * *} \\
(0.01)\end{array}$ & $\begin{array}{l}0.22^{* * *} \\
(0.01)\end{array}$ \\
\hline $\mathrm{N}$ & 7200 & 2400 & 4800 & 6408 & 6012 \\
\hline$k_{n} * l_{d}$ FEs & yes & yes & yes & yes & yes \\
\hline \multicolumn{6}{|c|}{$\begin{array}{l}{ }^{*} p<0.10,{ }^{* *} p<0.05,{ }^{* * *} p<0.01 \text {. Standard errors are clustered at the participant-level and shown in } \\
\text { parentheses. The results are from a linear probability model of the likelihood to choose a main bundle in } \\
\text { the Self(150)/Charity version of Study } 2 \text { in Panel A and in the Charity }(A R C) / \text { Charity version of Study } 2 \\
\text { in Panel B, where }\left({ }^{+} 0\right) \text { is an indicator for an } n / 5 \text {-bundle that is constructed by adding a fifth amount that } \\
\text { is equal to zero to a baseline } n / 4 \text {-bundle, }\left({ }^{+} 1\right) \text { is an indicator for an }(n+1) / 5 \text {-bundle that is constructed by } \\
\text { adding a fifth amount that is non-zero to a baseline } n / 4 \text {-bundle, } k_{n} * l_{d} \text { FEs include all possible interactions } \\
\text { of dummies for the number of non-zero amounts within the underlying baseline } n / 4 \text {-bundle (see Table A.1) } \\
\text { and dummies for the value of the non-zero amount } d \text { in the bundle to fully control for the sum of the amounts } \\
\text { in the baseline bundle. Columns } 1-3 \text { analyze all participants' decisions: in all main bundles in Column } 1 \text {, } \\
\text { involving the baseline } 4 / 4 \text {-bundles in Column } 2 \text {, and involving the baseline } 2 / 4 \text { - and } 3 / 4 \text {-bundles in Column } \\
\text { 3. Column } 4 \text { analyzes all main bundles but among a restricted sample of participants who choose the bundle } \\
\text { at least once and choose their outside option at least once across all } 48 \text { decisions. Column } 5 \text { analyzes all } \\
\text { main bundles but among a restricted sample of participants with outside option } X \text { set to the lower bound } \\
\text { of their indifference range (and thus excludes participants with a zero lower bound). }\end{array}$} \\
\hline
\end{tabular}




\section{B.3 Additional Results from Study 2 on Information Avoidance}

There is a vast literature on how individuals avoid information in order to maintain "moral wiggle room" about the extent to which a decision is selfish. The canonical example involves the hidden information treatment in Dana, Weber and Kuang (2007): subjects frequently avoid learning how their decisions influence the payoffs of others, and this avoidance results in more selfish behavior (as compared to when subjects cannot avoid learning how their decisions influence the payoffs of others). There is a subsequent literature that finds similar results (Larson and Capra, 2009; Matthey and Regner, 2011; Conrads and Irlenbusch, 2013; Feiler, 2014; Grossman, 2014; van der Weele et al., 2014; Exley and Petrie, 2018; Serra-Garcia and Szech, 2019); that shows how willful ignorance may help agents rationalize discriminatory behavior (Bartoš et al., 2016) and avoid learning about refugees (Freddi, 2018); that shows how willful ignorance can help agents avoid blame from others (Bartling, Engl and Weber, 2014); that shows how willful ignorance depends on what individuals expect to learn and how motivated information acquisition can also occur (Spiekermann and Weiss, 2016); and that develops related theoretical models (Nyborg, 2011; Grossman and van der Weele, 2017). ${ }^{41}$

As discussed in our Introduction, when individuals make decisions under uncertainty (even if they could have resolved that uncertainty), they may appeal to preferences under uncertainty to rationalize self-serving decisions. Dana, Weber and Kuang (2007) indeed note that participants in their hidden payoff treatment "appear to exploit the payoff uncertainty as an excuse." How our results differ from that finding, and differ from the larger motivated information avoidance literature, is that participants in the Self/Charity study versions cannot avoid payoff information on how their decisions influence others. In addition, there is no payoff uncertainty in the decisions they make, so they cannot appeal to preferences under uncertainty to rationalize self-serving decisions. Moreover, since we document self-serving decisions in response to payoff-irrelevant information, they cannot appeal to any preference or belief over payoffs to rationalize their self-serving decisions.

However, since we also conduct study versions in which participants can avoid payoff information on how their decisions influence others - the Self/Charity-Choice and the Charity/Charity-Choice versions - we can speak to this motivated information avoidance literature directly. In the results that follow, we will only consider results from the Study 2 since we did not run a Charity/CharityChoice version of Study 1.

First, we show that we can replicate a common finding in the information avoidance literature: participants who avoid information make more selfish decisions. As shown in the two bars on the left side of Panel A of Figure B.1, when we look at settings where information is likely to encourage giving (i.e., decisions where the sum of donations in the bundle is greater than 150 cents), participants

\footnotetext{
${ }^{41}$ Closely related to motivated information avoidance is the literature on motivated avoidance of prosocial asks (Jacobsen et al., 2011; DellaVigna, List and Malmendier, 2012; Lazear, Malmendier and Weber, 2012; Kamdar et al., 2015; Trachtman et al., 2015; Andreoni, Rao and Trachtman, 2016; Lin, Schaumberg and Reich, 2016), and for a review of more broadly related literature, including other motives for information avoidance, see Golman, Hagmann and Loewenstein (2017).
} 
who can avoid information are significantly less likely to choose the bundle than participants who are forced to fully reveal information in the Self/Charity version. These bundles are chosen $49 \%$ of the time in the Self/Charity-Choice version and $41 \%$ in the Self/Charity version $(p<0.05$ with standard errors clustered at the participant level). This increased selfish behavior is also consistent with motivated information avoidance, as participants in the Self/Charity-Choice version choose to avoid revealing all the information about these bundles $70 \%$ of the time.

Second, unlike most of the prior literature, our experiments additionally include decisions in which information is likely to discourage giving (i.e., decisions where the sum of donations in the bundle is less than 150 cents). ${ }^{42}$ In these bundles, we again observe that participants in the Self/Charity-Choice version frequently choose to avoid revealing all information (such avoidance occurs $68 \%$ of the time). This avoidance — perhaps not surprisingly given the nature of the information - no longer results in reduced giving. As shown in the two bars on the right side of Panel A of Figure B.1, participants who can avoid the information in the Self/Charity-Choice version are, if anything, more likely to choose bundles than participants who are forced to fully reveal information in the Self/Charity version. These bundles are chosen $23 \%$ of the time in Self/CharityChoice version and $28 \%$ in the Self/Charity version $(p=0.16$ with standard errors clustered at the participant level). This finding suggests that in settings where there is uncertainty about whether revealing information is going to encourage or discourage giving, information avoidance may backfire as a strategy to behave selfishly.

Third, our results provide the first test, to our knowledge, of whether individuals avoid information more when they have a self-serving motive than when they do not (even though, given our calibration procedure, the stakes involved are the same). This test is worth performing because there may be other, unmotivated reasons to avoid information in decision environments, including the implicit costs of collecting and processing information. Pooling across all 48 bundles, we observe significant unmotivated information avoidance: participants avoid fully revealing information about the bundles in 50\% of decisions in the Charity/Charity-Choice version when self-serving motives are not relevant. However, we also observe evidence of motivated information avoidance. The rate at which participants avoid fully revealing information about the bundles is $70 \%$ in the Self/Charity-Choice version when self-serving motives are relevant (this is statistically significantly higher than the $50 \%$ in the Charity/Charity-Choice version, $p<0.01$ with standard errors clustered

\footnotetext{
${ }^{42}$ In Dana, Weber and Kuang (2007), revealing information either eliminates the possibility to engage in costly prosocial behavior (i.e., when subjects find themselves in an "aligned" state where the option that is most beneficial to them is also most beneficial to another subject) or encourages costly prosocial behavior (i.e., when subjects find themselves in an "unaligned" state and thus learn that sacrificing some of their own payoff would be very beneficial to another subject). In our study, while revealing information may also encourage costly prosocial behavior (e.g., if participants learn that sacrificing the outside option that benefits themselves would be very beneficial to charity, resulting in a large donation of more than 150 cents), it may also discourage costly prosocial behavior (e.g., if participants learn that sacrificing the outside option would be only somewhat beneficial to charity, resulting in a small donation of less than 150 cents). Also, while our findings are in similar in spirit to Spiekermann and Weiss (2016) since they also examine information that may encourage or discourage giving, our findings differ in that participants cannot ex-ante know whether information may encourage or discourage giving.
} 
Figure B.1: In the Self/Charity, Self/Charity-Choice, Charity/Charity, and Charity/Charity-Choice versions of Study 2, fraction choosing a main bundle

Panel A: Self/Charity(-Choice)

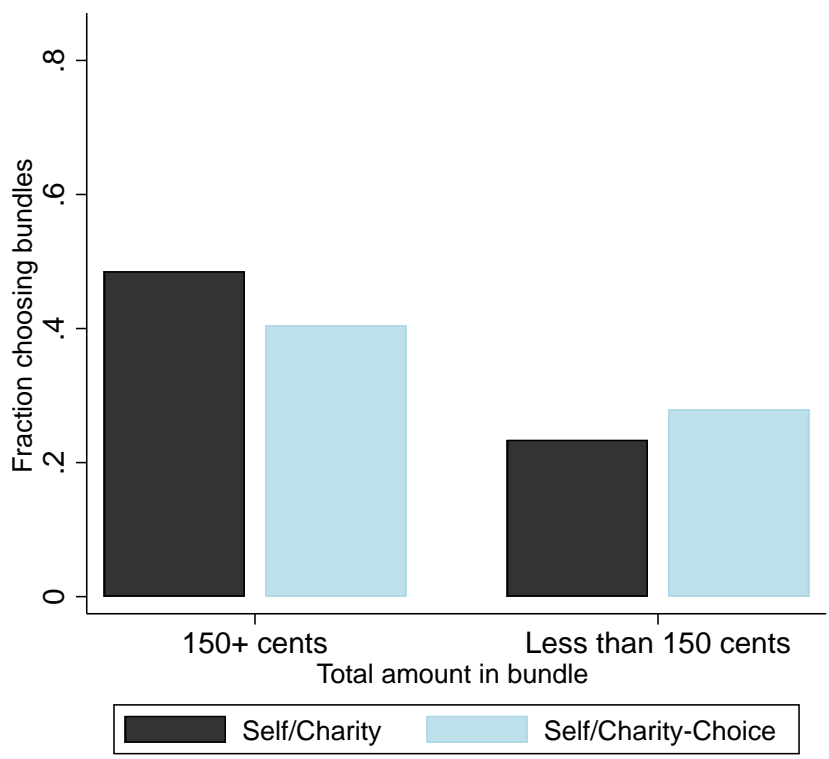

Panel B: Charity/Charity(-Choice)

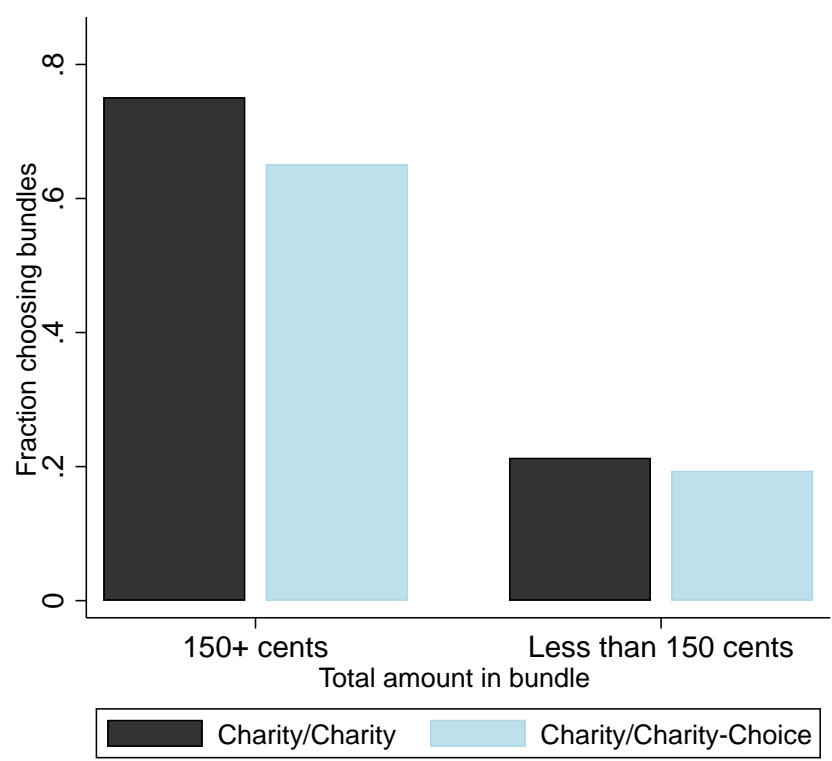

Data include all participants' decisions in all 48 bundles: in the Self/Charity and Self/Charity-Choice versions of Study 2 in Panel A and the Charity/Charity and Charity/Charity-Choice versions of Study 2 in Panel B.

at the participant level). Thus, our estimates suggest that $71 \%$ (i.e., $0.50 / 0.70$ ) of the information avoidance we observe in the Self/Charity-Choice version is unmotivated in nature while only $29 \%$ (i.e., 0.20/0.70) is due to self-serving motives. Moreover, the two bars on the left side of Panel B of Figure B.1 show that being able to avoid information also decreases giving to bundles with a sum greater than 150 cents when self-serving motives are removed.

In light of these results, future work on motivated information avoidance and its impact on decisions may seek to net out possible unmotivated information avoidance and its impact on decisions by considering settings where self-serving motives are and are not relevant. Related to this, recent results from Serra-Garcia and Szech (2019) provide evidence of more information avoidance when self-serving motives are relevant in settings in which subjects are incentivized to avoid or to acquire information. 


\section{Additional Information on Study 4}

\section{C.1 Experimental Design}

Study 4 included 588 participants randomized into one of four study versions arising from a $2 \times 2$ design of $\{$ Self/Charity, Charity/Charity $\} \times\{$ Baseline, Correlated $\} .{ }^{43}$ Each participant received $\$ 2$ for completing the 15-minute study. In addition, one decision was randomly selected for each participant and determined any additional bonus payment.

Study 4 largely follows a similar procedure as Study 3. First, as in Study 3, in all versions of Study 4, participants complete 17 calibration decisions to determine their $X$ value such that they are indifferent between $X$ cents for themselves and 150 cents for the Make-A-Wish Foundation. Each decision involves a binary choice between: (i) 150 cents for charity and (ii) $Y_{i}$ cents for themselves where $Y_{i} \in\{0,5,10,20,30, \ldots, 150\}$. Second, as in Study 3, after completing the calibration decisions in Study 4, participants make one final decision in which they choose between a 200-cent donation to the Make-A-Wish Foundation national chapter and an "outside option." The outside option equals a $X$-cent bonus payment for the participant in the Self/Charity versions and a 150-cent donation to the Make-A-Wish Foundation national chapter in the Charity/Charity versions. Third, as in Study 3, in the Baseline versions of Study 4, the information on the 200-cent donation directly states that the donation amount equals 200 cents.

Study 4 only differs from Study 3 in its introduction of the Correlated versions. In these versions, the information on the 200-cent donation indirectly states the donation amount. In particular, participants are informed that: (i) the donation amount equals the sum of Amounts 1 and 2; (ii) Amount 1 equals 0; (iii) the estimate of Amount 2 equals the average of Amount 1 and Amount 2 , which equals $(0+$ Amount 2$) / 2$; and (iv) the estimate of Amount 2 equals 100 cents. We chose this implementation to present correlated information in a similar (but even simpler) manner as it is presented in the low complexity treatment of Enke and Zimmermann (2019).

\section{C.2 Experimental Results}

Figure C.1 shows the results from the Self/Charity and Charity/Charity versions of Study 4. Panel A shows that, in the Self/Charity versions, the Correlated version dramatically decreases the rate at which participants choose the 200-cent donation for charity. Panel B, however, shows that this effect is also massive in the Charity/Charity versions when self-serving motives are absent.

Table C.1 presents results from Figure C.1 in a regression framework. The coefficient on Correlated in Column 1 of Panel A shows that the correlated information decreases willingness to choose the 200-cent donation by 30 percentage points in the Self/Charity version. The coefficient on Correlated in Column 1 of Panel B shows that this decrease is also significant but larger - equal to 68

\footnotetext{
${ }^{43}$ On November 8, 2019, we recruited and randomized 588 participants from Amazon's Mechanical Turk (MTurk) into one of these four versions. We intended to recruit 600 participants, but due to some subjects submitting invalid completion codes (mostly from participation in prior studies), we ended up with 588 participants. To be eligible, workers must have previously completed at least 100 HITs with a $95 \%$ or better approval rating and must be working from a United States IP address. Full instructions for Study 4 can be found in Appendix D.4.
} 
percentage points - in the Charity/Charity version. Columns 2 and 3 show similar results among more restricted samples.

Clearly, as discussed in Section 5, this evidence does not support individuals exploiting correlation neglect as an excuse. That said, given the extent to which the correlated information decreases individuals' willingness to choose the 200-cent donation absent self-serving motives in the Charity/Charity version, it is also clear that it would be close to - if not entirely — impossible to identify more errors due to self-serving motives in this setting. ${ }^{44}$

Figure C.1: In the Self/Charity version and the Charity/Charity version of Study 4, fraction choosing the 200-cent donation

Panel A: Self/Charity

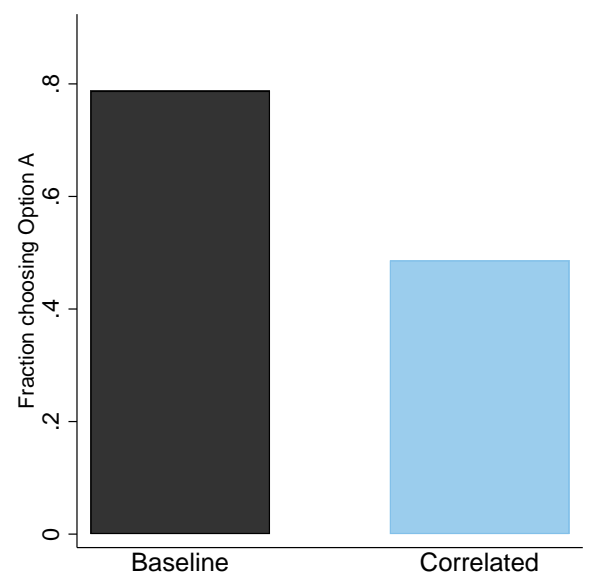

Panel B: Charity/Charity

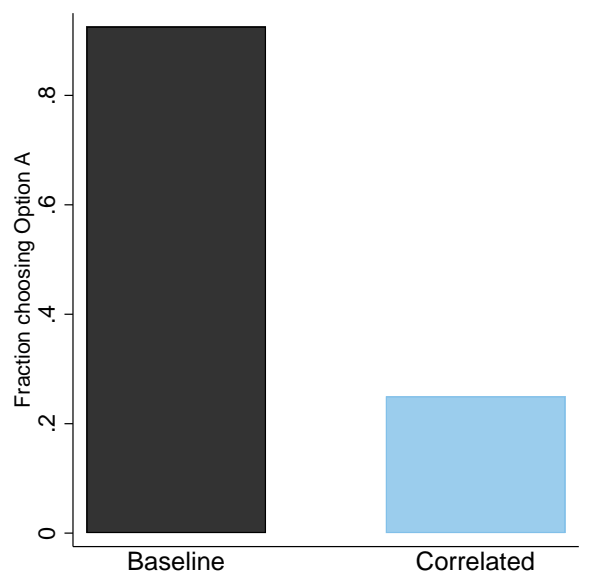

Data include all participants' decisions in the Self/Charity version of Study 4 in Panel A and the Charity/Charity version of Study 4 in Panel B.

\footnotetext{
${ }^{44}$ We ran a small pilot $(\mathrm{n}=77)$ at the Wharton Behavioral Lab to examine if we could reduce the impact of correlated information in the Charity/Charity version - and thus plausibly be able to test for an additional impact of self-serving motives - by using a subject pool of University of Pennsylvania students. In this pilot, however, the correlated information still resulted in a substantial decrease in the willingness to choose a donation amount described with correlated information in the Charity/Charity versions, without self-serving motives. We saw a 59 and 56 percentage point decrease when information was presented in a manner similar to the standard treatment and the low complexity treatment, respectively, of Enke and Zimmermann (2019). These results suggest that when participants are making binary choices between two payoff options (rather than being incentivized to accurately produce an estimate based on correlated information), the impact of correlated information is substantial.
} 
Table C.1: In the Self/Charity and Charity/Charity versions of Study 4, regression of choosing the 200-cent donation

\begin{tabular}{|c|c|c|c|}
\hline Sample: & $\begin{array}{l}\text { full } \\
\text { (1) }\end{array}$ & $\begin{array}{c}X \text { is lower bound } \\
(2) \\
\end{array}$ & $\begin{array}{c}\text { monotonic } \\
\text { calibration } \\
(3)\end{array}$ \\
\hline \multicolumn{4}{|c|}{ Panel A: Self/Charity version } \\
\hline Correlated & $\begin{array}{c}-0.30^{* * *} \\
(0.05)\end{array}$ & $\begin{array}{c}-0.38^{* * *} \\
(0.06)\end{array}$ & $\begin{array}{c}-0.39^{* * *} \\
(0.06)\end{array}$ \\
\hline Constant & $\begin{array}{c}0.79^{* * *} \\
(0.03)\end{array}$ & $\begin{array}{c}0.86^{* * *} \\
(0.03)\end{array}$ & $\begin{array}{c}0.77^{* * *} \\
(0.04)\end{array}$ \\
\hline $\mathrm{N}$ & 292 & 218 & 209 \\
\hline \multicolumn{4}{|c|}{ Panel B: Charity/Charity version } \\
\hline Correlated & $\begin{array}{c}-0.68^{* * *} \\
(0.04)\end{array}$ & $\begin{array}{c}-0.74^{* * *} \\
(0.04)\end{array}$ & $\begin{array}{c}-0.81^{* * *} \\
(0.04)\end{array}$ \\
\hline Constant & $\begin{array}{c}0.93^{* * *} \\
(0.02)\end{array}$ & $\begin{array}{c}0.94^{* * *} \\
(0.02)\end{array}$ & $\begin{array}{c}0.95^{* * *} \\
(0.02)\end{array}$ \\
\hline $\mathrm{N}$ & 296 & 217 & 215 \\
\hline
\end{tabular}

${ }^{*} p<0.10,{ }^{* *} p<0.05,{ }^{* * *} p<0.01$. Standard errors are robust and shown in parentheses. The results are from a linear probability model of the likelihood to choose the 200-cent donation in the Self/Charity version of Study 4 in Panel A and in the Charity/Charity version of Study 4 in Panel B, where Correlated is an indicator for the Correlated version. Column 1 involves the full sample, Column 2 involves a restricted sample of participants with outside option $X$ set to the lower bound of their indifference range (and thus excludes participants with a zero lower bound), and Column 3 involves a restricted sample of participants who are monotonic in their calibration decisions. 


\title{
D Experimental Instructions
}

\section{D.1 Full instructions for Study 1}

\section{D.1.1 Instructions for Self/Charity version of Study 1}

After consenting to participate in the study, each participant is informed of the $\$ 4$ study completion fee and of the opportunity to earn additional payment for themselves or the Make-A-Wish Foundation. Figure D.1 shows how this payment information is explained and the corresponding understanding question that must be answered correctly in order for the participant to proceed.

\section{Figure D.1: Payment Information}

\begin{abstract}
Your Payment: This study involves two Parts -- Part 1 and Part 2 -- followed by a short survey. For completing this study, you will receive a minimum payment of $\$ 4$ dollars within 24 hours. Also, Part 1 or Part 2 will be randomly selected as the part-that-counts. According to the instructions in the part-that-counts, you may also have the chance to earn additional payments.
\end{abstract}

Any additional payment you earn for yourself will be distributed via a bonus payment within one week.

Any additional payments you earn not for yourself will be distributed to the national chapter of Make-A-Wish Foundation as a donation. Make-A-Wish Foundation is a 501(c)(3) charitable organization that organizes and funds "wishes" for children with life-threatening medical conditions. On their website (http://wish.org), Make-A-Wish Foundation describes their activities as follows: "We grant the wishes of children with life-threatening medical conditions to enrich the human experience with hope, strength and joy [... ] Most wish requests fall into four major categories:

- I wish to go:

Some wish kids want to travel to their favorite theme park, while others want to visit an exotic beach, go on a cruise, see snow for the first time, or attend a major sporting event or concert.

- I wish to be: Children search the depths of their imagination when they wish to be someone for a day-a firefighter, a police officer or a model.

- I wish to meet:

Many want to meet their favorite athlete, recording artist, television personality, movie star, politician or public figure.

- I wish to have:

Children often wish for a special gift, such as a computer, a tree house, a shopping spree or something that they have coveted for a long time."

Understanding Question: Which of the following statements is true?

All of my decisions will influence the resulting payments from this study.

None of my decisions will influence the resulting payments from this study.

My decisions in the part-that-counts can only result in me receiving a bonus payment within one week.

My decisions in the part-that-counts will result in me receiving a bonus payment within one week and/or Make-A-Wish Foundation receiving a donation. 
In Part 1, each participant completes a multiple price list that allows us to calibrate the outside option used for the decisions in Part 2. In particular, the outside option equals $X$ cents for participants, where we calibrate $X$ to make the participant indifferent between $X$ cents for themselves and 150 cents for the Make-A-Wish Foundation. Figure D.2 presents the instructions for the multiple price list and corresponding understanding questions that the participant must answer correctly to proceed. Figure D.3 shows how the multiple price list appears.

\section{Figure D.2: Part 1 Instructions}

\section{$\underline{\text { Part } 1 \text { Instructions }}$}

In Part 1, you will have to make several decisions by completing one list. Each row of the list will present two payment options.

- The payment option on the left will always involve the Make-A-Wish Foundation receiving 150 cents as a donation.

- The payment option on the right will involve you receiving some amount of money as a bonus payment. The amount of money will increase from 0 to 150 cents as you proceed down the rows of the list.

Your task is to decide which payment option you prefer on each row by clicking on the row at which you prefer to switch from choosing the option on the left to the option on the right.

If Part 1 is randomly selected as the part-that-counts, one row from this list will be randomly selected. The payment option you select on that row would then be distributed.

Understanding Question: If Part 1 is randomly selected as the part-that-counts and you chose the option on the left in the randomly selected row, what would happen?

Make-A-Wish Foundation would receive 150 cents as a donation.

I would receive some amount of money as a bonus payment.

Understanding Question: If Part 1 is randomly selected as the part-that-counts and you chose the option on the right in the randomly selected row, what would happen?

Make-A-Wish Foundation would receive 150 cents as a donation.

I would receive some amount of money as a bonus payment. 
Figure D.3: Part 1 Decisions: Multiple Price List

Before decisions are indicated

Please indicate which payment option you prefer on each row by clicking on the row where you would like to switch from choosing the option on the left to choosing the option on the right.

(Note that you cannot click on the submit button until you have selected an answer.)

\begin{tabular}{|c|c|c|}
\hline $\begin{array}{l}\text { DONATION FOR } \\
\text { MAKE-A-WISH } \\
\text { FOUNDATION }\end{array}$ & & $\begin{array}{c}\text { BONUS PAYMENT } \\
\text { FOR YOU }\end{array}$ \\
\hline 150 CENTS & OR & 0 CENTS \\
\hline 150 CENTS & OR & 5 CENTS \\
\hline 150 CENTS & OR & 10 CENTS \\
\hline 150 CENTS & OR & 15 CENTS \\
\hline 150 CENTS & OR & 20 CENTS \\
\hline 150 CENTS & OR & 25 CENTS \\
\hline 150 CENTS & OR & 30 CENTS \\
\hline 150 CENTS & OR & 35 CENTS \\
\hline 150 CENTS & OR & 40 CENTS \\
\hline 150 CENTS & OR & 45 CENTS \\
\hline 150 CENTS & OR & 50 CENTS \\
\hline 150 CENTS & OR & 55 CENTS \\
\hline 150 CENTS & OR & 60 CENTS \\
\hline 150 CENTS & OR & 65 CENTS \\
\hline 150 CENTS & OR & 70 CENTS \\
\hline 150 CENTS & OR & 75 CENTS \\
\hline 150 CENTS & OR & 80 CENTS \\
\hline 150 CENTS & OR & 85 CENTS \\
\hline 150 CENTS & OR & 90 CENTS \\
\hline 150 CENTS & OR & 95 CENTS \\
\hline 150 CENTS & OR & 100 CENTS \\
\hline 150 CENTS & OR & 105 CENTS \\
\hline 150 CENTS & OR & 110 CENTS \\
\hline 150 CENTS & OR & 115 CENTS \\
\hline 150 CENTS & OR & 120 CENTS \\
\hline 150 CENTS & OR & 125 CENTS \\
\hline 150 CENTS & OR & 130 CENTS \\
\hline 150 CENTS & OR & 135 CENTS \\
\hline 150 CENTS & OR & 140 CENTS \\
\hline 150 CENTS & OR & 145 CENTS \\
\hline 150 CENTS & OR & 150 CENTS \\
\hline
\end{tabular}

After decisions are indicated if $X=100$

Please indicate which payment option you prefer on each row by clicking on the row where you would like to switch from choosing the option on the left to choosing the option on the right.

(Note that you cannot click on the submit button until you have selected an answer.)

\begin{tabular}{|c|c|c|}
\hline $\begin{array}{l}\text { DONATION FOR } \\
\text { MAKE-A-WISH } \\
\text { FOUNDATION }\end{array}$ & & $\begin{array}{l}\text { BONUS PAYMENT } \\
\text { FOR YOU }\end{array}$ \\
\hline 150 CENTS & OR & O CENTS \\
\hline 150 CENTS & OR & 5 CENTS \\
\hline 150 CENTS & OR & 10 CENTS \\
\hline 150 CENTS & OR & 15 CENTS \\
\hline 150 CENTS & OR & 20 CENTS \\
\hline 150 CENTS & OR & 25 CENTS \\
\hline 150 CENTS & OR & 30 CENTS \\
\hline 150 CENTS & OR & 35 CENTS \\
\hline 150 CENTS & OR & 40 CENTS \\
\hline 150 CENTS & OR & 45 CENTS \\
\hline 150 CENTS & OR & 50 CENTS \\
\hline 150 CENTS & OR & 55 CENTS \\
\hline 150 CENTS & OR & 60 CENTS \\
\hline 150 CENTS & OR & 65 CENTS \\
\hline 150 CENTS & OR & 70 CENTS \\
\hline 150 CENTS & OR & 75 CENTS \\
\hline 150 CENTS & OR & 80 CENTS \\
\hline 150 CENTS & OR & 85 CENTS \\
\hline 150 CENTS & OR & 90 CENTS \\
\hline 150 CENTS & OR & 95 CENTS \\
\hline 150 CENTS & OR & 100 CENTS \\
\hline 150 CENTS & OR & 105 CENTS \\
\hline 150 CENTS & OR & 110 CENTS \\
\hline 150 CENTS & OR & 115 CENTS \\
\hline 150 CENTS & OR & 120 CENTS \\
\hline 150 CENTS & OR & 125 CENTS \\
\hline 150 CENTS & OR & 130 CENTS \\
\hline 150 CENTS & OR & 135 CENTS \\
\hline 150 CENTS & OR & 140 CENTS \\
\hline 150 CENTS & OR & 145 CENTS \\
\hline 150 CENTS & OR & 150 CENTS \\
\hline
\end{tabular}


In Part 2, each participant makes 48 binary decisions between a bundle that changes from decision to decision and an outside option that is fixed for all 48 decisions. Choosing the outside option results in the participants receiving $X$ cents for themselves, where $X$ is calibrated from Part 1 as previously explained. Choosing a bundle results in Make-A-Wish Foundation receiving the sum of the 4 or 5 amounts in the bundle. Appendix Tables A.1 and A.2 in the paper detail the amounts that comprise each bundle. The first amount in a bundle is always revealed by default, and a participant is required to reveal all of the remaining amounts in a bundle by clicking on the header above each amount before proceeding onto the next decision screen. Also, the order of these decision screens varies. It is randomly determined whether a participant first makes the 24 decisions involving bundles with four amounts or instead first makes the 24 decisions involving bundles with five amounts. Within each block of 24 decisions, the order of those decisions is also randomly determined.

Prior to making these 48 decisions, participants face extensive instructions and understanding questions. Figure D.4 shows the first and second pages of the instructions for Part 2 along with the corresponding understanding questions that the participant must answer correctly to proceed. These understanding questions ensure that participants understand the payoffs that result from choosing a bundle versus the outside option and that they must reveal all amounts in a bundle before making a decision. Figure D.5 shows the subsequent three example bundles and corresponding understanding questions that the participant must answer correctly to proceed. These understanding questions ensure that participants know how to determine the total donation amount made by a bundle. 


\title{
Figure D.4: Part 2 Instructions
}

$$
\text { First Page (if } X=100 \text { ) }
$$

\section{$\underline{\text { Part } 2 \text { Instructions }}$}

\begin{abstract}
In Part 2, you will face 48 decisions. In each decision, you may choose between two payment options, Option A and Option B, which are as follows:
\end{abstract}

- Option A: Make-A-Wish Foundation receives a donation equal to the sum of several amounts. The exact amount of this sum may vary across the decisions.

- Option B: You receive a bonus payment of 100 cents.

If Part 2 is randomly selected as the part-that-counts, one decision will be randomly selected. The payment option you select in that decision would then be distributed.

Understanding Question: If Part 2 is randomly selected as the part-that-counts and you chose Option A in the randomly selected decision, what would happen?

Make-A-Wish Foundation would receive a donation of 150 cents

How much Make-A-Wish Foundation would receive as a donation would depend on the sum of the amounts in that decision.

Understanding Question: If Part 2 is randomly selected as the part-that-counts and you chose Option B in the randomly selected decision, what would happen?

I would receive 100 cents as a bonus payment.

I would receive an amount that may be more than or less than 100 cents as a bonus payment.

\section{Second Page}

\section{Part 2 Instructions Continued ...}

In each decision in Part 2, choosing Option A will result in Make-A-Wish Foundation receiving the sum of the donation amounts shown in Option A. Across decisions, this sum may vary.

Prior to making each decision in Part 2, you will always have the opportunity to learn all of the amounts in Option A. While you will have the opportunity to learn this information, you may choose to make decisions with or without learning this information.

Understanding Question: Prior to making each decision in Part 2, do you have to learn all of the amounts in Option A? 
Figure D.5: Part 2 Examples

\section{Example 1}

Understanding Question: If Part 2 is randomly selected as the part-that-counts and the below set of amounts were presented for Option A in the randomly selected decision, what would happen if you chose Option A?

In total, Make-A-Wish Foundation would receive less than 200 cents as a donation.

In total, Make-A-Wish Foundation would receive exactly 200 cents as a donation.

In total, Make-A-Wish Foundation would receive more than 200 cents as a donation.

Note that the first amount in Option $\mathbf{A}$ is shown and to learn the remaining amounts you may click on the relevant headers.

Amount 1:
48 cents
- Amount 2:
, Amount 3:
, Amount 4:

Example 3

Understanding Question: If Part 2 is randomly selected as the part-that-counts and the below set of donation amounts were presented for Option $\mathrm{A}$ in the randomly selected decision, what would happen if you chose Option A?

In total, Make-A-Wish Foundation would receive less than 100 cents as a donation.

In total, Make-A-Wish Foundation would receive more than 100 cents as a donation.

In total, Make-A-Wish Foundation would receive exactly 100 cents as a donation.

Note that the first amount in Option $\mathbf{A}$ is shown, and to learn the remaining amounts, you may elick on the relevant headers.

\section{Amount 1:}

0 cents

Amount 2:

Amount 3:

Amount 4:
Example 2

Understanding Question: If Part 2 is randomly selected as the part-that-counts and the below set of amount were presented for Option A in the randomly selected decision, what would happen if you chose Option A?

In total, Make-A-Wish Foundation would receive less than 150 cents as a donation.

In total, Make-A-Wish Foundation would receive more than 150 cents as a donation.

In total, Make-A-Wish Foundation would receive exactly 150 cents as a donation

Note that the first amount in Option $\mathbf{A}$ is shown, and to learn the remaining amounts, you may click on the relevant headers.

\section{Amount 1:}

54 cents

Amount 2:

Amount 3:

Amount 4 
Only after completing all of these understanding questions successfully do participants proceed to make their 48 decisions. Each decision appears on a separate screen, and Figure D.6 shows an example of one such decision.

Figure D.6: Part 2: Example Decision Screen

If this is your randomly selected decision, which option would you prefer?

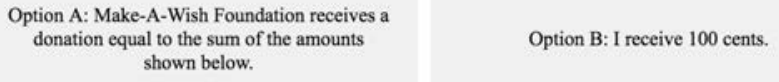

\section{Amount 1}

54 cents

- Amount 2

Amount 3

Amount 4

After completing all 48 decisions in Part 2, participants answer follow-up questions about their decisions in the study and provide demographic information. We distributed the relevant payments after the study was completed. 


\section{D.1.2 Instructions for other versions of Study 1}

The previous section details the instructions for the Self/Charity version of Study 1. In this section, we describe how these instructions differ for the remaining five versions of Study 1.

In the Self/Charity-Choice version, all that differs is that - aside from the first amount in a bundle still being revealed by default - participants can choose whether or not to reveal the other amounts in a bundle. Thus, how decision screens appear in Part 2 is still as shown in Figure D.6, but the participant can make a decision without clicking on all the headers.

In the Self/Charity-Sum version, all that differs is that participants are also shown the sum of amounts in the bundle on the decision screen, as shown in Figure D.7.

Figure D.7: Part 2: Example Decision Screen for Self/Charity-Sum version of Study 2

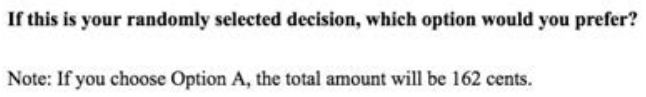

\section{Amount 1}

54 cents

Amount 2

Amount 3

Amount 4 
In the Self/Charity-Unavoidable Sum version, there are two main differences. First, prior to each decision screen, participants face a screen where they are informed of, and must accurately report, the sum of the amounts in the bundle that will be on the decision screen, as shown in Figure D.8. Second, participants are shown the sum of amounts in the bundle on the decision screen in a manner that is arguably more salient than in the Self/Charity-Sum version, as shown in Figure D.9.

Figure D.8: Part 2: Example Before-Decision-Screen Screen for Self/Charity-Unavoidable Sum version of Study 2

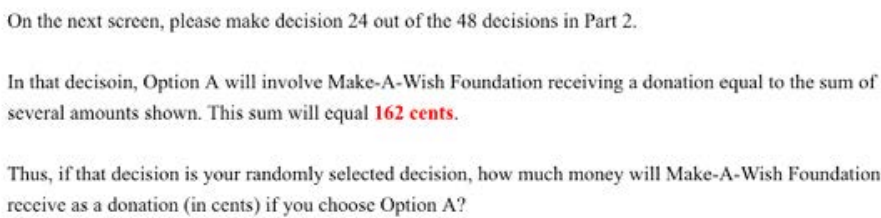

Figure D.9: Part 2: Example Decision Screen for Self/Charity-Unavoidable Sum version of Study 2

If this is your randomly selected decision, which option would you prefer?

Option A: Make-A-Wish Foundation receives a donation equal to 162 cents, which is the sum of the amounts shown below.

Option B: I receive 100 cents

\section{Amount 1}

54 cents

Amount 2

Amount 3

Amount 4 
In the Charity/Charity version, choosing the outside option now results in 150 cents being given to Make-A-Wish Foundation (regardless of the decisions in Part 1), as shown in Figure D.10.

Figure D.10: Part 2: Example Decision Screen for Charity/Charity version of Study 2

If this is your randomly selected decision, which option would you prefer?

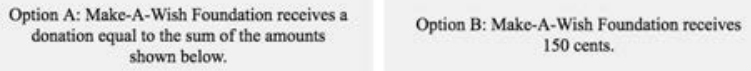

\section{Amount 1}

54 cents

Amount 2

Amount 3

Amount 4

In the Self(150)/Self version, choosing the outside option now results in 150 cents being given to the participant (regardless of the participant's decisions in Part 1) and choosing a bundle now results in the amount of money in the bundle being given to the participant, as shown in Figure D.11.

Figure D.11: Part 2: Example Decision Screen for Self(150)/Self version of Study 2

If this is your randomly selected decision, which option would you prefer?

Option A: I receive a bonus payment equal to the sum of the amounts shown below.
Option B: I receive a bonus payment of 150

cents.

\section{Amount 1}

54 cents

Amount 2

Amount 3

Amount 4 


\section{D.2 Full instructions for Study 2}

\section{D.2.1 Instructions for Self/Charity version of Study 2}

After consenting to participate in the study, each participant is informed of the $\$ 4$ study completion fee and of the opportunity to earn additional payment for either themselves or the MakeA-Wish Foundation. Figure D.12 shows how this payment information is explained along with the corresponding understanding question that the participant must answer correctly to proceed.

\section{Figure D.12: Payment Information}

Your Payment: This study involves two Parts -- Part 1 and Part 2 -- followed by a short survey. For completing this study, you will receive a minimum payment of $\$ 4$ dollars within 24 hours. Also, Part 1 or Part 2 will be randomly selected as the part-that-counts. According to the instructions in the part-that-counts, you may also have the chance to earn additional payments.

Any additional payment you earn for yourself will be distributed via a bonus payment within one week.

Any additional payments you earn not for yourself will be distributed to the national chapter of or a state chapter of Make-A-Wish Foundation as a donation. Make-A-Wish Foundation is a 501(c)(3) charitable organization that organizes and funds "wishes" for children with life-threatening medical conditions. On their website (http://wish.org), Make-A-Wish Foundation describes their activities as follows: "We grant the wishes of children with life-threatening medical conditions to enrich the human experience with hope, strength and joy [... ] Most wish requests fall into four major categories:

- I wish to go:

Some wish kids want to travel to their favorite theme park, while others want to visit an exotic beach, go on a cruise, see snow for the first time, or attend a major sporting event or concert.

- I wish to be:

Children search the depths of their imagination when they wish to be someone for a day - a firefighter, a police officer or a model.

- I wish to meet:

Many want to meet their favorite athlete, recording artist, television personality, movie star, politician or public figure.

- I wish to have:

Children often wish for a special gift, such as a computer, a tree house, a shopping spree or something that they have coveted for a long time."

Understanding Question: Which of the following statements is true?

All of my decisions will influence the resulting payments from this study.

None of my decisions will influence the resulting payments from this study.

My decisions in the part-that-counts can only result in me receiving a bonus payment within one week.

My decisions in the part-that-counts will result in me receiving a bonus payment within one week and/or Make-A-Wish Foundation chapter(s) receiving a donation. 
In Part 1, each participant completes a multiple price list that allows us to calibrate the outside option used for the decisions in Part 2. In particular, the outside option equals $X$ cents for participants, where we calibrate $X$ to make the participant indifferent between $X$ cents for themselves and 150 cents for the national chapter of the Make-A-Wish Foundation. Figure D.13 presents the instructions for the multiple price list and corresponding understanding questions that the participant must answer correctly to proceed. Figure D.14 shows how the multiple price list appears.

\section{Figure D.13: Part 1 Instructions}

\section{$\underline{\text { Part } 1 \text { Instructions }}$}

In Part 1 , you will have to make several decisions by completing one list. Each row of the list will present two payment options.

- The payment option on the left will always involve the national chapter of Make-A-Wish Foundation receiving 150 cents as a donation.

- The payment option on the right will involve you receiving some amount of money as a bonus payment. The amount of money will increase from 0 to 150 cents as you proceed down the rows of the list.

Your task is to decide which payment option you prefer on each row by clicking on the row at which you prefer to switch from choosing the option on the left to the option on the right.

If Part 1 is randomly selected as the part-that-counts, one row from this list will be randomly selected. The payment option you select on that row would then be distributed.

Understanding Question: If Part 1 is randomly selected as the part-that-counts and you chose the option on the left in the randomly selected row, what would happen?

The national chapter of Make-A-Wish Foundation would receive 150 cents as a donation.

I would receive some amount of money as a bonus payment.

Understanding Question: If Part 1 is randomly selected as the part-that-counts and you chose the option on the right in the randomly selected row, what would happen?

The national chapter of Make-A-Wish Foundation would receive 150 cents as a donation.

I would receive some amount of money as a bonus payment. 
Figure D.14: Part 1 Decisions: Multiple Price List

Before decisions are indicated

Please indicate which payment option you prefer on each row by clicking on the row where you would like to switch from choosing the option on the left to choosing the option on the right.

(Note that you cannot click on the submit button until you have selected an answer.)

\begin{tabular}{|c|c|c|}
\hline $\begin{array}{l}\text { DONATION FOR } \\
\text { MAKE-A-WISH } \\
\text { FOUNDATION } \\
\text { NATIONAL } \\
\text { CHAPTER } \\
\end{array}$ & & $\begin{array}{l}\text { BONUS PAYMENT } \\
\text { FOR YOU }\end{array}$ \\
\hline 150 CENTS & OR & $O$ CENTS \\
\hline 150 CENTS & OR & 5 CENTS \\
\hline 150 CENTS & OR & 10 CENTS \\
\hline 150 CENTS & OR & 15 CENTS \\
\hline 150 CENTS & OR & 20 CENTS \\
\hline 150 CENTS & OR & 25 CENTS \\
\hline 150 CENTS & OR & 30 CENTS \\
\hline 150 CENTS & OR & 35 CENTS \\
\hline 150 CENTS & OR & 40 CENTS \\
\hline 150 CENTS & OR & 45 CENTS \\
\hline 150 CENTS & OR & 50 CENTS \\
\hline 150 CENTS & OR & 55 CENTS \\
\hline 150 CENTS & OR & 60 CENTS \\
\hline 150 CENTS & OR & 65 CENTS \\
\hline 150 CENTS & OR & 70 CENTS \\
\hline 150 CENTS & OR & 75 CENTS \\
\hline 150 CENTS & OR & 80 CENTS \\
\hline 150 CENTS & OR & 85 CENTS \\
\hline 150 CENTS & OR & 90 CENTS \\
\hline 150 CENTS & OR & 95 CENTS \\
\hline 150 CENTS & OR & 100 CENTS \\
\hline 150 CENTS & OR & 105 CENTS \\
\hline 150 CENTS & OR & 110 CENTS \\
\hline 150 CENTS & OR & 115 CENTS \\
\hline 150 CENTS & OR & 120 CENTS \\
\hline 150 CENTS & OR & 125 CENTS \\
\hline 150 CENTS & OR & 130 CENTS \\
\hline 150 CENTS & OR & 135 CENTS \\
\hline 150 CENTS & OR & 140 CENTS \\
\hline 150 CENTS & OR & 145 CENTS \\
\hline 150 CENTS & OR & 150 CENTS \\
\hline
\end{tabular}

After decisions are indicated if $X=100$

Please indicate which payment option you prefer on each row by clicking on the row where you would like to switch from choosing the option on the left to choosing the option on the right.

(Note that you cannot click on the submit button until you have selected an answer.)

\begin{tabular}{|c|c|c|}
\hline $\begin{array}{l}\text { DONATION FOR } \\
\text { MAKE-A-WISH } \\
\text { FOUNDATION } \\
\text { NATIONAL } \\
\text { CHAPTER }\end{array}$ & & $\begin{array}{l}\text { BONUS PAYMENT } \\
\text { FOR YOU }\end{array}$ \\
\hline 150 CENTS & OR & $O$ CENTS \\
\hline 150 CENTS & OR & 5 CENTS \\
\hline 150 CENTS & OR & 10 CENTS \\
\hline 150 CENTS & OR & 15 CENTS \\
\hline 150 CENTS & OR & 20 CENTS \\
\hline 150 CENTS & OR & 25 CENTS \\
\hline 150 CENTS & OR & 30 CENTS \\
\hline 150 CENTS & OR & 35 CENTS \\
\hline 150 CENTS & OR & 40 CENTS \\
\hline 150 CENTS & OR & 45 CENTS \\
\hline 150 CENTS & OR & 50 CENTS \\
\hline 150 CENTS & OR & 55 CENTS \\
\hline 150 CENTS & OR & 60 CENTS \\
\hline 150 CENTS & OR & 65 CENTS \\
\hline 150 CENTS & OR & 70 CENTS \\
\hline 150 CENTS & OR & 75 CENTS \\
\hline 150 CENTS & OR & 80 CENTS \\
\hline 150 CENTS & OR & 85 CENTS \\
\hline 150 CENTS & OR & 90 CENTS \\
\hline 150 CENTS & OR & 95 CENTS \\
\hline 150 CENTS & OR & 100 CENTS \\
\hline 150 CENTS & OR & 105 CENTS \\
\hline 150 CENTS & OR & 110 CENTS \\
\hline 150 CENTS & OR & 115 CENTS \\
\hline 150 CENTS & OR & 120 CENTS \\
\hline 150 CENTS & OR & 125 CENTS \\
\hline 150 CENTS & OR & 130 CENTS \\
\hline 150 CENTS & OR & 135 CENTS \\
\hline 150 CENTS & OR & 140 CENTS \\
\hline 150 CENTS & OR & 145 CENTS \\
\hline 150 CENTS & OR & 150 CENTS \\
\hline
\end{tabular}


In Part 2, each participant makes 48 binary decisions between a bundle that changes from decision to decision and an outside option that is fixed for all 48 decisions. Choosing the outside option results in the participants receiving $X$ cents for themselves, where $X$ is calibrated from Part 1 as previously explained. Choosing a bundle results in various state chapters of the Make-A-Wish Foundation each receiving an amount from the bundle. Appendix Tables A.1 and A.2 in the paper detail the amounts that comprise each bundle. Due to constraints (related to which chapters were IRB approved and to how some states shared Make-A-Wish Foundation chapters), we randomly drew states for each bundle from a list of 28 states that we matched with corresponding MakeA-Wish Foundation chapters. This list of states was: Alaska, California, Colorado, Connecticut, Florida, Georgia, Illinois, Indiana, Iowa, Kentucky, Louisiana, Maine, Michigan, Missouri, Nebraska, Nevada, New Hampshire, New York, North Carolina, Ohio, Oklahoma, South Carolina, Tennessee, Texas, Utah, Virginia, Washington, and Wisconsin.

The first amount in a bundle is always revealed by default, and a participant is required to reveal all of the remaining amounts in a bundle by clicking on the header above each amount before proceeding onto the next decision screen. Also, the order of these decision screens varies. It is randomly determined whether a participant first makes the 24 decisions involving bundles with four amounts or instead first makes the 24 decisions involving bundles with five amounts. Within each block of 24 decisions, the order of those decisions is also randomly determined.

Prior to making these 48 decisions, participants face extensive instructions and understanding questions. Figure D.15 shows the first and second pages of the instructions for Part 2 along with the corresponding understanding questions that the participant must answer correctly to proceed. These understanding questions ensure that participants understand the payoffs that result from choosing a bundle versus the outside option and that they must reveal all amounts in a bundle before making a decision. Figure D.16 shows the subsequent three example bundles and corresponding understanding questions that the participant must answer correctly to proceed. These understanding questions ensure that participants know the number of state chapters that receive a donation from the bundle and the total donation amount made by a bundle. 


\section{Figure D.15: Part 2 Instructions}

First Page (if $X=100$ )

\section{Part 2 Instructions}

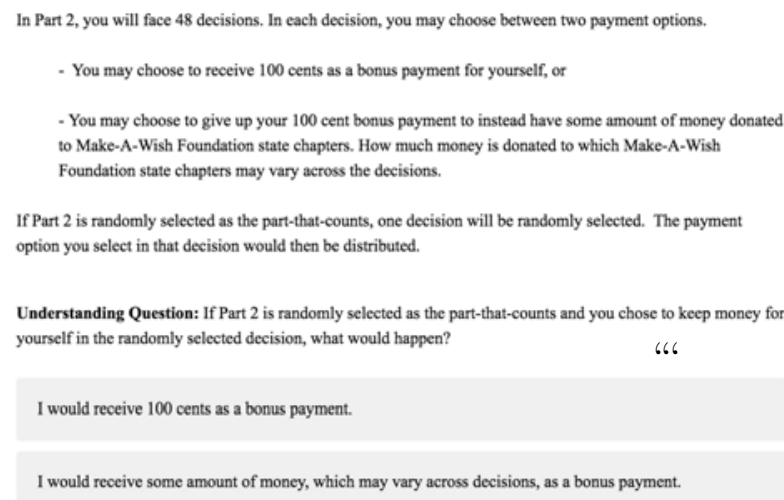

Understanding Question: If Part 2 is randomly selected as the part-that-counts and you chose give up your 100 cents bonus payment in the randomly selected decision to instead give to Make-A-Wish Foundation state chapters, what would happen?

One state chapter of Make-A-Wish Foundation would receive a donation of 100 cents. State chapters of Make-A-Wish Foundation would receive donation amounts as indicated in the selected decision.

\section{Second Page}

\section{Part 2 Instructions Continued.}

In each decision in Part 2, you will be presented with a set of Make-A-Wish Foundation state chapters. Each Make-A-Wish Foundation state chapter presented in a particular deeision will either receive a donation or not receive a donation. All Make-A-Wish Foundation state chapters that receive a donation in a particular decision will receive the same amount.

Across decisions, the donation amounts may vary and the number of Make-A-Wish Foundation state chapters that receive no donation may vary.

Prior to making each decision in Part 2, you will always have to learn exactly how much money would be given to which Make-A-Wish Foundation state chapters. You cannot make a decision without learning this information, as the button to proceed onto the next page will be disabled until you learn this information.

Understanding Question: Prior to making each decision in Part 2, do you have to learn exactly how much money would be given to which Make-A-Wish Foundation state chapters? 
Figure D.16: Part 2 Examples (if $X=100$ )

\section{Example 2}

\section{Example 1}

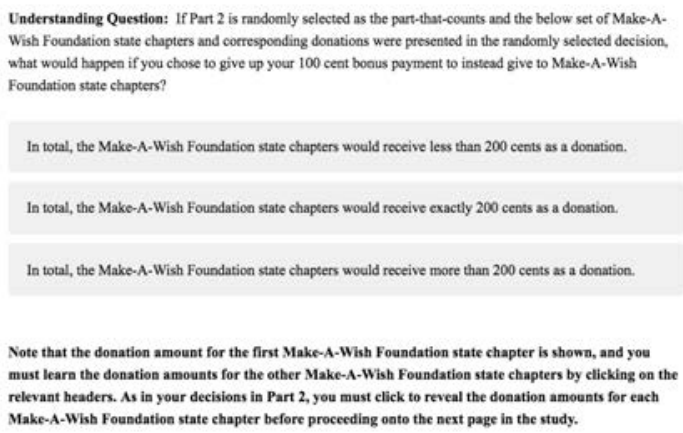

If you choose to give to Make A-Wish Foundation state chapters, the South Carolina chapter will receive:

48 cents

If you choose to give to Make A-Wish Foundation state chapters, the Michigan chapter will receive:

If you choose to give to Make A-Wish Foundation state chapters, the Kentucky chapter will receive:

If you choose to give to Make A-Wish Foundation state chapters, the Washington chapter will receive:

\section{Example 3}

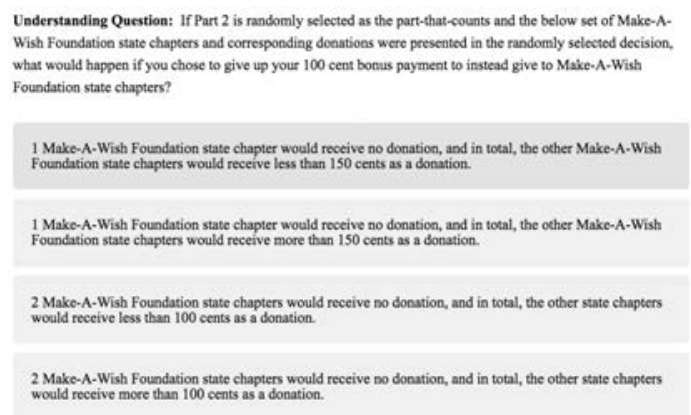

Note that the donation amount for the first Make-A-Whih Foundation state chapter is shown, and you must learn the donation amounts for the other Make-A-Wish Foundation state chapters by clicking on the relevant headers. As in your decisions in Part 2, you must click to reveal the donation amounts for each Make-A-Wish Foundation state chapter before proceeding onto the nest page in the study.

If you choose to give to Make A-Wish Foundation state chapters, the Ohio chatper will receive:

NO DONATION

If you choose to give to Make A-Wish Foundation state chapters, the Florida chapter will receive:

If you choose to give to Make A-Wish Foundation state chapters, the Wisconsin chapter will receive:

If you choose to give to Make A-Wish Foundation state chapters, the lowa chapter will receive:

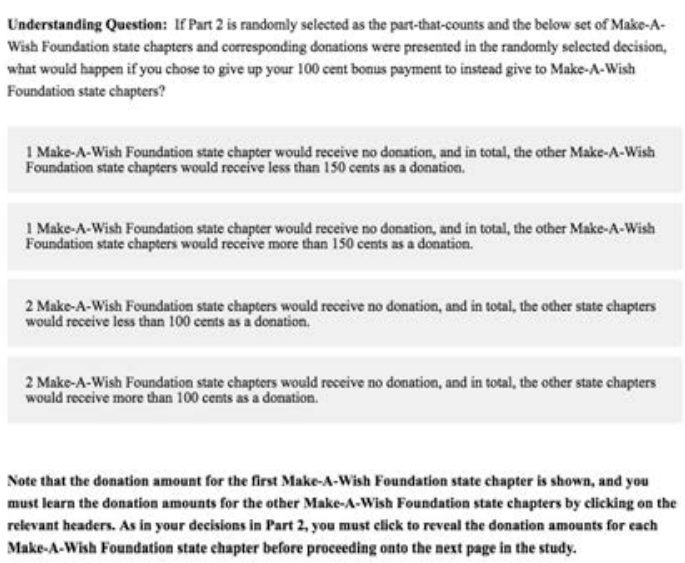

If you choose to give to Make A-Wish Foundation state chapters, the New Hampshire chapter will receive:

52 cents

If you choose to give to Make A-Wish Foundation state chapters, the Alaska chapter will receive:

If you choose to give to Make A-Wish Foundation state chapters, the Oklahoma chapter will receive:

If you choose to give to Make A-Wish Foundation state chapters, the New York chapter will receive: 
Only after completing all of these understanding questions successfully do participants proceed to make their 48 decisions. Each decision appears on a separate screen, and Figure D.17 shows an example of one such decision.

Figure D.17: Part 2: Example Decision Screen

If this is your randomly selected decision, would you like to give up your 100 cent bonus payment to

instead have the Make-A-Wish Foundation state chapter donations detailed below to occur?

Yes - I would like to give up my 100 cent bonus

payment to instead have the Make-A-Wish

Foundation state chapter donations detailed below to occur.
No - I would like to keep my 100 cent bonus payment.

If you choose to give to Make A-Wish Foundation state chapters,

the Louisiana chapter will receive:

54 cents

If you choose to give to Make A-Wish Foundation state chapters, the Washington chapter will receive:

If you choose to give to Make A-Wish Foundation state chapters, the North Carolina chapter will receive:

If you choose to give to Make A-Wish Foundation state chapters, the Georgia chapter will receive:

After completing all 48 decisions in Part 2, participants answer follow-up questions about their decisions in the study and provide demographic information. We distributed the relevant payments after the study was completed. 


\section{D.2.2 Instructions for other versions of Study 2}

The previous section details the instructions for the Self/Charity version of Study 2. In this section, we describe how these instructions differ for the remaining seven versions of Study 2.

In the Self/Charity-Choice version, all that differs is that - aside from the first amount in a bundle that is still revealed by default - participants can choose whether or not to reveal the other amounts in a bundle. Thus, how decision screens appear in Part 2 is still as shown in Figure D.17, but the participant can make a decision without clicking on all the headers.

In the Self/Charity-Sum version, all that differs is that participants are also shown the sum of amounts in the bundle on the decision screen, as shown in Figure D.18.

Figure D.18: Part 2: Example Decision Screen for Self/Charity-Sum version of Study 2

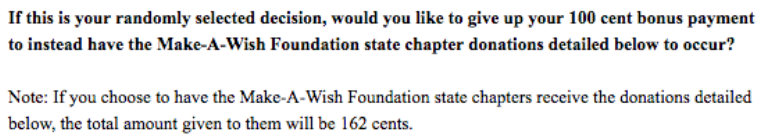
below, the total amount given to them will be 162 cents.

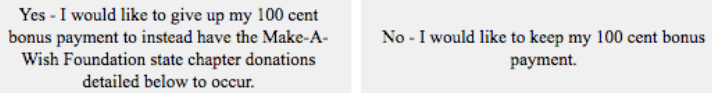

If you choose to give to Make A-Wish Foundation state chapters,

the Louisiana chapter will receive:

54 cents

If you choose to give to Make A-Wish Foundation state chapters, the Washington chapter will receive:

If you choose to give to Make A-Wish Foundation state chapters, the North Carolina chapter will receive:

If you choose to give to Make A-Wish Foundation state chapters, the Georgia chapter will receive: 
In the Self(150)/Charity version, choosing a bundle results in the same payoffs, but choosing the outside option now results in results in 150 cents being given to the participant (regardless of the participant's decisions in Part 1), as shown in Figure D.19.

Figure D.19: Part 2: Example Decision Screen for Self(150)/Charity version of Study 2

If this is your randomly selected decision, would you like to give up your 150 cent bonus payment to instead have the Make-A-Wish Foundation state chapter donations detailed below to occur?

Yes - I would like to give up my 150 cent bonus payment to instead have the Make-A. Wish Foundation state chapter donations detailed below to occur.
No - I would like to keep my 150 cent bonus payment.

If you choose to give to Make A-Wish Foundation state chapters, the Louisiana chapter will receive:

54 cents

If you choose to give to Make A-Wish Foundation state chapters, the Washington chapter will receive:

If you choose to give to Make A-Wish Foundation state chapters, the North Carolina chapter will receive:

If you choose to give to Make A-Wish Foundation state chapters, the Georgia chapter will receive: 
In the Charity/Charity version, choosing the outside option now results in 150 cents being given to the national chapter of Make-A-Wish Foundation (regardless of the participant's decisions in Part 1), as shown in Figure D.20.

Figure D.20: Part 2: Example Decision Screen for Charity/Charity version of Study 2

If this is your randomly selected decision, would you like to give up the 150 cent donation for the Make-AWish Foundation national chapter to instead have the Make-A-Wish Foundation state chapter donations detailed below to occur?

Yes - I would like to give up the 150 cent
donation for the Make-A-Wish Foundation Wish Found detailed below to occur.
No - I would like to keep the 150 cent donation for the Make-A-Wish Foundation national for the Make-A-Wish Found
chapter.

If you choose to give to Make A-Wish Foundation state chapters, the Louisiana chapter will receive:

54 cents

If you choose to give to Make A-Wish Foundation state chapters, the Washington chapter will receive:

If you choose to give to Make A-Wish Foundation state chapters, the North Carolina chapter will receive:

If you choose to give to Make A-Wish Foundation state chapters, the Georgia chapter will receive: 
In the Charity/Charity-Choice version, subjects face the same bundles and outside options as in the Charity/Charity version. All that differs is that - aside from the first amount in a bundle that is still revealed by default - participants can choose whether or not to reveal the other amounts in a bundle. Thus, how decision screens appear in Part 2 is still as shown in Figure D.20, but the participant can make a decision without clicking on all the headers.

In the Charity/Charity-Sum version, subjects face the same bundles and outside options as in the Charity/Charity version. All that differs is that participants are also shown the sum of amounts in the bundle on the decision screen, as shown in Figure D.21.

Figure D.21: Part 2: Example Decision Screen for Charity/Charity-Sum version of Study 2

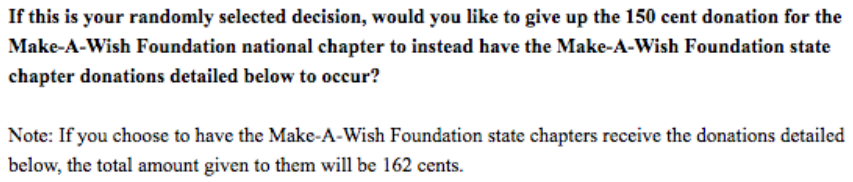

No - I would like to keep the 150 cent donation for the Make-A-Wish Foundation national chapter.

If you choose to give to Make A-Wish Foundation state chapters,

the Louisiana chapter will receive:

54 cents

If you choose to give to Make A-Wish Foundation state chapters, the Washington chapter will receive:

If you choose to give to Make A-Wish Foundation state chapters, the North Carolina chapter will receive:

If you choose to give to Make A-Wish Foundation state chapters, the Georgia chapter will receive: 
In the Charity $(A R C) /$ Charity version, subjects face the same bundles as in the Charity/Charity version, but choosing the outside option now results in 150 cents being given to the American Red Cross, as shown in Figure D.22.

Figure D.22: Part 2: Example Decision Screen for Charity $(A R C) /$ Charity version of Study 2

If this is your randomly selected decision, would you like to give up the $\mathbf{1 5 0}$ cent donation for the American Red Cross to instead have the Make-A-Wish Foundation state chapter donations detailed below to occur?

Yes - I would like to give up the 150 cent donation for the American Red Cross to instead have the Make-A-Wish Foundation state chapter donations detailed below to occur
No - I would like to keep the 150 cent donation for the American Red Cross.

If you choose to give to Make A-Wish Foundation state chapters, the Louisiana chapter will receive:

54 cents

If you choose to give to Make A-Wish Foundation state chapters, the Washington chapter will receive:

If you choose to give to Make A-Wish Foundation state chapters, the North Carolina chapter will receive:

If you choose to give to Make A-Wish Foundation state chapters, the Georgia chapter will receive: 


\section{D.3 Full instructions for Study 3}

\section{D.3.1 Instructions for Self/Charity-Baseline version of Study 3}

After consenting to participate in the study, each participant is informed of the $\$ 2$ study completion fee and of the opportunity to earn additional payment. Figure D.23 shows how this payment information is explained along with the corresponding understanding question that the participant must answer correctly to proceed.

Figure D.23: Payment Information

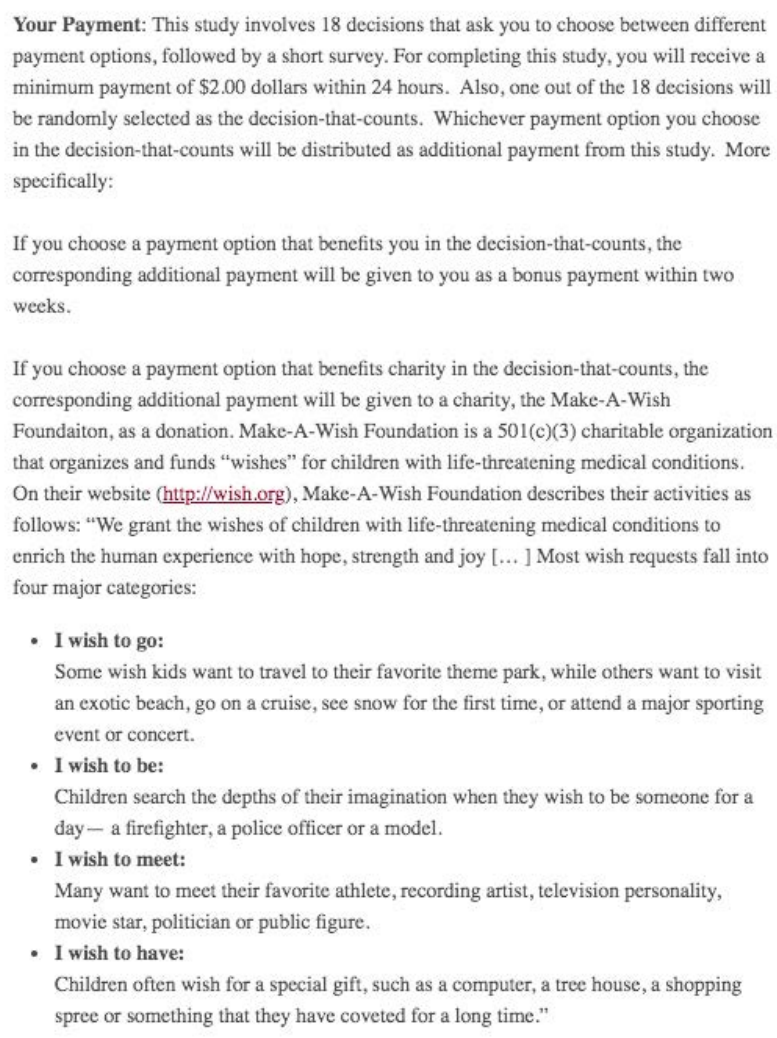

Participants first complete the "calibration decisions" by making 17 binary decisions between (i) 150 cents fro the national chapter of Make-A-Wish Foundation and (ii) $Z$ cents for themselves where $Z \in\{0,5,10,20,30,40,50,60,70,80,90,100,110,120,130,140,150\}$. The calibration decisions are randomized on the subject-level and allow us to calibrate the outside option used for each subject's 
subsequent main decision. In particular, the outside option equals $X$ cents for participants, where we calibrate $X$ to make the participant indifferent between $X$ cents for themselves and 150 cents for the national chapter of the Make-A-Wish Foundation. Figure D.24 presents the instructions for the calibration decisions and the corresponding understanding question that the participant must answer correctly to proceed. Figure D.25 shows an example of one of these decisions.

Figure D.24: Instructions for Calibration Decisions

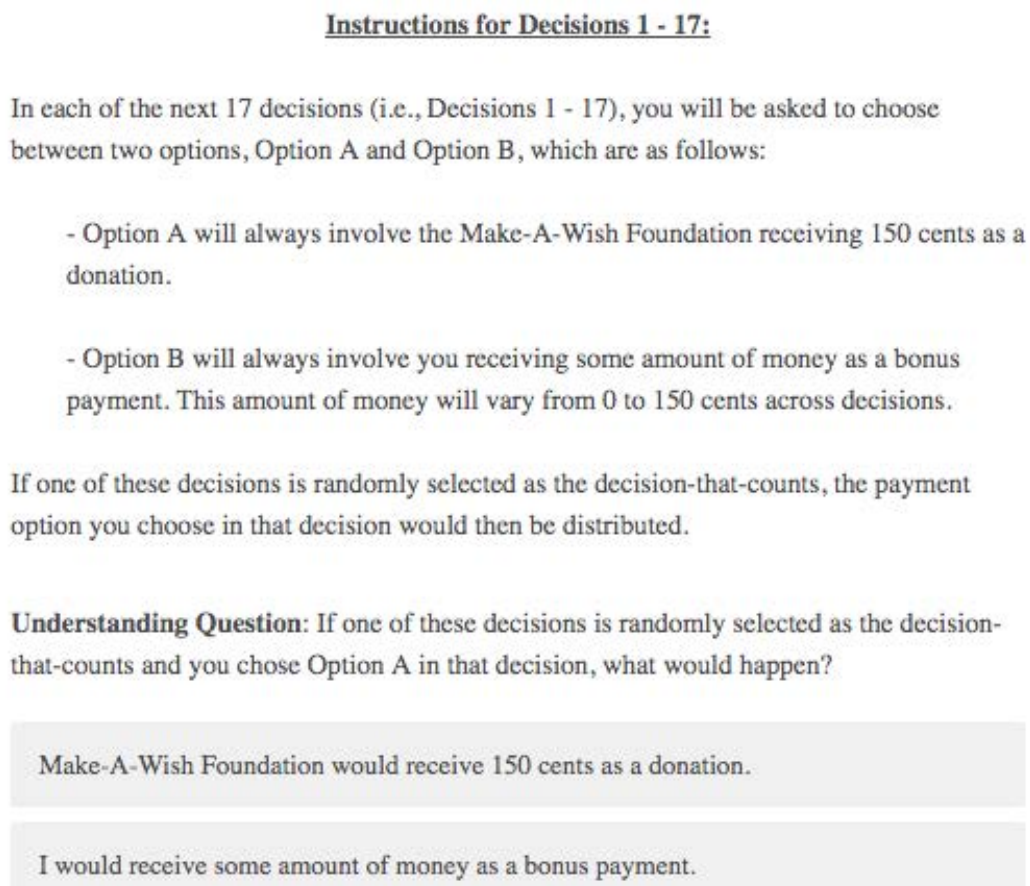


Figure D.25: Example of a Calibration Decision

In this decision, choosing:

- Option A means that a donation of 150 cents will be given to Make-A-Wish Foundation.

- Option B means that a bonus payment of 80 cents will be given to you.

Decision 1: Which option do you prefer?

Option A

Option B

Participants then complete their main decision. Figure D.26 presents the instructions and corresponding understanding questions that the participant must answer correctly to proceed to this decision, and Figure D.27 shows the corresponding decision screen.

\title{
Figure D.26: Instructions for Main Decision
}

\author{
Instructions for Decision 18:
}

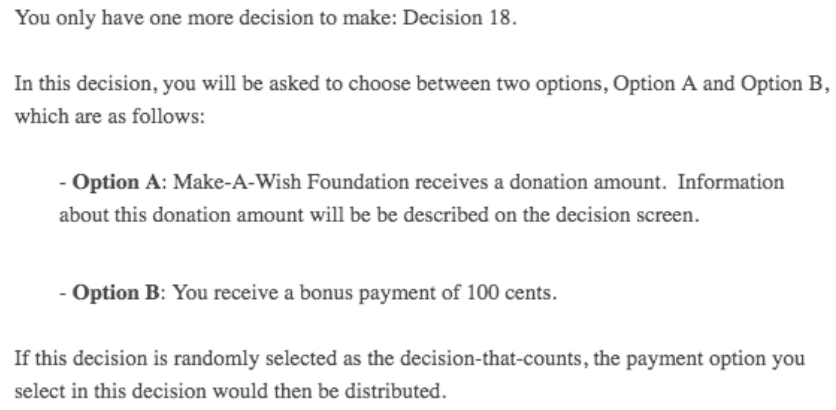

Understanding Question: If the next decision is randomly selected as the decision-thatcounts and you chose Option B in that decision, what would happen?

I would receive a bonus payment of 100 cents.

I would receive a bonus payment that may or may not equal 100 cents. The bonus payment amount will be described on the decision screen. 
Figure D.27: Main Decision

In this decision, choosing:

- Option A means that a donation will be given to Make-A-Wish Foundation.

This donation equals 200 cents.

-Option B means that a bonus payment will be given to you.

This bonus payment equals 100 cents.

Decision 18: Which option do you prefer?

Option A

Option B 


\section{D.3.2 Instructions for other versions of Study 3}

The previous section details the instructions for the Self/Charity-Baseline version of Study 3. In this section, we will detail how these instructions differ for the remaining seven versions of the Study 3.

Relative to theSelf/Charity-Baseline version of Study 3, all that differs in the Self/CharityAnchor-1, Self/Charity-Anchor-2, Self/Charity-Addition versions is the main decision screen. Figures D.28 - D.30 show these decision screens.

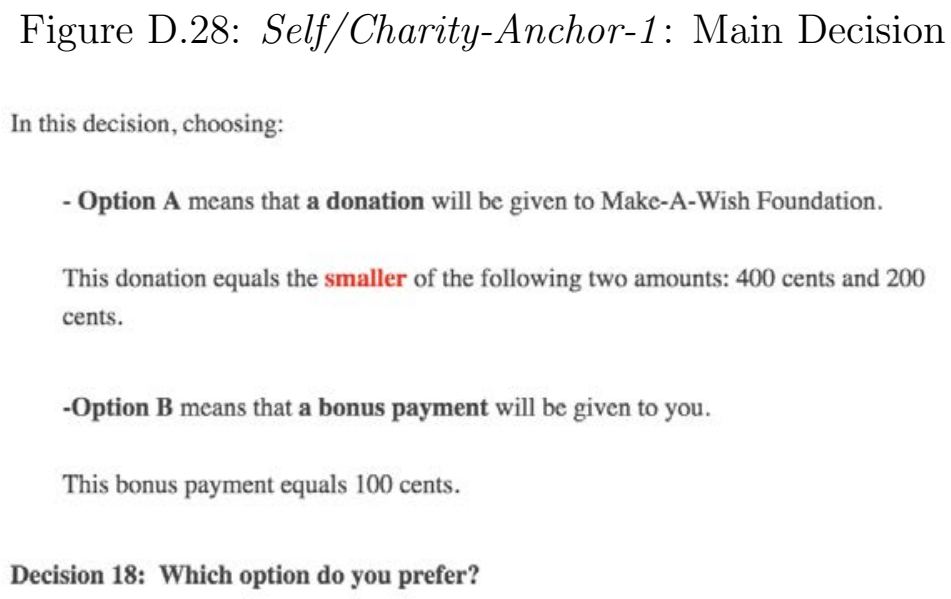

Figure D.29: Self/Charity-Anchor-2: Main Decision

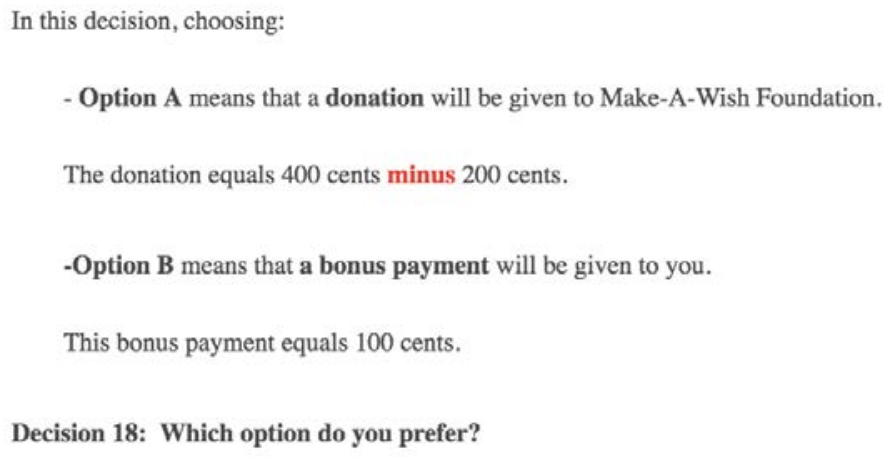


Figure D.30: Self/Charity-Addition: Main Decision

\author{
In this decision, choosing: \\ - Option A means that a donation will be given to Make-A-Wish Foundation. \\ The donation equals 50 cents +50 cents +50 cents +50 cents +0 cents. \\ -Option B means that a bonus payment will be given to you. \\ This bonus payment equals 100 cents. \\ Decision 18: Which option do you prefer?
}

Option A

Option B

Relative to theSelf/Charity-Baseline version of Study 3, all that differs in the Charity/CharityBaseline, the Charity/Charity-Anchor-1, Charity/Charity-Anchor-2, Charity/Charity-Addition versions are the instructions for the main decision and the decision screen for the main decision. Figure D.31 shows the instructions and Figures D.32 - D.34 show these decision screens.

Figure D.31: Charity/Charity: Instructions for Main Decision

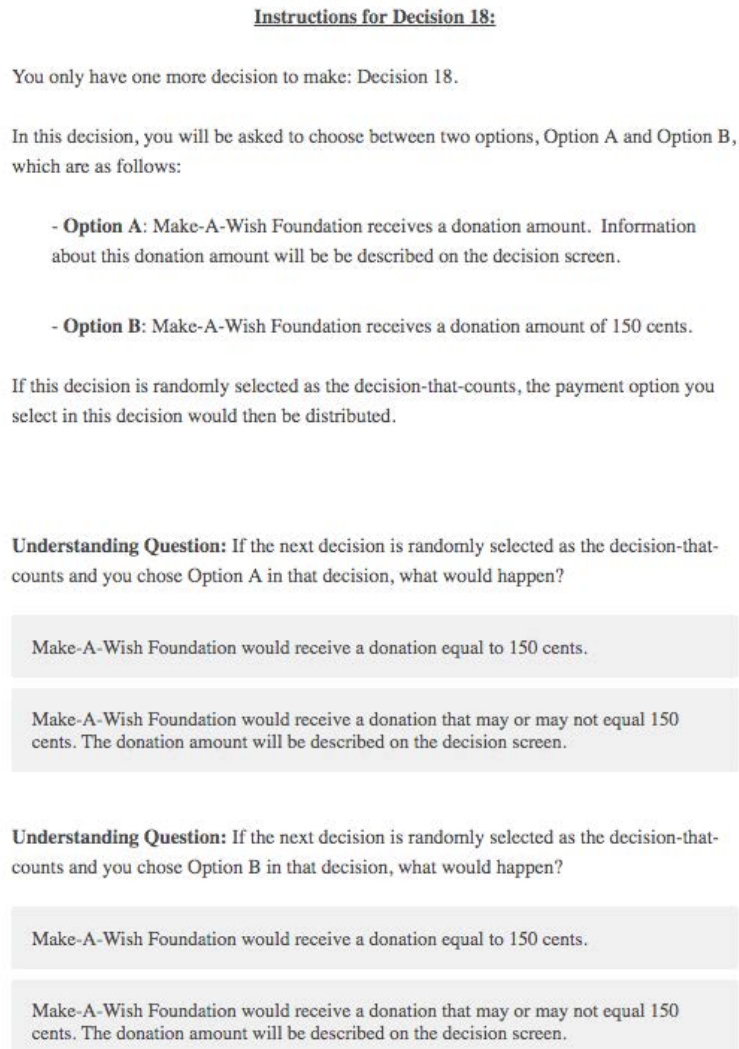


Figure D.32: Charity/Charity-Anchor-1: Main Decision

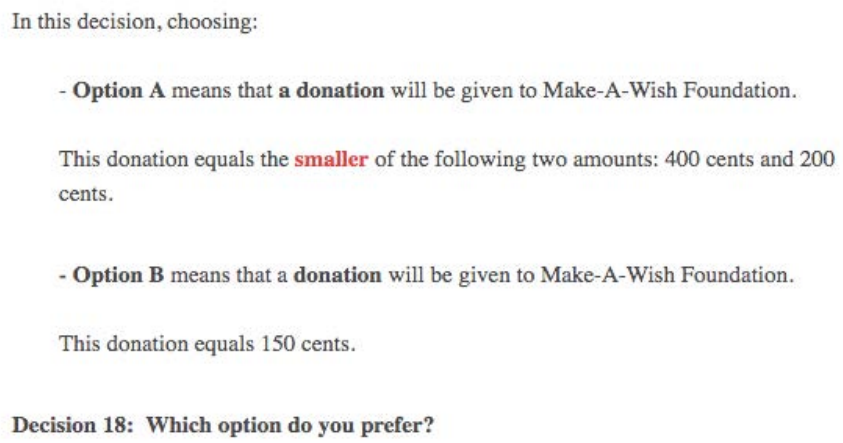

Figure D.33: Charity/Charity-Anchor-2: Main Decision

In this decision, choosing:

- Option A means that a donation will be given to Make-A-Wish Foundation.

The donation equals 400 cents minus 200 cents.

- Option B means that a donation will be given to Make-A-Wish Foundation.

This donation equals 150 cents.

Decision 18: Which option do you prefer?

Option A

Option B

Figure D.34: Charity/Charity-Addition: Main Decision

In this decision, choosing:

- Option A means that a donation will be given to Make-A-Wish Foundation.

The donation equals 50 cents +50 cents +50 cents +50 cents +0 cents.

- Option B means that a donation will be given to Make-A-Wish Foundation.

This donation equals 150 cents.

Decision 18: Which option do you prefer?

Option A

Option B 


\section{D.4 Full Instructions for Study 4}

Appendix D.3 details the instructions for Study 3. Study 4 involves four versions: Self/Charity Baseline, Charity/Charity - Baseline, Self/Charity - Correlated, and Charity/Charity - Correlated. The first two Baseline versions are identical to those in Study 3. For the latter two Correlated versions, all that differs relative to the Baseline versions are the instructions, understanding questions, and decision screen for the main decision.

Figures D.35 and D.36 shows the instructions and understanding questions for the Self/Charity Correlated and Charity/Charity - Correlated, respectively. Figures D.37 and D.38 show the decision screens. 


\section{Figure D.35: Self/Charity - Correlated: Instructions for Main Decision}

\section{Instructions for Decision 18 out of 18:}

You have one, final decision to make: Decision 18.

In this decision, you will be asked to choose between two options, Option A and Option B, which are as follows:

- Option A: Make-A-Wish Foundation receives a donation. Information about this donation will be be described on the decision screen.

In particular, you will be informed that the donation equals the sum of Amounts 1 and 2 , although you will NOT be directly told the donation. Rather, you will be informed that Amount 1 equals 0, and you will be informed of the estimate of Amount 2. The estimate of Amount 2 will equal the average of Amount 1 and Amount 2. Thus, you will be informed of the following:

*Amount 1 equals 0

*The estimate of Amount 2 equals the average of Amount 1 and Amount 2, which equals $(0+$ Amount 2$) / 2$.

- Option B: You receive a bonus payment of 100 cents.

If this decision is randomly selected as the decision-that-counts, the payment option you select in this decision would then be distributed.

Understanding Question: If the next decision is randomly selected as the decision-thatcounts and you chose Option A in that decision, what would happen?

Make-A-Wish Foundation would receive a donation equal to 150 cents for sure.

Make-A-Wish Foundation would receive a donation that depends on the information provided on the decision screen.

Understanding Question: If the next decision is randomly selected as the decision-thatcounts and you chose Option B in that decision, what would happen?

I would receive a bonus payment of 100 cents.

I would receive a bonus payment that depends on the information provided on the decision screen.

Understanding Question: If Amount 2 in Option A equals 80, what would the estimate of Amount 2 equal?

20

120 
Figure D.36: Charity/Charity - Correlated: Instructions for Main Decision

\section{Instructions for Decision 18 out of 18:}

You have one, final decision to make: Decision 18.

In this decision, you will be asked to choose between two options, Option A and Option B, which are as follows:

- Option A: Make-A-Wish Foundation receives a donation. Information about this donation will be be described on the decision screen.

In particular, you will be informed that the donation equals the sum of Amounts 1 and 2 , although you will NOT be directly told the donation. Rather, you will be informed that Amount 1 equals 0, and you will be informed of the estimate of Amount 2. The estimate of Amount 2 will equal the average of Amount 1 and Amount 2. Thus, you will be informed of the following:

*Amount 1 equals 0

*The estimate of Amount 2 equals the average of Amount 1 and Amount 2, which equals $(0+$ Amount 2$) / 2$.

- Option B: Make-A-Wish Foundation receives a donation of 150 cents.

If this decision is randomly selected as the decision-that-counts, the payment option you select in this decision would then be distributed.

Understanding Question: If the next decision is randomly selected as the decision-thatcounts and you chose Option A in that decision, what would happen?

Make-A-Wish Foundation would receive a donation equal to 150 cents for sure.

Make-A-Wish Foundation would receive a donation that depends on the information provided on the decision screen.

Understanding Question: If the next decision is randomly selected as the decision-thatcounts and you chose Option B in that decision, what would happen?

Make-A-Wish Foundation would receive a donation equal to 150 cents.

Make-A-Wish Foundation would receive a donation that depends on the information provided on the decision screen.

Understanding Question: If Amount 2 in Option A equals 80, what would the estimate of Amount 2 equal?

20

40

120 
Figure D.37: Self/Charity - Correlated: Main Decision

In this decision, choosing:

- Option A means that a donation will be given to Make-A-Wish Foundation.

This donation equals the sum of Amounts 1 and 2. More specifically, note that:

*Amount 1 equals 0 cents

*The estimate of Amount 2 equals 100 cents.

Remember, the estimate of Amount 2 equals the average of Amount 1 and Amount 2, which equals $(0+$ Amount 2$) / 2$.

- Option B means that a bonus payment will be given to you.

This bonus payment equals 100 cents.

Decision 18: Which option do you prefer?

Option A

Option B

Figure D.38: Charity/Charity - Correlated: Main Decision

In this decision, choosing:

- Option A means that a donation will be given to Make-A-Wish Foundation.

This donation equals the sum of Amounts 1 and 2. More specifically, note that:

*Amount 1 equals 0 cents

*The estimate of Amount 2 equals 100 cents.

Remember, the estimate of Amount 2 equals the average of Amount 1 and Amount 2, which equals $(0+$ Amount 2$) / 2$.

- Option B means that a donation will be given to Make-A-Wish Foundation.

This donation equals 150 cents.

Decision 18: Which option do you prefer?

Option A

Option B 